\title{
Toward a Sustainable and Resilient Future
}

\section{Coordinating Lead Authors:}

Karen O'Brien (Norway), Mark Pelling (UK), Anand Patwardhan (India)

\section{Lead Authors:}

Stephane Hallegatte (France), Andrew Maskrey (Switzerland), Taikan Oki (Japan), Úrsula Oswald-Spring (Mexico), Thomas Wilbanks (USA), Pius Zebhe Yanda (Tanzania)

\section{Review Editors:}

Carlo Giupponi (Italy), Nobuo Mimura (Japan)

\section{Contributing Authors:}

Frans Berkhout (Netherlands), Reinette Biggs (South Africa), Hans Günter Brauch (Germany), Katrina Brown (UK), Carl Folke (Sweden), Lisa Harrington (USA), Howard Kunreuther (USA), Carmen Lacambra (Colombia), Robin Leichenko (USA), Reinhard Mechler (Germany), Claudia Pahl-Wostl (Germany), Valentin Przyluski (France), David Satterthwaite (UK), Frank Sperling (Germany), Linda Sygna (Norway), Thomas Tanner (UK), Petra Tschakert (Austria), Kirsten Ulsrud (Norway), Vincent Viguié (France)

This chapter should be cited as:

O'Brien, K., M. Pelling, A. Patwardhan, S. Hallegatte, A. Maskrey, T. Oki, U. Oswald-Spring, T. Wilbanks, and P.Z. Yanda, 2012: Toward a sustainable and resilient future. In: Managing the Risks of Extreme Events and Disasters to Advance Climate Change Adaptation [Field, C.B., V. Barros, T.F. Stocker, D. Qin, D.J. Dokken, K.L. Ebi, M.D. Mastrandrea, K.J. Mach, G.-K. Plattner, S.K. Allen, M. Tignor, and P.M. Midgley (eds.)]. A Special Report of Working Groups I and II of the Intergovernmental Panel on Climate Change (IPCC). Cambridge University Press, Cambridge, UK, and New York, NY, USA, pp. 437-486 


\section{Table of Contents}

Executive Summary

8.1. Introduction

8.2. Disaster Risk Management as Adaptation: Relationship to Sustainable Development Planning

8.2.1. Concepts of Adaptation, Disaster Risk Reduction, and Sustainable Development and how they are Related..............443

8.2.2. Sustainability of Ecosystem Services in the Context of Disaster Risk Management and Climate Change Adaptation......445

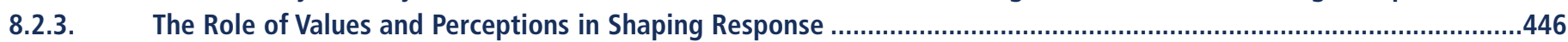

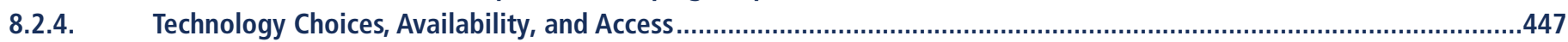

8.2.5. Tradeoffs in Decisionmaking: Addressing Multiple Scales and Stressors .............................................................448

8.3. Integration of Short- and Long-Term Responses to Extremes...........................................450

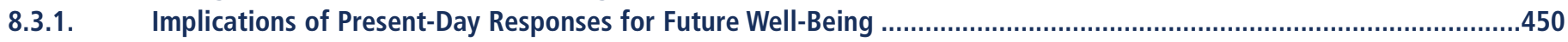

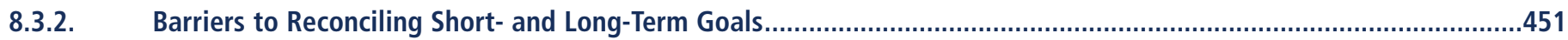

8.3.3. Connecting Short- and Long-Term Actions to Promote Resilience ......................................................................453

8.4. Implications for Access to Resources, Equity, and Sustainable Development .......................454

8.4.1. Capacities and Resources: Availability and Limitations.......................................................................................454

8.4.2. Local, National, and International Winners and Losers .....................................................................................456

8.4.3. Potential Implications for Human Security ..........................................................................................................457

8.4.4. Implications for Achieving Relevant International Goals ......................................................................................458

8.5. Interactions among Disaster Risk Management, Adaptation to

Climate Change Extremes, and Mitigation of Greenhouse Gas Emissions.............................458

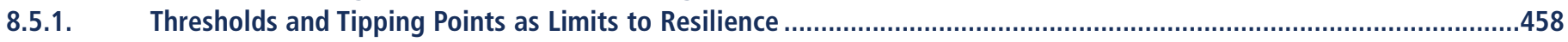

8.5.2. Adaptation, Mitigation, and Disaster Risk Management Interactions .....................................................................459

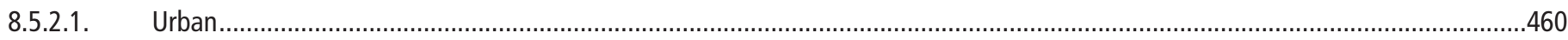

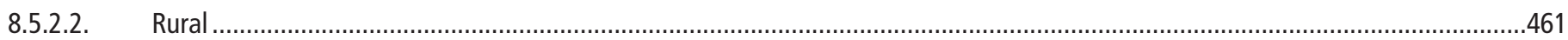

8.6. Options for Proactive, Long-Term Resilience to Future Climate Extremes..............................462

8.6.1. Planning for the Future ....................................................................................................................................462

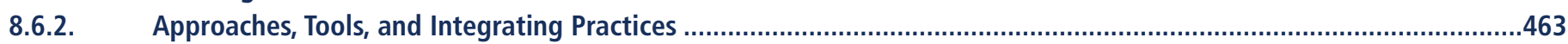

8.6.2.1. Improving Analysis and Modeling Tools......................................................................................................................464

8.6.2.2. Institutional Approaches ....................................................................................................................................................... 464

8.6.2.3. Transformational Strategies and Actions for Achieving Multiple Objectives...............................................................................465

8.6.3. Facilitating Transformational Change ...............................................................................................................466

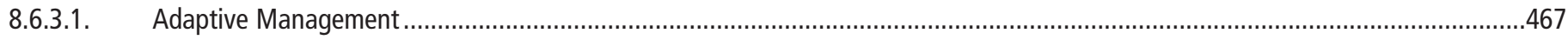

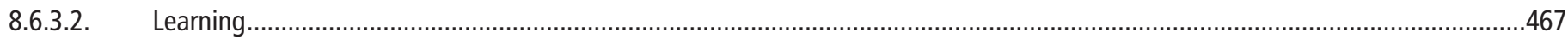

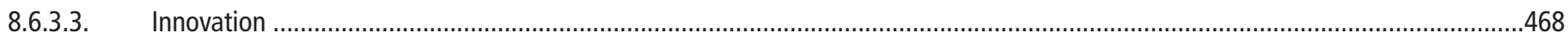

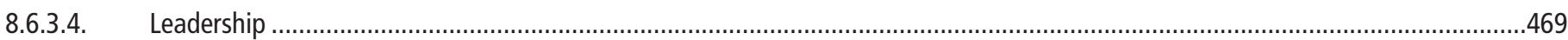

8.7. Synergies between Disaster Risk Management and

Climate Change Adaptation for a Resilient and Sustainable Future.......................................469

References 


\section{Executive Summary}

Actions that range from incremental steps to transformational changes are essential for reducing risk from weather and climate extremes (high agreement, robust evidence). [8.6, 8.7] Incremental steps aim to improve efficiency within existing technological, governance, and value systems, whereas transformation may involve alterations of fundamental attributes of those systems. The balance between incremental and transformational approaches depends on evolving risk profiles and underlying social and ecological conditions. Disaster risk, climate change impacts, and capacity to cope and adapt are unevenly distributed. Vulnerability is often concentrated in poorer countries or groups, although the wealthy can also be vulnerable to extreme events. Where vulnerability is high and adaptive capacity relatively low, changes in extreme climate and weather events can make it difficult for systems to adapt sustainably without transformational changes. Such transformations, where they are required, are facilitated through increased emphasis on adaptive management, learning, innovation, and leadership.

Evidence indicates that disaster risk management and adaptation policy can be integrated, reinforcing, and supportive - but this requires careful coordination that reaches across domains of policy and practice (high agreement, medium evidence). [8.2, 8.3, 8.5, 8.7] Including disaster risk management in resilient and sustainable development pathways is facilitated through integrated, systemic approaches that enhance capacity to cope with, adapt to, and shape unfolding processes of change, while taking into consideration multiple stressors, different prioritized values, and competing policy goals.

Development planning and post-disaster recovery have often prioritized strategic economic sectors and infrastructure over livelihoods and well-being in poor and marginalized communities. This can generate missed opportunities for building local capacity and integrating local development visions into longer-term strategies for disaster risk reduction and adaptation to climate change (high agreement, robust evidence). $[8.4 .1,8.5 .2]$ A key constraint that limits pathways to post-disaster resilience is the time-bound nature of reconstruction funding. The degradation of ecosystems providing essential services also limits options for future risk management and adaptation actions locally.

Learning processes are central in shaping the capacities and outcomes of resilience in disaster risk management, climate change adaptation, and sustainable development (high agreement, robust evidence). $[8.6 .3,8.7]$ An iterative process of monitoring, research, evaluation, learning, and innovation can reduce disaster risks and promote adaptive management in the context of extremes. Technological innovation and access may help achieve resilience, especially when combined with capacity development anchored in local contexts.

Progress toward resilient and sustainable development in the context of changing climate extremes can benefit from questioning assumptions and paradigms, and stimulating innovation to encourage new patterns of response (medium agreement, robust evidence). [8.2.5, 8.6.3, 8.7] Successfully addressing disaster risk, climate change, and other stressors often involves embracing broad participation in strategy development, the capacity to combine multiple perspectives, and contrasting ways of organizing social relations.

Multi-hazard risk management approaches provide opportunities to reduce complex and compound hazards in rural and urban contexts (high agreement, robust evidence). [8.2.5, 8.5.2, 8.7] Considering multiple types of hazards reduces the likelihood that risk reduction efforts targeted at one type of hazard will increase exposure and vulnerability from other hazards, both in the present and future. Building adaptation into multi-hazard risk management involves consideration of current climate variability and projected changes in climate extremes, which pose different challenges to affected human and natural systems than changes in the means. Where changes in extremes cause greater stresses on human and natural systems, direct impacts may be more unpredictable, increasing associated adaptation challenges.

The most effective adaptation and disaster risk reduction actions are those that offer development benefits in the relative near term, as well as reductions in vulnerability over the longer term (high agreement, 
medium evidence). [8.2.1, 8.3.1, 8.3.2, 8.5.1, 8.6.1] There are tradeoffs between current decisions and long-term goals linked to diverse values, interests, and priorities for the future. Short-term and long-term perspectives on both disaster risk management and adaptation to climate change thus can be difficult to reconcile. Such reconciliation involves overcoming the disconnect between local risk management practices and national institutional and legal frameworks, policy, and planning. Resilience thinking offers some tools for reconciling short- and long-term responses, including integrating different types of knowledge, an emphasis on inclusive governance, and principles of adaptive management. However, limits to resilience are faced when thresholds or tipping points associated with social and/or natural systems are exceeded.

Building a strong foundation for integrating disaster risk management and adaptation to climate change includes making transparent the values and interests that underpin development, including who wins and loses from current policies and practices, and the implications for human security (high agreement, medium evidence). [8.2.3, 8.2.4, 8.4.2, 8.4.3, 8.6.1.2] Both disaster risk management and adaptation to climate change share challenges related to (1) reassessing and potentially transforming the goals, functions, and structure of institutions and governance arrangements; (2) creating synergies across temporal and spatial scales; and (3) increasing access to information, technology, resources, and capacity. These challenges are particularly demanding in countries and localities with the highest climate-related risks and weak capacities to manage those risks. Countries with significant capacity and strong risk management records also benefit from addressing these challenges.

Social, economic, and environmental sustainability can be enhanced by disaster risk management and adaptation approaches. A prerequisite for sustainability is addressing the underlying causes of vulnerability, including the structural inequalities that create and sustain poverty and constrain access to resources (medium agreement, robust evidence). $[8.6 .2,8.7]$ This involves integrating disaster risk management in other social and economic policy domains, as well as a long-term commitment to managing risk.

The interactions among climate change mitigation, adaptation, and disaster risk management will have a major influence on resilient and sustainable pathways (high agreement, low evidence). [8.2.5, 8.5.2, 8.7] Interactions between the goals of mitigation and adaptation in particular will play out locally, but have global consequences.

There are many approaches and pathways to a sustainable and resilient future. Multiple approaches and development pathways can increase resilience to climate extremes (medium agreement, medium evidence). $[8.2 .3,8.4 .1,8.6 .1,8.7]$ Choices and outcomes for adaptive actions to climate extremes must reflect divergent capacities and resources and multiple interacting processes. Actions are framed by tradeoffs between competing prioritized values and objectives, and different visions of development that can change over time. Iterative, reflexive approaches allow development pathways to integrate risk management so that diverse policy solutions can be considered, as risk and its measurement, perception, and understanding evolve over time. Choices made today can reduce or exacerbate current or future vulnerability, and facilitate or constrain future responses. 


\subsection{Introduction}

This chapter focuses on the implications of changing climate extremes for development, and considers how disaster risk management and climate change adaptation together can contribute to a sustainable and resilient future. Changes in the frequency, timing, magnitude, and characteristics of extreme events pose challenges to the goals of reducing disaster risk and vulnerability, both in the present and in the future (see Chapter 3). Enhancing the capacity of social-ecological systems to cope with, adapt to, and shape change is central to building sustainable and resilient development pathways in the face of climate change. The concept for social-ecological systems recognizes the interdependence of social and ecological factors in the generation and management of risk, as well as in the pursuit of sustainable development. Despite 20 years on the policy agenda, sustainable development remains contested and elusive (Hopwood et al., 2005). However, within the context of climate change, it is becoming increasingly clear that the sustainability of humans on the Earth is closely linked to resilient social-ecological systems, which is influenced by social institutions, human agency, and human capabilities (Pelling, 2003; Bohle et al., 2009; Adger et al., 2011).

Extremes are translated into impacts by the underlying conditions of exposure and vulnerability associated with development contexts. For example, there is robust evidence that institutional arrangements and governance weaknesses can transform extreme events into disasters (Hewitt, 1997; Pelling, 2003; Wisner et al., 2004; Ahrens and Rudolph, 2006). The potential for concatenated global impacts of extreme events continues to grow as the world's economy becomes more interconnected, but in relative terms most impacts will occur in contexts with severe environmental, economic, technological, cultural, and cognitive limits to adaptation (see Section 5.5.3). In relation to extreme events, global risk assessments show that social losses - as well as economic losses as a proportion of livelihood or GDP - are disproportionately concentrated in developing countries, and within these countries in poorer communities and households (UNDP, 2004; UNISDR, 2009, 2011; World Bank, 2010a).

This chapter recognizes that outcomes of changing extreme events depend on responses and approaches to disaster risk reduction and climate change adaptation, both of which are closely linked to development processes. The assessment of literature presented in this chapter shows that changes in extreme events call for greater alignment and integration of climate change responses and sustainable development strategies, and that this alignment depends on greater coherence between shortand long-term objectives. Yet there are different interpretations of development, different preferences and prioritized values and motivations, different visions for the future, and many tradeoffs involved. Research on the resilience of social-ecological systems provides some lessons for addressing the gaps among these objectives. Transformative social, economic, and environmental responses can facilitate disaster risk reduction and adaptation (see Box 8-1). Transformations often include questioning of social values, institutions, and technical practices (Loorbach et al., 2008; Hedrén and Linnér, 2009; Pelling 2010a). A resilient and sustainable future is a choice that involves proactive measures that promote transformations, including adaptive management, learning, innovation, and leadership capacity to manage risks and uncertainty.

In this chapter, we assess a broad literature presenting insights on how diverse understandings and perspectives on disaster risk reduction and climate change adaptation can help to promote a more sustainable and resilient future. Drawing on many of the key messages from earlier chapters, the objective is to assess scientific knowledge on the incremental and transformative changes needed, particularly in relation to integrating disaster risk reduction and climate change adaptation into development policies and pathways. Bringing together experience from a range of disciplines, this chapter identifies proven pathways that can help move from an incremental to an integrative approach that also

\section{Box 8-1 | Transformation in Response to Changing Climate Extremes}

Transformation involves fundamental changes in the attributes of a system, including value systems; regulatory, legislative, or bureaucratic regimes; financial institutions; and technological or biophysical systems (see Glossary). This chapter focuses on the transformation of disaster risk management systems in the context of climate extremes, through integration with climate change adaptation strategies and wider systems of human development. This is similar to, yet distinct from, other types of transformation associated with climate change. For example, there have been attempts to understand climate change and development failures by identifying the scope for political (Harvey, 2010), social (Kovats et al., 2005), economic (Jackson, 2009), and value (Leiserowitz et al., 2006) transformation, and so too for disaster risk management (Klein, 2007). Across these cases, observed processes of stasis and change are analogous (often using common language), but actors and objectives are distinct. That said, transformation in wider political, economic, social, and ethical systems can open or close policy space for a more resilient and sustainable form of disaster risk management (Birkland, 2006), just as acts aimed at transformation in managing climate extremes can have implications for wider systems. This is particularly true where contemporary development goals, paths, and hierarchies are identified and addressed as part of the root or proximate causes of vulnerability and risk, that is, when they are seen as part of the solution for building resilient and sustainable futures (Wisner, 2003; Pelling, 2010a). Although there has been some research on how and why social lock-in makes it difficult to move away from established development priorities and trajectories (Pelling and Manuel-Navarrete, 2011), there has been only limited academic work to date on the ways in which wider transformations impact on disaster risk management, and vice versa. 


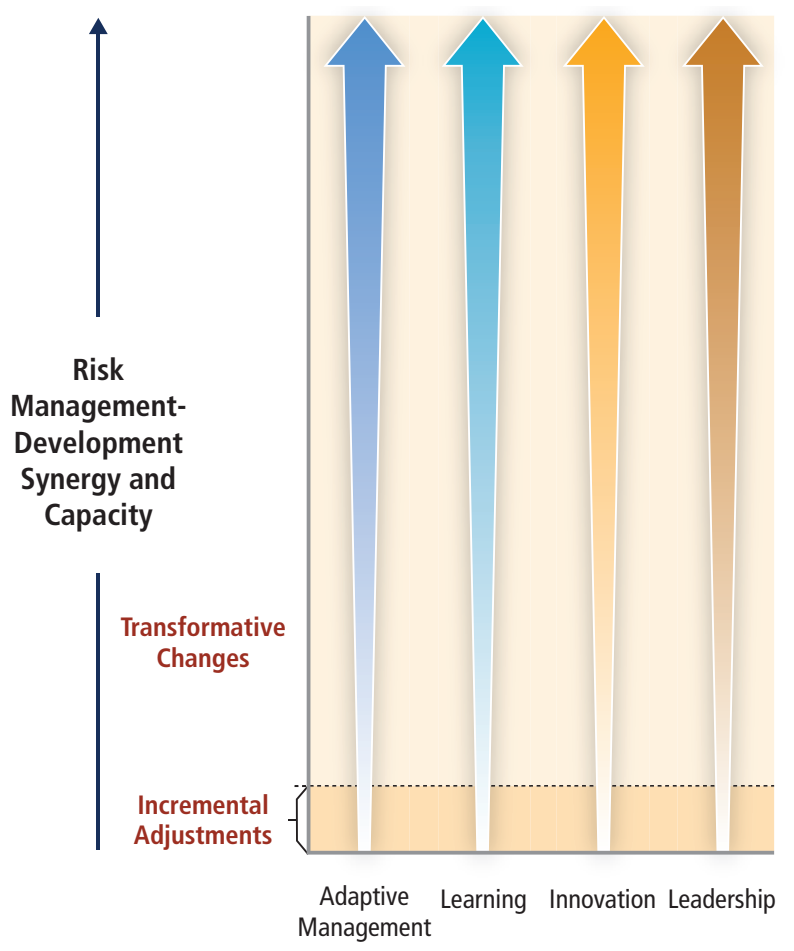

Figure 8-1 | Incremental and transformative pathways to resilience.

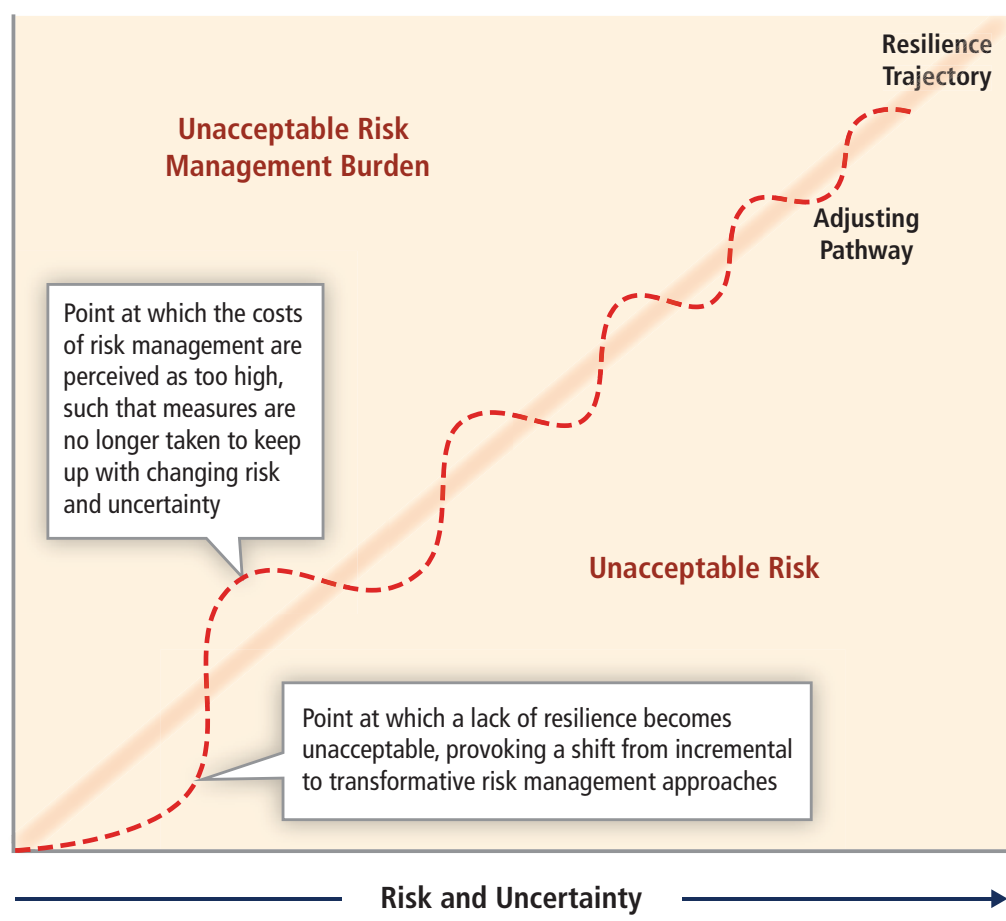

embraces transformation - as illustrated in Figure 8-1, which depicts resilience as a moving target that is positioned somewhere between the acceptability of residual risk and the costs of risk management. The target moves as the relationship between risk and uncertainty changes (driven by climate extremes, as well as development trends such as urbanization) in relation to the capacity for risk management (which integrates climate change adaptation, disaster risk management, and development). As risk and uncertainty increase, incremental adjustments in practices may no longer be sufficient to achieve resilience, and at some point the growing resilience gap will provoke a search for transformative solutions. Through enhanced experimentation and learning approaches, climate change adaptation, disaster risk management, and development may provide a pathway for keeping pace with the dynamic drivers and expressions of risk.

After this introduction, this chapter discusses the relationship between disaster risk management, climate change adaptation, and sustainable and resilient development (Section 8.2), highlighting the synergies and conflicts between these objectives and the common obstacles to reaching them (Section 8.2.1) and the specific role of ecosystems and biodiversity (Section 8.2.2). In particular, it emphasizes the importance of values and perceptions (Section 8.2.3) and the role of technologies (Section 8.2.4) in designing sustainability policies. Finally, it highlights the importance of tradeoffs between temporal scales, spatial scales, and multiple stressors (Section 8.2.5).

Focusing on time perspectives, Section 8.3 then discusses options to integrate short- and long-term objectives, by looking at the long-term consequences of present-day responses to disasters (Section 8.3.1), investigating the barriers to integrating short- and long-term responses (Section 8.3.2), and proposing options to overcome these barriers and promote resilience (Section 8.3.3).

Section 8.4 assesses the implications of disaster risk reduction and climate change adaptation for equity and access to resources, and in particular the importance of capacities and resource availability to implement policies for adaptation and disaster risk reduction (Section 8.4.1). It also highlights the existence of losers and winners from disasters and disaster risk reduction and adaptation policies (Section 8.4.2), and the consequences of these distributive effects for human security (Section 8.4.3) and for the possibility to achieve international goals such as the Millennium Development Goals (Section 8.4.4).

Section 8.5 focuses on the specific issue of combining disaster risk management and adaptation with climate change mitigation policies. It starts by stressing the role of thresholds and tipping points as limits to what can be achieved in terms of disaster risk management and adaptation, and thus the importance of considering the three policies together (Section 8.5.1). It then discusses synergies and conflicts between mitigation, adaptation, and disaster risk management in urban and rural areas (Section 8.5.2).

Section 8.6 identifies the tools and options to promote resilience to climate extremes and combine adaptation, disaster risk management, and other policy goals. It first discusses various approaches to planning for the future, including the use of scenarios (Section 8.6.1). It then highlights the existence of a continuum of options to make progress over the short and long term, from incremental to transformational 
changes (Section 8.6.2). These increasingly ambitious changes include the use of analysis and modeling tools to improve disaster risk management and adaptation (Section 8.6.2.1), the implementation of new institutional tools (Section 8.6.2.2), and transformational strategies to reach multiple objectives (Section 8.6.2.3). Such transformational changes can be facilitated using a combination of approaches (Section 8.6.3), including adaptive management (Section 8.6.3.1), learning (Section 8.6.3.2), innovation (Section 8.6.3.3), and leadership (Section 8.6.3.4). The chapter concludes (Section 8.7) by discussing synergies between disaster risk reduction and climate change adaptation to achieve a resilient and sustainable future.

\subsection{Disaster Risk Management as Adaptation: Relationship to Sustainable Development Planning}

Earlier chapters discussed the concepts of and relationship between disaster risk management (including disaster risk reduction) and climate change adaptation. The two concepts and practices overlap considerably and are strongly complementary. Disaster risk management considers hazards other than those that are climate-derived, such as earthquakes and volcanoes, while climate change adaptation considers and addresses vulnerabilities related to phenomena that would not normally be classified as discrete disasters, such as gradual changes in precipitation, temperature, or sea level. Examples of hazards that are addressed by both communities include flooding, droughts, and heat waves.

Disaster risk management is increasingly considered as one of the 'frontlines' of adaptation, and perhaps one of the most promising arenas for mainstreaming or integrating climate change adaptation into sustainable development planning (Sperling and Szekely, 2005; G. O'Brien et al., 2006; Schipper and Pelling, 2006; Schipper, 2009). However, it requires modifying development policies, mechanisms, and tools, and identifying and responding to those who gain and lose from living with and creating risk. Contested notions of development and hence differing perspectives on sustainable development planning lead to different conclusions about how disaster risk reduction can contribute to adaptation. This section reviews the definitions of some of the key concepts used in this chapter, and considers the roles that ecosystems services, values and perceptions, technologies, and tradeoffs in decisionmaking can play in influencing sustainable development planning and outcomes. It also considers the tradeoffs that are involved in decisionmaking.

\subsubsection{Concepts of Adaptation, Disaster Risk Reduction, and Sustainable Development and how they are Related}

Adaptation can be defined as the process of adjustment to actual or expected climate and its effects in order to moderate harm or exploit beneficial opportunities (see Section 1.1.2). Adaptation actions may be undertaken by public or private actors, and can be anticipatory or reactive, and incremental or transformative (Adger et al., 2007; Stafford Smith et al., 2011). In both principle and practice, adaptation is more than a set of discrete measures designed to address climate change; it is an ongoing process that encompasses responses to many factors, including evolving experiences with both vulnerabilities and vulnerability reduction planning and actions, as well as risk perception (Tschakert and Dietrich, 2010; Weber, 2010; Wolf, 2011).

Adaptive capacity underlies action and is defined in this report as the combination of strengths, attributes, and resources available to an individual, community, society, or organization that can be used to prepare for and undertake adaptation. Adaptive capacity can also be described as the capability for innovation and anticipation (Armitage, 2005), the ability to learn from mistakes (Adger, 2003), and the capacity to generate experience in dealing with change (Berkes et al., 2003). Enhancing adaptive capacity under climate change entails paying attention to learning about past, present, and future climate threats, accumulated memory of adaptive strategies, and anticipatory action to prepare for surprises and discontinuities in the climate system (Nelson et al., 2007).

Adaptive capacity is uneven across and within sectors, regions, and countries (K. O'Brien et al., 2006). Although wealthy countries and regions have more resources to direct to adaptation, the availability of financial resources is only one factor determining adaptive capacity (Moss et al., 2010; Ford and Ford, 2011). Other factors include the ability to recognize the importance of the problem in the context of multiple stresses, to identify vulnerable sectors and communities, to translate scientific knowledge into action, and to implement projects and programs (Moser and Ekstrom, 2010). The capacity to adapt is in fact dynamic and influenced by economic and natural resources, social networks, entitlements, institutions and governance, human resources, and technology (Parry et al., 2007). It is particularly important to understand that places with greater wealth are not necessarily less vulnerable to climate impacts and that a socioeconomic system might be as vulnerable as its weakest link (K. O'Brien et al., 2006; Tol and Yohe, 2007). Therefore, even wealthy locations can be severely impacted by extreme events, socially as well as economically, as Europeans experienced during the 2003 heat wave (Salagnac, 2007; see also Case Study 9.2.1).

Current adaptation planning in many countries, regions, and localities involves identification of a wide range of options, although the available knowledge of their costs, benefits, wider consequences, potentials, and limitations is still incomplete (NRC, 2010; see Section 4.5). In many cases, the most attractive adaptation actions are those that offer development benefits in the relatively near term, as well as reductions of vulnerabilities in the longer term (Agrawala, 2005; Klein et al., 2007; McGray et al., 2007; Hallegatte, 2008a; NRC, 2010). This is a lesson already noted, though not always practiced, in disaster preparedness and risk reduction (IFRC, 2002; Pelling, 2010b). An emerging literature discusses adaptation through the lens of sustainability, recognizing that not all adaptation responses are necessarily benign; there are tradeoffs, potentials for negative outcomes, competing interests, different types of knowledge, 
and winners and losers inherent in adaptation responses (Eriksen and O'Brien, 2007; Ulsrud et al., 2008; Barnett and O'Neill, 2010; Beckman, 2011; Brown, 2011; Eriksen et al., 2011; Gachathi and Eriksen, 2011; Owuor et al., 2011). Sustainable adaptation is defined as a process that addresses the underlying causes of vulnerability and poverty, including ecological fragility; it is considered a way of generating social transformation, or changes in the fundamental attributes of society that contribute to vulnerability (Eriksen and O'Brien, 2007; Eriksen and Brown, 2011).

Disaster risk can be defined in many ways (see Section 1.1.2). In general, however, it is closely associated with the concepts of hazards, exposure, and vulnerability. Hazards are defined in this report as the potential occurrence of a natural or human-induced physical event that may cause negative consequences. Exposure is defined as the presence of people, livelihoods, environmental services and resources, infrastructure, and economic, social, and cultural assets in places that could be adversely affected by climate extremes. Hazards and exposure are changing, not only as the result of climate change, but also due to human activities. For example, hazards associated with floods, landslides, storm surges, and fires can be influenced by declines in ecosystem services that regulate runoff, erosion, etc. The drainage of wetlands, deforestation, the destruction of mangroves, and the changes associated with urban development (such as the impermeability of surfaces and overexploitation of groundwater) are all factors that can modify hazard patterns (Nobre et al., 1991, 2005; MEA, 2005; Nicholls et al., 2008). Consequently, most weather-related hazards now have an anthropogenic element (Cardona, 1999; Lavell, 1999).

Vulnerability has many different (and often conflicting) definitions and interpretations, both across and within the disaster risk and climate communities (see Sections 1.1.2 and 2.2). Vulnerability can increase or decrease over time as a result of both environmental and socioeconomic changes (Blaikie et al., 1994; Leichenko and O'Brien, 2008). In general, improvements in a country's development indicators have been associated with reduced mortality risk, yet an increase in economic loss and insurance claims (UNDP, 2004; Pielke Jr. et al., 2008; Schumacher and Strobl, 2008; ECA, 2009; UNISDR, 2009; World Bank, 2010a). Indeed, recent evidence confirms that, despite increasing exposure, mortality risk from tropical cyclones and floods is now decreasing globally, as well as in heavily exposed regions like Asia (UNISDR, 2011). In contrast, the risk of economic loss is increasing globally because reductions in vulnerability are not compensating for rapid increases in the exposure of economic assets. In the Organisation for Economic Co-operation and Development (OECD) countries, for example, economic losses are increasing at a faster rate than GDP per capita. In other words, the risk of losing wealth in disasters is increasing faster than that wealth is being created (UNISDR, 2011). However, some types of development may increase vulnerability or transfer it between social groups, particularly if development is unequal or degrades ecosystem services (Guojie, 2003). Even where growth is more equitable, vulnerabilities can be generated (e.g., when modern buildings are not constructed to prescribed safety standards) (Hewitt, 1997; Satterthwaite, 2007).
Climate change can magnify many preexisting risks through changes in the frequency, severity, and spatial distribution of weather-related hazards, as well as through increases in vulnerability due to climate impacts (e.g., decreased water availability, decreased agricultural production and food availability, or increased heat stress) (see Section 4.3). Like adaptation, disaster risk reduction may be anticipatory (ensuring that new development does not increase risk) or corrective (reducing existing risk levels) (Lavell, 2009). Given expected population increases in hazard-prone areas, anticipatory disaster risk reduction is fundamental to addressing the risk associated with future climate extremes. At the same time, investments in corrective disaster risk reduction are required to address the accumulation of exposure and susceptibility to existing climate risks, for example, those inherited from past urban planning or rural infrastructure decisions.

Climate change adaptation and disaster risk management (especially disaster risk reduction) are critical elements of long-term sustainability for economies, societies, and environments at all scales (Wilbanks and Kates, 2010). The generally accepted and most widespread definition of sustainable development comes from the Brundtland Commission Report, which defined sustainable development as "development that meets the needs of the present without compromising the ability of future generations to meet their own needs" (WCED, 1987). A number of principles of sustainable development have emerged, including the achievement of a standard of human well-being that meets human needs and provides opportunities for social and economic development; that sustains the life support systems of the planet; that broadens participation in development processes and decisions; and that accelerates the movement of knowledge into action in order to provide a wider range of options for resolving issues (WCED, 1987; Meadowcroft, 1997; NRC, 1999; Swart et al., 2003; MEA, 2005). Because sustainable development means finding pathways that achieve socioeconomic and environmental goals without sacrificing either, it is a concept that is fundamentally political (Wilbanks, 1994).

Discussions of the relationships between sustainable development and climate change have increased over the past decades (Cohen et al., 1998; Yohe et al., 2007; Bizikova et al., 2010). The literature on development has considered how development paths relate to vulnerabilities both to climate change and to climate change policies (e.g., Davis, 2001; Garg et al., 2009), as well as to other hazards. Clearly, some climate changerelated environmental shifts are potentially threatening to sustainable development, but they can also help move toward sustainability, especially if the trends or events are severe enough to require significant adjustment of unsustainable development practices or development paths (e.g., the relocation of population or economic activities to less vulnerable areas). In such cases, both disaster risk reduction and climate change adaptation can be important - even essential - contributors to sustainable development.

There are some examples of successful decreases in vulnerability through disaster risk management, but less evidence in relation to climate change adaptation, in part because the ability to attribute observed 
environmental stresses from and responses to climate change is still limited (Fankhauser et al., 1999; Adger et al., 2007; Repetto, 2008). In terms of disaster risk reduction, a large number of lives have been saved over the last decade due to improved disaster early warning systems (IFRC, 2005), and to increased development and human welfare (UNISDR, 2011). There remains, however, much more that can be done to reduce mortality and counteract growth in the number of people affected by disasters and climate extremes. For example, recent selfassessments of progress by over 100 countries on the objectives of the Hyogo Framework of Action (UNISDR, 2009, 2011) indicate that few developing countries have conducted comprehensive, accurate, and accessible risk assessments, which are a prerequisite for both anticipatory and corrective disaster risk reduction. Furthermore, the assessment shows that few countries are able to quantify their investment in disaster risk reduction. There are numerous ways to evaluate success of disaster risk management or climate adaptation, including gauging the extent to which the goals of a given action (determined in anticipation of a given environmental stressor) are achieved, independent of whether the environmental stressor materializes. Both climate adaptation and disaster risk management can contribute to responses to changes in extreme events due to climate change, yet neither approach alone is sufficient.

Econometric analyses at the national scale have reached different conclusions about the impact of disasters on economic growth, but the balance of evidence suggests a negative impact. Whereas Noy and Nualsri (2007), Noy (2009), Hochrainer (2009), Jaramillo (2009), and Raddatz (2007) suggest that the overall impact on growth is negative, Albala-Bertrand (1993) and Skidmore and Toya (2002) argue that natural disasters have a positive influence on long-term economic growth, often due to both the stimulus effect of reconstruction and the productivity effect. As suggested by Cavallo and Noy (2009) and Loayza et al. (2009), this difference may arise from the different impacts of small and large disasters, the latter having a negative impact on growth and the former enhancing growth. In any case, whether or not disaster losses translate into other social and economic impacts depends on how each individual disaster is managed (Moreno and Cardona, 2011) which in turn is related to capacities and political priorities. At the local scale, Strobl (2011) investigates the impact of hurricane landfall on county-level economic growth in the United States. This analysis shows that a county that is struck by at least one hurricane in a year sees its economic growth reduced on average by $0.79 \%$, and increased by only $0.22 \%$ the following year. Noy and Vu (2010) investigate the impact of disasters on economic growth at the province level in Vietnam, and find that lethal disasters decrease economic production while costly disasters increase shortterm growth. Rodriguez-Oreggia et al. (2009) focus instead on poverty and the World Bank's Human Development Index at the municipality level in Mexico. They show that municipalities affected by disasters experienced an increase in poverty by 1.5 to $3.6 \%$. Considering these important links between disasters and development, there is a need to consider disaster risk reduction, climate change adaptation, and sustainable development in a consistent and integrated framework (G. O'Brien et al., 2006; Schipper and Pelling, 2006).

\subsubsection{Sustainability of Ecosystem Services in the Context of Disaster Risk Management and Climate Change Adaptation}

Reducing human pressures on ecosystems and managing natural resources more sustainably can facilitate efforts to mitigate climate change and to reduce vulnerabilities to extreme climate and weather events. The degradation of ecosystems is undermining their capacity to provide ecosystem goods and services upon which human livelihoods and societies depend (MEA, 2005; WWF, 2010), and to withstand disturbances, including climate change. There is evidence that the likelihood of collapse and subsequent regime shifts in ecological and coupled social-ecological systems may be increasing in response to the magnitude, frequency, and duration of climate change and other disturbance events (Folke et al., 2004; MEA, 2005; Woodward, 2010). Large, persistent shifts in ecosystem services not only affect the total level of welfare that people in a community can enjoy, they also impact the welfare distribution between people within and between generations and hence may give rise to new conflicts over resource use and questions on inter-generational equity as a component of sustainable development (Thomas and Twyman, 2005). They could result in domino effects of increased pressure on successive resource systems, as has been suggested in the case of depletion of successive fish stocks (Berkes et al., 2006). However, the thresholds at which ecosystems undergo regime shifts and the points at which these may catalyze social stress remain largely unknown, partly due to variability over space and time (Biggs et al., 2009; Scheffer, 2009).

Ecosystems can act as natural barriers against climate-related hazardous extremes, reducing disaster risk (Conde, 2001; Scholze et al., 2005). For example, mangrove forests are a highly effective natural flood control mechanism that will become increasingly important with sea level rise, and are already used as a coastal defense against extreme climatic and non-climatic events (Adger et al., 2005). The benefits of such ecosystem services are determined by ecosystem health, hazard characteristics, local geomorphology, and the geography and location of the system with respect to the hazard (Lacambra and Zahedi, 2011). In assessing the ecological limits of adaptation to climate change, Peterson (2009) emphasizes that ecosystem regime shifts can occur as the result of extreme climate shocks, but that such shifts depend upon the resilience of the ecosystem, and are influenced by processes operating at multiple scales. In particular, there is evidence that the loss of regulating services (e.g., flood regulation, regulation of soil erosion) erodes ecological resilience (MEA, 2005).

Ecosystems and ecosystem approaches can also facilitate adaptation to changing climatic conditions (Conde, 2001; Scholze et al., 2005). Conservation of water resources and wetlands that provide hydrological sustainability can further aid adaptation by reducing the pressures and impacts on human water supply, while forest conservation for carbon sinks and alternative sources of energy such as biofuels can reduce carbon emissions and have multiple benefits (Reid, 2006), as can coastal defenses and avalanche protection (Silvestri and Kershaw, 2010). In New York, for example, untreated storm water and sewage regularly 
flood the streets because the aging sewage system is no longer adequate. After heavy rains, overflowing water flows directly into rivers and streams instead of reaching water treatment plants. The US Environmental Protection Agency has estimated that around US\$300 billion over 20 years would be needed to upgrade sewage infrastructure across the country (UNISDR, 2011). In response, New York City will invest US\$ 5.3 billion in green infrastructure on roofs, streets, and sidewalks. This promises multiple benefits: the new green spaces may absorb more rainwater and reduce the burden on the city's sewage system, improve air quality, and reduce water and energy costs. Such changes in the constituents of an ecosystem can be used as levers to enhance the resilience of coupled social-ecological systems (Biggs et al., 2009).

Biodiversity is also important to adaptation. Functionally diverse systems have more scope to adapt to climate change and climate variability than functionally impoverished systems (Elmqvist et al., 2003; Hughes et al., 2003; Lacambra and Zahedi, 2011). A larger gene pool will facilitate the emergence of genotypes that are better adapted to changed climatic conditions. Conservation of biodiversity and maintenance of ecosystem integrity may therefore be a key objective in improving the adaptive capacity of society to cope with climate change extremes (Peterson et al., 1997; Elmqvist et al., 2003; SCBD, 2010).

Strategies that are adopted to reduce climate change through greenhouse gas mitigation can affect biodiversity both negatively and positively (Edenhofer et al., 2011), which in turn influences the capacity to adapt to climate extremes. For example, some bioenergy plantations replace sites with high biodiversity, introduce alien species, and use damaging agrochemicals, which in turn may reduce ecosystem resilience and hence their capacity to respond to extreme events (Foley et al., 2005; Fargione et al., 2009). Large hydropower schemes can cause loss of terrestrial and aquatic biodiversity, inhibit fish migration, and lead to mercury contamination (Montgomery et al., 2000), as well as change watershed sediment dynamics, leading to sediment starvation in coastal areas, which in turn could lead to coastal erosion and make coasts more vulnerable to sea level rise and storm surges (Silvestri and Kershaw, 2010).

The increasing international attention and support for efforts focused on Reducing Emissions from Deforestation and Forest Degradation, maintaining/enhancing carbon stocks, and promoting sustainable forest management (REDD+) is an example of where incentives for the protection and sustainable management of natural resources driven by mitigation concerns also have the potential of generating co-benefits for adaptation. By mediating runoff and reducing flood risk, protecting soil from water and wind erosion, providing climate regulation, and providing migration corridors for species, ecosystem services supplied by forests can increase the resilience to some climatic changes (Locatelli et al., 2010). Primary forests tend to be more resilient to disturbance and environmental changes, such as climate change, than secondary forests and plantations (Thompson et al., 2009). However, forests are also vulnerable to climatic extremes (Nepstad et al., 2007) and the modeled effects of global warming (Vergara and Scholz, 2011). Hence, the role of forest ecosystems in climate change mitigation and adaptation will itself depend on the rate and magnitude of climate change and whether the crossing of ecological tipping points can be avoided.

\subsubsection{The Role of Values and Perceptions in Shaping Response}

Values and perceptions are important in influencing action on climate change extremes, and they can have significant implications for sustainable development. The disaster risk community has used several points of view for resolving decisions about where to invest limited resources, including considerations of economic rationality and moral obligation (Sen, 2000). Value judgments are embedded in problem framing, solutions, development decisions, and evaluation of outcomes, thus it is important to make them explicit and visible. Values describe what is desirable or preferable, and they can be used to represent the subjective, intangible dimensions of the material and nonmaterial world (O'Brien and Wolf, 2010). They are closely linked to worldviews and beliefs, including perceptions of change and causality (Rohan, 2000; Leiserowitz, 2006; Weber, 2010). Values both inform and are shaped by action, judgment, choice, attitude, evaluation, argument, exhortation, rationalization, and attribution of causality (Rokeach, 1979). However, values do not always clearly translate to particular behaviors (Leiserowitz et al., 2005). Recognizing and reconciling conflicting values increases the need for inclusiveness in decisionmaking and for finding ways to communicate across social and professional boundaries (Rosenberg, 2007; Vogel et al., 2007; Oswald Spring and Brauch, 2011).

Losses from extreme events can have implications beyond objective, measurable impacts such as loss of lives, damage to infrastructure, or economic costs. They can lead to a loss of what matters to individuals, communities, and groups, including the loss of elements of social capital, such as sense of place or of community, identity, or culture. This has long been observed within the disaster risk community (Hewitt, 1997; Mustafa, 2005) and in more recent work in the climate change community (O'Brien, 2009; Adger et al., 2010; Pelling, 2010a). A values-based approach recognizes that socioeconomic systems are continually evolving, driven by innovations, aspirations, and changing values and preferences of the constituents (Simmie and Martin, 2010; Hedlund-de Witt, 2011). This approach raises not only the ethical question of 'whose values count?', but also the important political question of 'who decides?'. These questions have been asked in relation to both disaster risk (Blaikie et al., 1994; Wisner, 2003; Wisner et al., 2004) and climate change (Adger, 2004; Hunt and Taylor, 2009; Adger et al., 2010; 0'Brien and Wolf, 2010), and are significant when considering the interaction of climate change and disaster risk, including the complexity of the temporal consequences of policies and decisions (Pelling, 2003).

The probabilistic risk assessments that form the basis for current models of cost-benefit analysis (CBA) rarely take into account the wider consequences that account for a substantial proportion of disaster 
damage for poorer households and communities (UNISDR, 2004, 2009; Marulanda et al., 2010). These include outcomes such as increased poverty and inequality (Hallegatte, 2006; de la Fuente et al., 2009), health effects (Murray and Lopez, 1996; Grubb et al., 1999; Viscusi and Aldy, 2003), cultural assets and historical building losses (ICOMOS, 1998), and environmental impacts, which are often very difficult to measure in monetary terms. Specific approaches allow accounting for distributive effects in CBA (e.g., distributional-weight CBA, see Harberger, 1978; basic-needs CBA, see Harberger, 1984; or social welfare function built as a sum of individual welfare function that increases nonlinearly with income), but none of them are consensual. Other types of valuation emphasize institutional elements such as the 'moral economy' associated with the collective memory and identities of people living in non-western cultures in many parts of the world (Rist, 2000; Hughes, 2001; Trawick, 2001; Scott, 2003).

Two important philosophical value frameworks have dominated attempts to establish priorities for risk management: human rights and utilitarian approaches. Human rights-based approaches (Wisner, 2003; Gardiner, 2010) emphasize moral obligation to reduce avoidable risk and contain loss, which was recognized in the UN Universal Declaration of Human Rights in 1948: Article 3 provides for the right to "life, liberty and security of person," while Article 25 protects "a standard of living adequate for the health and well-being ... in the event of unemployment, sickness, disability, widowhood, or old age or other lack of livelihood in circumstances beyond his [sic] control."

The humanitarian community, and civil society more broadly, has made considerable progress in addressing these aspirations (Kent, 2001), perhaps best exemplified by the Sphere standards. These are a set of self-imposed guidelines for good humanitarian practices that require impartiality in post-disaster actions including shelter management and access to and distribution of relief and reconstruction aid (Sphere, 2004). The ethics and equity dimensions of risk management have also been explored in adaptation through the application of Rawls' theory of justice (Rawls, 1971; Paavola, 2005; Paavola and Adger 2006; Paavola et al., 2006; Grasso, 2009, 2010). From this perspective, priority is given to reducing risk for the most vulnerable, even if this limits the absolute numbers who benefit.

In contrast to focusing on the most excluded or economically poor, utilitarian approaches assume that interpersonal welfare comparisons are possible, and that a social welfare function that summarizes the welfare of a population can be built (Pigou, 1920). Assuming its existence, maximizing this social welfare function reveals where economic benefits of public investments exceed costs. The calculated economic benefits of investing in risk reduction vary, but are often considered significant (see Ghesquiere et al., 2006; World Bank 2010a; UNISDR, 2011). There are, however, extreme difficulties in accounting for the complexity of disaster costs and risk reduction investment benefits (Pelling et al., 2002; Hallegatte and Przyluski, 2010). A key point here is that value frameworks can significantly influence the types of responses to climate and weather extremes.

\subsubsection{Technology Choices, Availability, and Access}

Technology choices can contribute to both risk reduction and risk enhancement, relative to extreme climate and weather events. As discussed in Section 7.4.3, technologies receive prominent attention in both climate change adaptation and disaster risk reduction. Continuing transitions from one socio-technological state to another frame many aspects of responses to climate change risks. Assessments of roles of technology choices, availability, and access in responding to climate extremes are enmeshed in a wide range of technologies that must be considered within a broad range of development contexts. However, in nearly every case, issues are raised about the balance between risk reduction and risk creation. Technology is a broad concept that embraces a range of areas, including information and communication technologies, roads and infrastructure, food and production technologies, energy systems, and so on. Technology choices can alleviate disaster risk, but they can also significantly increase risks and add to adaptation challenges (Jonkman et al., 2010). For example, some modern energy systems and centralized communication systems are dependent on physical structures that can be vulnerable to storm damage. It has been suggested that relatively centralized high-technology systems are 'brittle,' offering efficiencies under normal conditions but subject to cascading effects in the event of emergencies (Lovins and Lovins, 1982).

In many cases, technologies are considered to be an important part of responses to climate extremes and disaster risk. This includes, for example, attention to physical infrastructure, including how to 'harden' built infrastructure such as bridges or buildings, or natural systems such as hillsides or river channels, such that they are able to withstand higher levels of stress (UNFCCC, 2006; Larsen et al., 2007; CCSP, 2008). Another focus is on technologies that assist with information collection and diffusion, including technologies to monitor possible stresses and vulnerabilities, technologies to communicate with populations and responders in the event of emergencies, and technology applications to disseminate information about possible threats and contingencies although access to such technologies may be limited in some developing regions. Seasonal climate forecasts based on the results from numerical climate models have been developed in recent decades to provide multi-month forecasts, which can be used to prepare for floods and droughts (Stern and Easterling, 1999). Modern technological development is exploring a wide variety of innovative concepts that may eventually hold promise for disaster risk reduction, for example, through new food production technologies, although ecological, ethical, and human health implications are often as yet unresolved (Altieri and Rosset, 1999).

Attention to technology alternatives and their benefits, costs, potentials, and limitations in cases where disaster risk is created and when risk reduction takes place involve two different time horizons. In the near term, technologies to be considered are those that currently exist or that can be modified relatively quickly. In the longer term, it is possible to consider potentials for new technology development, given identified needs (Wilbanks, 2010). In some circumstances, technologies put in place to reduce short-term risk and vulnerability can increase future 


\section{FAQ 8.1 | Why is there not a greater emphasis on technology as the solution to climate extremes?}

Technology is an essential part of responses to climate extremes, at least partly because technology choices and uses are so often a part of the problem. Enhancing early warning systems is one example where technology can play an important role in disaster risk management. This example also flags the importance of considering 'hard' (engineering) and 'soft' (social and administrative) technology. Great advances have been made in hard technology around hazard identification, and this has saved many lives. Communicating warnings through the 'soft' technology of institutional reform and communication networks has been less well developed. Both hard and soft technology systems must be responsive to different cultures, environments, and types of governance. Most fundamentally, it is clear that technologies are the product of research and development choices, which reflect particular values, interests, and priorities. The successful transfer of technology is sensitive to local needs, capacities, and development goals. Technologies can have unintended consequences that contribute to maladaptations. For example, some modern agricultural technologies may reduce local biodiversity and constrain future adaptation. Technologies only matter if they are both appropriate and accessible. Technology development and use are necessary for reducing vulnerabilities to climate extremes, both through mitigation and adaptation, but they need to be the right technologies that are deployed in the right ways. This calls for greater reflection on the social, economic, and environmental consequences of technology across both space and time. In many cases, responses to climate extremes can be improved by addressing social vulnerability, rather than focusing exclusively on technological responses.

vulnerability to extreme events or ongoing trends. For example, the use of irrigation has reduced farmer vulnerabilities to low and variable precipitation patterns. However, when the irrigation water is from a nonrenewable source (e.g., the Ogallala-High Plains aquifer system of the United States), the foreseeable reduction in future irrigation opportunities would mean an increase in vulnerability and the risk of increasing crop failures (AAG, 2003; Harrington, 2005).

Similarly, while large dams could mitigate drought and generate electricity, well known costs of social and ecological displacement may be unacceptable (Baghel and Nusser, 2010). Furthermore, unless dams are constructed to accommodate future climate change, they may present new risks to society by encouraging a sense of security that ignores departures from historical experience (Wilbanks and Kates, 2010). In the Mekong region, dikes, dams, drains, and diversions established for flood protection have unexpected consequences for risk over the longer term, because they influence risk-taking behavior (Lebel et al., 2009). In the United States, past building in floodplain areas downstream from dams that have now exceeded their design life has become a major concern; tens of thousands of dams are now considered as having high hazard potential (McCool, 2005; FEMA, 2009; ASCE, 2010).

Investments in physical infrastructure cast long shadows through time, because they tend to assume lifetimes of three to four decades or longer. The gradual modernization of a city's housing stock, transport, or water and sanitation infrastructure takes many decades without targeted planning. If they are maladaptive rather than adaptive, the consequences can be serious. This suggests a reappraisal of technology that might promote more distributed solutions, for example, multiple, smaller dams that can resolve local as well as more distant needs, or widely spread, local energy production (perhaps utilizing micro-solar, wind and water, or geothermal power) that can reduce exposure to secondary impacts from natural disasters when large power generators or power transmission lines are lost during a natural disaster, or when power plants generate secondary disasters after being impacted by a natural hazard, as has happened recently in Japan. The goal of a more distributed and less maximizing development vision has been expressed in Thailand's 'Sufficiency Economy' approach, where local development is judged against its contribution to local, national, and international wealth generation (UNDP, 2007a).

Technology choices, availability, and access depend on more than technology development alone. Unless the technologies, the skills required to use them, and the institutional approaches appropriate to deploy them are effectively transferred from providers to users ('technology transfer'), the effects of technology options, however promising, are minimized (see Section 7.4.3). Challenges in putting science and technology to use for sustainable development have received considerable attention (e.g., Nelson and Winter, 1982; Patel and Pavit, 1995; NRC, 1999; ICSU, 2002; Kristjanson et al., 2009), emphasizing the wide range of contexts that shape both barriers and potentials. If obstacles related to intellectual property rights can be overcome, however, the growing power of the information technology revolution could accelerate technology transfer (linked with local knowledge) in ways that would be very promising (Wilbanks and Wilbanks, 2010).

\subsubsection{Tradeoffs in Decisionmaking: Addressing Multiple Scales and Stressors}

Sustainable development involves finding pathways that achieve a variety of socioeconomic and environmental goals, without sacrificing any one for the sake of the others. As a result, the relationships between adaptation, disaster risk management, and sustainability are highly political. Successful reconciliation of multiple goals "lies in answers to such questions as who is in control, who sets agendas, who allocates resources, who mediates disputes, and who sets rules of the game" 
(Wilbanks, 1994, p. 544). This means that conflicts of interest must be acknowledged and addressed, whether they are between government departments, sectors, or policy arenas, and suggests that simple panaceas are unlikely without tradeoffs in decisionmaking (Brock and Carpenter, 2007).

There is no single or optimal way of adapting to climate change or managing risks, because contexts for risk management vary so widely. For example, risk management decisions can be oriented toward incremental responses to frequent events that are disruptive but perhaps not 'extreme.' Often, tradeoffs between multiple objectives are ambiguous. For example, focusing on and taking actions to protect against frequent events may lead to greater vulnerability to larger and rarer extreme events (Burby, 2006). This is a particular challenge for investing in fixed physical infrastructure. Social investments and risk awareness, including early warning systems, can be strengthened by more frequent low-impact events that maintain risk visibility and allow preparedness for larger, less frequent events (see Case Studies 9.2.11 and 9.2.14). Pielke Jr. et al. (2007) also warn that locating adaptation policy in a narrow risk framework by concentrating only on identifiable anthropogenic risks can distort public policy because vulnerabilities are created through multiple stresses.

As one salient example, during disaster reconstruction, tensions frequently arise between demands for speed of delivery and sustainability of outcome. Response and reconstruction funds tend to be time-limited, often requiring expenditure within 12 months or less from the time of disbursement. This pressure is compounded by multiple agencies working with often limited coordination. Time pressure and competition between agencies tends to promote centralized decisionmaking and the subcontracting of purchasing and project management to non-local commercial actors. Both outcomes save time but miss opportunities to include local people in decisionmaking and learning from the event, with the resulting reconstruction in danger of failing to support local cultural and economic priorities (Berke et al., 1993; Pearce, 2003). At the same time it is important not to romanticize local actors or their viewpoints, which might at times be unsustainable or point to maladaptation, or to accept local voices as representative of all local actors. When successful, participatory reconstruction planning has been shown to build local capacity and leadership, bind communities, and provide mechanisms for information exchange with scientific and external actors (Lyons et al., 2010). As part of any participatory or community-based reconstruction, the importance of a clear conflict resolution strategy has been recognized.

Tradeoffs may also arise through conflicts between economic development and risk management (Kahl, 2003, 2006). The current trend of development in risk-prone areas (e.g., coastal areas in Asia) is driven by socioeconomic benefits yielded by these locations, with many benefits accruing to private investors or governments through tax revenue. For example, export-driven economic growth in Asia favors production close to large ports to reduce transportation time and costs. Consequently, the increase in risk has to be balanced against the socioeconomic gains of development in at-risk areas. Additional construction in at-risk areas is not unacceptable a priori, but has to be justified by other benefits, and sometimes complemented by other risk-reducing actions (e.g., early warning and evacuation, improved building norms, specific flood protection). This introduces the possibility for those benefiting financially to offset produced risk through risk reduction mechanisms ranging from fair wages and disaster-resistant housing (to enhance worker resilience) to support for early warning, preparedness, and reconstruction. Such approaches have been considered in some businesses through corporate social responsibility agendas (Twigg, 2001).

One climate change/development tradeoff linked both to timeframes and the magnitude of climate extremes is the future need for risk reduction infrastructure that would require changes in ecologically or historically important areas. For example, when considering additional protection (e.g., dikes and seawalls) in historical centers, aesthetic and cultural elements as well as building costs will be taken into account. Existing planning and design standards to protect cultural heritage or ecological integrity may need to be balanced with the needs of adaptation (Hallegatte et al., 2011a). Difficulties in attributing value to cultural and ecological assets mean that CBAs are not the best tool to approach these types of problems. Multi-criteria decisionmaking tools (Birkmann, 2006) that incorporate a participatory element and can recognize the political, ethical, and philosophical aspects of such decisions can also be useful (Mercer et al., 2008). But the magnitude of emerging climate extremes is an important issue. If climate change is relatively severe, rather than moderate, then the focus on preserving iconic areas is likely to increase, as will the costs.

Another contextual complication that introduces tradeoffs is the fact that impacts of climate change extremes extend across multiple scales. The challenge is to find ways to combine the strengths of addressing multiple scales, rather than having them work against each other (Wilbanks, 2007, 2009). Local scales offer potentials for bottom-up actions that ensure participation, flexibility, and innovation. At the same time, efforts to develop initiatives from the bottom up are often limited by a lack of information, limited resources, and limited awareness of larger-scale driving forces (AAG, 2003). Larger scales offer potentials for top-down actions that assure resource mobilization and cost sharing. Integrating these kinds of assets across scales is often essential for resilience to extremes, but in fact, integration is profoundly impeded by differences in who decides, who pays, and who benefits, and perceptions of scalar effects that often reflect striking ignorance and misunderstanding (Wilbanks, 2007). In recent years, there have been a number of calls for innovative co-management structures that cross scales in order to promote sustainable development (e.g., Bressers and Rosenbaum, 2003; Cash et al., 2006; Campbell et al., 2010).

What might be done to realize potentials for integrating actions at different scales to make them more complementary and reinforcing? Many top-down interventions (from international donor development and disaster response and reconstruction funding to new adaptation fund mechanisms and national programming) may unintentionally discourage local action by imposing bureaucratic conditions for access 
to financial and other resources (Christoplos et al., 2009). Top-down sustainability initiatives are often preoccupied with input metrics, such as criteria for partner selection and justifications (often based on relatively detailed quantitative analyses of such attributes as 'additionality'), rather than on outcome metrics, such as whether the results make a demonstrable contribution to sustainability (regarding metrics, see NRC, 2005).

To manage tradeoffs and conflicts in an open, efficient, and transparent way, institutional and legal arrangements are extremely important. The existing literature on legislation for adaptation at the state level is not comprehensive, but those countries studied lack many of the institutional mechanisms and legal frameworks that are important for coordination at the state level (Richardson et al., 2009). This has been found to be the case for Vietnam, Laos, and China (Lin, 2009). In the South Pacific, high exposure to climate change risk has yet to translate into legislative frameworks to support adaptation - with only Fiji, Papua New Guinea, and Western Samoa formulating national climate change regulatory frameworks (Kwa, 2009). Without a supporting and implemented national legislative structure, achieving local disaster reduction and climate change adaptation planning can be complicated (La Trobe and Davis, 2005; Pelling and Holloway, 2006; see also Section 6.4). Still, where local leadership is determined, skillful planning is possible, even without legislation. This has been the experience of Ethekwini Municipality (the local government responsible for the city of Durban, South Africa), which has developed a Municipal Climate Protection Programme with a strong and early focus on adaptation without nationallevel policy or legal frameworks to guide adaptation planning at the local level (Roberts, 2008, 2010).

One way around the challenges of tradeoffs is to 'bundle' multiple objectives through broader participation in strategy development and action planning, both to identify multiple objectives and to encourage attention to mutual co-benefits. In this sense, both the pathway and outcomes of development planning have scope to shape future social capacity and disaster risk management. Policies and actions to achieve multiple objectives include stakeholder participation, participatory governance (IRGC, 2009), capacity building, and adaptive organizations, including both private and public institutions where there is a considerable knowledge base reflecting both research and practice to use as a starting point (e.g., NRC, 2008). Multi-hazard risk management approaches provide opportunities to reduce complex and compound hazards, both in rural and urban contexts.

\subsection{Integration of Short- and Long-Term Responses to Extremes}

When considering the linkages between disaster management, climate change adaptation, and development, time scales play an important role. Disaster management increasingly emphasizes vulnerability reduction in addition to the more traditional emergency response and relief measures. This requires addressing underlying exposure and sensitivity in the context of hazards with different frequencies and return periods. As discussed in Chapter 2, there is now a converging focus on vulnerability reduction in the context of disaster risk management and adaptation to climate change (Sperling and Szekely, 2005).

Cross-scale (spatial and temporal) interactions between responses focusing on the short term and those required for long-term adjustment can potentially create both synergies and contradictions among disaster risk reduction, climate change adaptation, and development. This section assesses the literature regarding synergies and tradeoffs between shortand long-term adjustments. First, we consider the implications of presentday responses for future well-being. The barriers to reconciling shortand long-term goals are then assessed. Insights from research on the resilience of social-ecological systems are then considered as a potential means of addressing integration in a long-term perspective.

\subsubsection{Implications of Present-Day Responses for Future Well-Being}

The implications of present-day responses to both disaster risk and climate change can be either positive or negative for human security and well-being in the long term. Positive implications can include increased resilience, capacity building, broad social benefits from extensive participation in risk management and resilience planning, and the value of multi-hazard planning (see Sections 5.4 and 6.5). Negative implications can include threats to sustainability if the well-being of future generations is not considered; issues related to the economic discounting of future benefits; 'silo effects' of optimizing responses for one system or sector without considering interaction effects with others (see Burby et al., 2001); equity issues regarding who benefits and who pays; and the 'levee effect,' where the adaptive solution to a current risk management problem builds confidence that the problem has been solved, blinding populations to the possibility that conditions may change and make the present adaptation inadequate (Burby, 2006; Burby et al., 2006).

The terms 'coping' and 'adaptation' reflect strategies for adjustments to changing climatic and environmental conditions. In the case of a set of policy choices, both coping and adaptation denote forms of conduct that aim and indeed may achieve modifications in the ways in which society relates to nature, and nature to society (Stehr and von Storch, 2005). As discussed in Section 2.4, coping actions are those that take place when trying to alleviate the impacts or to live with the costs of a specific event. They are usually found during the unfolding of disaster impacts, which can continue for some time after an event - for example, if somebody loses their job or is traumatized. Coping strategies can help to alleviate the immediate impact of a hazard, but may also increase vulnerabilities over the medium to longer term (Swift, 1989; Davies, 1993; Sperling et al., 2008). The different time frames for coping and adaptation can present challenges for risk management. Focusing on short-term responses and coping strategies can limit the scope for adaptation in the long term. For example, drought can force agriculturalists 
to remove their children from school or delay medical treatment, which may have immediate survival benefits, yet in aggregate undermines the human resources available for long-term adaptation (Norris, 2005; Alderman et al., 2006; Santos, 2007; Sperling et al., 2008).

In both developed and developing countries, a focus on coping with the present is often fueled by the perception that climate change is a longterm issue and that other challenges, including economic growth, food security, water supply (Bradley et al., 2006), sanitation, education, and health care, require more immediate attention (Klein et al., 2005; Adly and Ahmed, 2009; Kameri-Mbote and Kindiki, 2009). Particularly in poor rural contexts, short-term coping may be a tradeoff that increases longer-term risks (UNISDR, 2009; Brauch and Oswald Spring, 2011). Adaptation, on the other hand, is often focused on minimizing potential risk to future losses (Oliver-Smith, 2007). This 'long-term' framing of adaptation can constrain both short-term coping and adaptive capacity, for example, when relocation of settlements to avoid coastal hazards undermines social capital and local livelihoods, limiting household coping and adaptive capacity (Hunter, 2005). There is a large literature and much experience related to slum relocation that is of direct relevance to urban coping and adaptation (Gilbert and Ward, 1984; Davidson et al., 1993; Viratkapan and Perera, 2006). Context is important in discussing tradeoffs between addressing short- and long-term risks, and even in wellgoverned systems, political expediency will often distort the regulatory process in a way that favors the short term (Platt, 1999).

Disasters can destroy assets and wipe out savings, and can push households into 'poverty traps,' that is, situations where productivity is reduced, making it impossible for households to rebuild their savings and assets (Zimmerman and Carter, 2003; Carter et al., 2007; Dercon and Outes, 2009; López, 2009; van den Berg, 2010). The process by which a series of events generates a vicious spiral of impacts, vulnerability, and risk was first recognized by Chambers (2006), who described it as the ratchet effect of disaster, risk, and vulnerability. These micro-level poverty traps can also be created by health and social impacts of natural disasters: it has been shown that disasters can have long-lasting consequences for psychological health (Norris, 2005), and for child development from reduction in schooling and diminished cognitive abilities (see Alderman et al., 2006; Santos, 2007; Bartlett, 2008).

Where disaster loss is widespread, micro-level poverty traps can aggregate to the regional level. Here, poor regions impacted by disaster are unable to fully recover so that capacity is reduced and vulnerability heightened, making future disasters more likely. Without enough time to rebuild between events, such regions may end up in a state of permanent reconstruction, with resources devoted to repairing and replacing rather than accumulating infrastructure and equipment. This obstacle to capital accumulation and infrastructure development can lead to a permanent disaster-related underdevelopment (Hallegatte et al., 2007; Hallegatte and Dumas, 2008). This can be amplified by other long-term mechanisms, such as changes in risk perception that reduce investments in the affected regions or reduced services that make qualified workers leave the region. These effects have been discussed by Benson and Clay (2004), and investigated by Noy (2009) and Hochrainer (2009), who found that natural disasters have a negative impact on economic growth and development, especially when direct losses are large. This negative impact is found to be larger when the disaster affects a smaller country, with lower GDP per capita, weaker institutions, lower openness to trade, lower literacy rates, and lower levels of government spending, and when foreign aid and remittances are lower. Such effects have been modeled by Hallegatte et al. (2007) and Hallegatte and Dumas (2008) using a reduced-form economic model that shows that the average GDP impact of natural disasters can be either close to zero if reconstruction capacity is large enough, or very large if reconstruction capacity is too limited, which may be the case in less-developed countries. There are, however, many uncertainties in the ways in which people's spontaneous and organized responses to increasing climate-related hazards feed back to influence long-term adaptive capacity and options. Migration, which can be traumatic for those involved, might lead to enhanced life chances for the children of migrants, building long-term capacities and potentially also contributing to the movement of populations away from places exposed to risk (IOM, 2007, 2009a,b; Ahmed, 2009; Oswald Spring, 2009b; UNDP, 2009).

A broad literature on experiences of community-based and local-level disaster risk reduction indicates options for transiting from short- to longer-term responses, at least in the context of frequently occurring risk manifestations (Lavell, 2009; UNISDR, 2009; Maskrey, 2011). Such approaches, many of which are based on community participation, have progressively moved from addressing disaster preparedness and capacities for emergency management toward addressing the vulnerability of livelihoods, the decline of ecosystems, the lack of social protection, unsafe housing, the improvement of governance, and other underlying risk factors (Bohle, 2009). While managing existing risk will contain loss, addressing underlying risk drivers will contribute to a reduction in future risk to climate extremes.

\subsubsection{Barriers to Reconciling Short- and Long-Term Goals}

Although there is robust evidence in the literature to support disaster risk reduction as a strategy for long-term climate change adaptation, there are numerous barriers to reconciling short- and long-term goals. Many poor countries are very vulnerable to natural hazards but cannot implement the measures that could reduce this vulnerability for financial reasons, or due to a lack of governance capacity or technology. The recent national self-assessments of progress toward achieving the UNISDR Hyogo Framework for Action indicated that some least-developed countries lack the human, institutional, technical, and financial capacities to address even emergency management concerns (UNISDR, 2009). A recently developed index that measures capacities and conditions for risk reduction shows that low- and lower-middle-income countries with weak governance have, with some exceptions, great difficulty addressing underlying drivers of vulnerability. Those at the bottom of the index, such as Haiti, Chad, or Afghanistan, are also experiencing conflict or political instability (UNISDR, 2011). Another obstacle to reconciling 
short- and long-term goals is access to technology and maintenance of infrastructure. An example is the introduction of water reuse technologies, which have been developed in a few countries, which could bring a great improvement in the management of droughts if they could be disseminated in many developing countries (Metcalf \& Eddy, 2005).

Money and technology are not enough to implement efficient disaster risk reduction and adaptation strategies. Indeed, differences in resources cannot explain the differences in exposure and vulnerability among regions (Nicholls et al., 2008). Governance capacities and the inadequacy of and lack of synergy between institutional and legislative arrangements for disaster risk reduction, climate change adaptation, and poverty reduction are also as much a part of the problem as the shortage of resources. Institutional and legal environments and political will are important, as illustrated by the difference in risk management in various regions of the world (Pelling and Holloway, 2006). In many countries disaster risk management and adaptation to climate change measures are overseen by different institutional structures (see Section 1.1.3). This is explained by the historical evolution of both approaches.

Disaster risk management originated from humanitarian assistance efforts, evolving from localized, specific response measures to preventive measures, which seek to address the broader environmental and socioeconomic aspects of vulnerability that are responsible for turning a hazard into a disaster in terms of human and/or economic losses. Within countries, disaster risk management efforts are often coordinated by civil defense agencies, while measures to adapt to climate change are usually developed by environment ministries. Responding to climate change was originally more of a top-down process, where advances in scientific research led to international policy discussions and frameworks. While the different institutional structures may represent an initial coordination challenge, the converging focus on vulnerability reduction represents an opportunity for managing disaster and climate risks more comprehensively within the development context (Sperling and Szekely, 2005). A change in the culture of public administration toward creative partnerships between national and local governments and empowered communities has been found in some cases to dramatically reduce costs (Dodman et al., 2008).

In addition to the barriers described above, there is also a tendency for individuals and groups to focus on the short-run and to ignore lowprobability, high-impact events. The following studies discuss some of the psychological and economic barriers shaping how people make decisions under uncertainty:

- Underestimation of the risk: Even when individuals are aware of the risks, they often underestimate the likelihood of the event occurring (Smith and McCarty, 2006). This bias can be amplified by natural variability (Pielke Jr. et al., 2008), where there is expert disagreement, and where there is uncertainty. Magat et al. (1987), Camerer and Kunreuther (1989), and Hogarth and Kunreuther (1995), for example, provide considerable empirical evidence that individuals do not seek information on probabilities in making their decisions.
- Budget constraints: If there is a high upfront cost associated with investing in adaptation measures, individuals will often focus on short-run financial goals rather than on the potential long-term benefits in the form of reduced risks (Kunreuther et al., 1978; Thaler, 1999).

- Difficulties in making tradeoffs: Individuals are also not skilled in making tradeoffs between costs and benefits of these measures, which requires comparing the upfront costs of the measure with the expected discounted benefits in the form of loss reduction over time (Slovic, 1987).

- Procrastination: Individuals are observed to defer choosing between ambiguous choices (Tversky and Shafir, 1992; Trope and Liberman, 2003).

- Samaritan's dilemma: Anticipated availability of post-disaster support can undermine self-reliance when there are no incentives for risk reduction (Burby et al., 1991).

- Politician's dilemma: Time delays between public investment in risk reduction and benefits when hazards are infrequent, and the political invisibility of successful risk reduction can be pressures for a 'not in my term of office' attitude that leads to inaction (MichelKerjan, 2008).

Work in West and East Africa has shown that rural communities tend to underestimate external forces that influence their region while overestimating their own response capacity (Enfors et al., 2008; Tschakert et al., 2010). Misjudging external drivers may be explained by the low degree of control people feel they have over these drivers, resulting in reactions that range from powerlessness to denial. Another issue that makes it difficult to reconcile short- and long-term goals arises from the challenges in projecting the long-term climate and corresponding risks (see Section 3.2.3). Examples of this challenge are reflected in the demographic growth of Florida in the 1970s and 1980s, which unfolded during a period of low hurricane activity but may expose larger populations to the risks associated with extreme climate and weather events. Major engineering projects with long lead times from planning to implementation have difficulty factoring in climate change futures, and have instead been planned according to historic hazard risk (Pielke Jr. et al., 2008). Managing natural risks and adapting to climate change requires anticipating how natural hazards will change over the next decades, but uncertainty about climate change and natural variability is a significant obstacle to such anticipation (Reeder et al., 2009).

Climate change is typically viewed as a slow-onset, multigenerational problem. Consequently, individuals, governments, and businesses have been slow to invest in adaptation measures. Research in South Asia shows that in those regions where past development had prioritized short-term gains over long-term resilience, agricultural productivity is in decline because of drought and groundwater depletion, rural indebtedness is increasing, and households are sliding into poverty with particularly insidious consequences for women, who face the brunt of nutritional deprivation as a result (Moench et al., 2003; Moench and Dixit, 2007). Connecting short- and long-term perspectives is thus seen as critical to 
realizing the synergies between disaster risk management and climate change adaptation.

\subsubsection{Connecting Short- and Long-Term Actions to Promote Resilience}

The previous section has highlighted the importance of linking shortand long-term responses so that disaster risk reduction and climate change adaptation mutually support each other. A systems approach that emphasizes cross-scale interactions can provide important insights on how to realize synergies between disaster risk management and climate change adaptation. Resilience, a concept fundamentally concerned with how a system, community, or individual can deal with disturbance and surprise, increasingly frames contemporary thinking about sustainable futures in the context of climate change and disasters (Folke, 2006; Walker and Salt, 2006; Brand and Jax, 2007; Bahadur et al., 2010). It has developed as a fusion of ideas from several bodies of literature: ecosystem stability (e.g., Holling, 1973; Gunderson, 2009), engineering robust infrastructures (e.g., Tierney and Bruneau, 2007), the behavioral sciences (Norris, 2010), psychology (e.g., Lee et al., 2009), disaster risk reduction (e.g., Cutter et al., 2008), vulnerabilities to hazards (Moser, 2009), and urban and regional development (e.g., Simmie and Martin, 2010). In the context of this report, resilience refers to a system's capacity to anticipate and reduce, cope with, and respond to and recover from external disruptions (see Sections 1.1.2.1 and 1.3.2). Resilience perspectives can be used as an approach for understanding the dynamics of humanenvironmental systems and how they respond to a range of different perturbations (Carpenter et al., 2001; Walker et al., 2004).

'Resilience thinking' (Walker and Salt, 2006) may provide a useful framework to understand the interactions between climate change and other challenges, and in reconciling and evaluating tradeoffs between short- and longer-term goals in devising response strategies. Approaches that focus on resilience emphasize the need to manage for change, to see change as an intrinsic part of any system, social or otherwise, and to 'expect the unexpected.' Resilience thinking goes beyond the conventional engineering systems' emphasis on capacity to control and absorb external shocks in systems assumed to be stable (Folke, 2006). For social-ecological systems (examined as a set of interactions between people and the ecosystems they depend on), resilience involves three properties: the amount of change a system can undergo and retain the same structure and functions; the degree to which it can reorganize; and the degree to which it can build capacity to learn and adapt (Folke, 2006). Resilience can also be considered a dynamic process linked to human agency, as expressed in the ability to deal with hazards or disturbance, to engage with uncertainty and future changes, to adapt, cope, learn, and innovate, and to develop leadership capacity (Bohle et al., 2009; Obrist et al., 2010).

Resilience approaches offer four key contributions for living with extremes: first, in providing a holistic framework to evaluate hazards in coupled social-ecological systems; second, in putting emphasis on the capacities to deal with hazard or disturbance; third, in helping to explore options for dealing with uncertainty and future changes; and fourth, in identifying enabling factors to create proactive responses (Berkes, 2007; Obrist et al., 2010).The concept of resilience is already being applied as a guiding principle to disaster risk reduction and adaptation issues, as well as to examine specific responses to climate change in different developed and developing country contexts (e.g., Cutter et al., 2008). Eakin and Webbe (2008) use a resilience framework to show that the interplay between individual and collective adaptation can be related to wider system sustainability. Goldstein (2009) uses resilience concepts to strengthen communicative planning approaches to dealing with surprise. Linnenluecke and Griffiths (2010) use a resilience framework to explore organizational adaptation to climate change and weather extremes, and suggest that organizations may need to develop multiple capabilities and response approaches in response to changing extremes. Nelson et al. (2007) have shown how resilience thinking can enhance analyses of adaptation to climate change: as adaptive actions affect not only the intended beneficiaries but have repercussions for other regions and times, adaptation is part of a path-dependent trajectory of change. Resilience also considers a distinction between incremental adjustments and system transformation, which may broaden the expanse of adaptation and also provide space for agency (Nelson et al., 2007). Resilience approaches can be seen as complementary to agent-based analyses of climate change responses that emphasize processes of negotiation and decisionmaking, as they can provide insights into the systems-wide implications. Adger et al. (2011) show that dealing with specific risks without taking into account the nature of system resilience can lead to responses that potentially undermine long-term resilience.

Recent work on resilience and governance has focused on communication of science between actors and depth of inclusiveness in decisionmaking as key determinants of the character of resilience. In support of these approaches it is argued that inclusive governance facilitates better flexibility and provides additional benefit from the decentralization of power. On the down side, greater participation can lead to loose institutional arrangements that may be captured and distorted by existing vested interests (Adger et al., 2005; Plummer and Armitage, 2007). Still, the balance of argument (and existing centrality of institutional arrangements) calls for a greater emphasis to be placed on the inclusion of local and lay voices and of diverse stakeholders in shaping agendas for resilience through adaptation and adaptive management (Nelson et al., 2007). Striking the right balance between top-down command-and-control approaches, which offer stability over the short term but reduced long-term resilience, and more flexible, adaptive forms of risk management is the core practical challenge that disaster risk management brings to climate change adaptation under conditions of climatic extremes and projected increases in disaster risk and impacts (Sperling and Szekely, 2005).

Resilience thinking is not without its critiques (Nelson, 2009; Pelling, 2010a). Shortcomings include the downplaying of human agency in systems approaches and difficulty in including analysis of power in explanations of change, which combine to effectively promote stability 
rather than flexibility, that is, maintaining the status quo and thus serving particular interests rather than supporting adaptive management, social learning, or inclusive decisionmaking. One challenge to enhancing resilience of desired system states is to identify how responses to any single stressor influence the larger, interconnected social-ecological system, including the system's ability to absorb perturbations or shocks, its ability to adapt to current and future changes, and its ability to learn and create new types or directions of change. Responses to one stressor alone may inadvertently undermine the capacity to address other stressors, both in the present and future. For example, coastal towns in eastern England, experiencing worsening coastal erosion exacerbated by sea level rise, are taking their own action against immediate erosion in order to protect livelihoods and homes, affecting sediments and erosion rates down the coast (Milligan et al., 2009). While such actions to protect the coast are effective in the short term, in the long term, investing to 'hold the line' may diminish capital resources for other adaptations and hence reduce adaptive capacity to future sea level rise. Thus, dealing with specific risks without a full accounting of the nature of system resilience can lead to responses that can potentially undermine longterm resilience. Despite an increasing emphasis on managing for resilience (Walker et al., 2002; Lebel et al., 2006), the resilience lens alone may not sufficiently illuminate how to enhance agency and move from the understanding of complex dynamics to transformational action.

\subsection{Implications for Access to Resources, Equity, and Sustainable Development}

The previous section assessed the links between short- and long-term responses to climate extremes. This section takes the idea of links further. It explores the relationships between climate change adaptation, disaster risk management, and mitigation, and larger issues related to equity, access to resources, environmental and ecosystem protection, and related development processes. This draws out the importance of governance in determining the relationship between disaster risk and underlying processes of unequal socioeconomic development and environmental injustices (Maskrey, 1994; Sacoby et al., 2010). The section discusses issues related to capacity and equity, the existence of winners and losers from disaster and disaster management policy, and opportunities for contributing to wider development goals including the enhancing of human security.

\subsubsection{Capacities and Resources: Availability and Limitations}

The capacity to manage risks and adapt to change is unevenly distributed within and across nations, regions, communities, and households (Hewitt, 1983; Wisner et al., 2004; Beck, 2007). The literature on how these capacities contribute to disaster risk management and climate change adaptation emphasizes the role of economic, financial, social, cultural, human, and natural capital, and of institutional context (see
Sections 1.4 and 2.4). When the poor are impacted by disasters, limited resources are quickly expended in coping actions that can further undermine household sustainability in the long run, reducing capital and increasing hazard exposure or vulnerability. In these vicious cycles of decline, households tend first to expend savings and then, if pressures continue, to withdraw members from non-productive activities such as school, and finally to sell productive assets. As households begin to collapse, individuals may be forced to migrate or in some cases enter into culturally inappropriate, dangerous, or illegal livelihoods such as the sex industry (Mgbako and Smith, 2010; Ferris, 2011). This poverty and vulnerability trap means that recovery to pre-disaster levels of wellbeing becomes increasingly difficult (Burton et al., 1993; Adger, 1996, Wisner et al., 2004; Chambers, 2006).

Children, the elderly, and women stand out as more vulnerable to extreme climate and weather events. The vulnerability of children and their capacity to respond to climate change and disasters is discussed in Box 8-2 (see also Section 5.5.1 and Case Study 9.2.14). Among the elderly, increasing numbers will become exposed to climate change impacts in the coming decades, particularly in OECD countries where populations are aging most rapidly. By 2050, it is estimated that one in three people will be older than 60 years in OECD countries, as well as one in five at the global scale (UN, 2002). The elderly are made additionally vulnerable to climate change-related hazards by characteristics that also increase vulnerability to other social and environmental hazards (thus compounding overall vulnerability): deterioration of health, personal lifestyles, social isolation, poverty, and inadequate access to health and social infrastructures (OECD, 2006). Gender impacts vulnerability in many ways. In the 1991 cyclone in Bangladesh, the death toll among women was reportedly five times higher than among men (UNDP, 2007b). Cultural as well as physiological factors are widely cited for the over-representation of female deaths from flooding. Gender inequality extends into female-headed households to compound the vulnerability of dependent children or elderly (Cannon, 2002; UNISDR, 2008; Oxfam, 2010). Inequality has many other important faces: race, caste, religious affiliation, and physical disability, all of which help determine individual and household vulnerability, and they cross-cut gender and age effects. Importantly, the social construction of vulnerability through these characteristics highlights the ways in which vulnerability changes over time - in this case with changes in family structure and access to services in response to economic cycles and political and cultural trends evolving as the climate changes with potentially compounding effects (Leichenko and O'Brien, 2008).

Studies also show that female-headed households more often borrow food and cash than rich and male-headed households during difficult times. This coping strategy is considered to be a dangerous one as the households concerned will have to return the food or cash soon after harvests, leaving them more vulnerable as they have less food or cash to last them the season and to be prepared if disaster strikes (Young and Jaspars, 1995). This may leave households in a cycle of poverty from one season to the next. Literature shows that this outcome is linked to unequal access by women to resources, land, and public and privately 


\section{Box 8-2 | Children, Extremes, and Equity in a Changing Climate}

The linkages between children and extreme events have been addressed through two principal lenses.

\section{Differentiated Impacts and Vulnerability}

The literature estimates that 66.5 million children are affected annually by disasters (Penrose and Takaki, 2006). Research on disaster impacts among children focuses on short- and long-term physical and psychological health impacts (Norris et al., 2002; Bunyavanich et al., 2003; del Ninno and Lindberg, 2005; Balaban, 2006; Waterson, 2006; Bartlett, 2008). Vulnerability to these impacts in part is due to the less-developed physical and mental state of children, and therefore differential capacities to cope with deprivation and stress in times of disaster (Cutter, 1995; Bartlett, 2008; Peek, 2008).

Most literature points toward higher mortality and morbidity rates among children due to climate stresses and extreme events (Cutter, 1995; Bunyavanich et al., 2003; Telford et al., 2006; Waterson, 2006; Bartlett, 2008; Costello et al., 2009). This is especially acute in developing countries, where climate-sensitive health outcomes such as malnutrition, diarrhea, and malaria are already common and coping capacities are lowest (Haines et al., 2006), although research in the United States found relatively low child mortality from disasters and considerable differences across age groups for different types of hazard (Zahran et al., 2008).

Recent studies conducted in Bolivia, Indonesia, Mexico, Mozambique, Nepal, the Philippines, and Vietnam provide evidence of how extensive (low impact/high frequency) disasters negatively affect children's education, health, and access to services such as water and sanitation, an issue of critical importance given the importance of primary education for human and long-term economic development. In areas in Bolivia that experienced the greatest incidence of extensive disasters, the gender gap in primary education achievement widened, preschool enrollment rates decreased, and dropout rates increased. Equivalent areas in Nepal and Vietnam saw, respectively, reduced primary enrollment rates and a drop in the total number of children in primary education. Extensive disasters also led to an increased incidence of diarrhea in children under five years of age in Bolivia, an increased proportion of malnourished children under three in Nepal, an increased infant mortality rate in Vietnam, and an increase in the incidence of babies born with low birth weight in Mozambique. This study also found evidence of negative impacts in terms of access to water and sanitation in Mexico and Vietnam (UNISDR, 2011).

These studies underpin the need for resources for child protection during and after disaster events (Last, 1994; Jabry, 2003; Bartlett, 2008; Lauten and Lietz, 2008; Weissbecker et al., 2008). These include protection from abuse, especially during displacement, social safety nets to guard against withdrawal from school due to domestic or livelihood duties, and dealing with psychological and physical health issues (Norris et al., 2002; Keenan et al., 2004; Evans and Oehler-Stinnett, 2006; Waterson, 2006; Bartlett, 2008; Davies et al., 2008; Lauten and Lietz, 2008; Peek, 2008).

\section{Children's Agency and Resource Access}

Rather than just vulnerable victims requiring protection, children also have a critical role to play in tackling extreme events in the context of climate change (Tanner, 2010). There is also increasing attention on child-centered approaches to preventing, preparing for, coping with, and adapting to extreme events (Peek, 2008; Tanner, 2010).

While often centered on disaster preparedness and climate change programs in education and schools (Wisner, 2006; Bangay and Blum, 2010), more recent work emphasizes the latent capacity of children to participate directly in disaster risk reduction or adaptation supported through child-centered programs (Back et al., 2009; Tanner et al., 2009). This emphasis acknowledges the unique risk perceptions and risk communication processes of children, and their capacity to act as agents of change before, during, and after disaster events (see collections of case studies in Peek, 2008; Back et al., 2009; and Tanner, 2010). Examples demonstrate the ability to reduce risk behavior at household and community scales, but also to mobilize adults and external policy actors to change wider determinants of risk and vulnerability (Mitchell et al., 2008; Tanner et al., 2009). 
provided services (Agarwal, 1991; Thomas-Slayter et al., 1995; Nemarundwe, 2003; Njuki et al., 2008). But women are also often the majority holders of social capital and the mainstay of social movements and local collective action, providing important mechanisms for household and local risk reduction and potentially transformative resilience. Important here are local saving groups and microcredit/micro-finance groups, some of which extend to micro-insurance. In a review of microfinance for disaster risk reduction and response in South Asia, Chakrabarti and Bhatt (2006) identify numerous initiatives, including those that build on extensive social networks and connect to the formal financial services sector.

Demographic and sociological diversity is also difficult to capture in decisionmaking, where non-scientific knowledge is less easily incorporated into formal decisionmaking. The importance of culture, including traditional knowledge, in shaping strategies for adaptation is recognized (Heyd and Brooks, 2009; ISET, 2010). There is a long tradition of seeking to identify and bring such knowledge into planned disaster risk management in urban and rural contexts through participatory and community-based disaster risk management (Bruner et al., 2001; Fearnside, 2001; Pelling, 2007; Mercer et al., 2008) and tools such as participatory geographic information systems that explicitly seek to bring scientific and local knowledge together (Tran et al., 2009). Both development planning and post-disaster recovery have tended to prioritize strategic economic sectors and infrastructure over local livelihoods and poor communities (Maskrey, 1989, 1996). However, this represents a missed opportunity for building local capacity and including local visions for the future in planning the transition from reconstruction to development - opportunities that could increase long-term sustainability (Christoplos, 2006).

\subsubsection{Local, National, and International Winners and Losers}

While climate-related disasters cannot always be prevented, the scale of loss and its social and geographical distribution do differ significantly, determined by the characteristics of those at risk and overarching structures of governance including the legacy of preceding development paths for social institutions, economies, and physical assets (OliverSmith, 1994). But some people also benefit from disasters. These may be organizations or individuals who benefit economically from reconstruction or response (West and Lenze, 1994; Hallegatte, 2008b), through supplying materials, equipment, and services - often at a premium price generated by local scarcity and inflationary pressures (Benson and Clay, 2004) or as a result of poorly managed tendering processes (Klein, 2007). Areas not impacted by disaster can also experience economic benefits, for example, in the Caribbean where hurricanes have caused international tourist flows to be redirected (Pelling and Uitto, 2001). Political actors can also benefit by demonstrating strong post-disaster leadership, at times even when past political decisions have contributed to generating disaster risk (Olson and Gawronski, 2003; Le Billon and Waizenegger, 2007; Gaillard et al., 2008). The same can be said for climate change, with very unequal consequences in various regions of the world and various economic sectors and social categories (Adger et al., 2003; O'Brien et al., 2004; Tol et al., 2004). Less directly, those who have benefited from policies and processes, such as expansion of commercial agriculture or logging, can also be described as benefiting from decisions that have generated vulnerability and prefigured disaster for others. Such costs and benefits are often separated geographically and temporally, making any efforts at distributional equity challenging. For example, in the case of Hurricane Mitch, which killed more than 10,000 people and caused as much as US\$ 8.5 billion in damages, deforestation and rapid urban growth are often cited among the key causes of the disaster-related losses (Alves, 2002; Pielke Jr. et al., 2003), with those benefiting from such development including distant speculators.

Analyses of winners and losers associated with climate change and discrete hazards need differentiation. In almost every circumstance, what one part of society views as a win can be viewed by another part as a loss. In examining possible responses to risks of climate extremes, it is essential to recognize that possible impacts interact with vested interests of different locations, sectors, and population groups in very different ways. In virtually every case, the question is: benefits for whom? Who says that this course of action is best for society as a whole? What compensation is offered for those who are losers? In particular, who is listening to views of those parts of society that have less political power and influence?

While individual events can be assessed as a snapshot of winners and losers, climate change as an ongoing process has no final state. Over time, it may produce different distributions of winners and losers, for example, as areas experience positive and then negative consequences of changes in temperature or precipitation. Whether or not a particular place produces winners or losers from an extreme event or a combination of climate extremes and other driving forces also depends on perceptions. These may be shaped by the recovery process, but are strongly influenced by prioritized values (Quarantelli, 1984, 1995; O'Brien, 2009; O'Brien and Wolf, 2010). In considering winners and losers from extreme climate and weather events, and also from the outcomes of policies directed at reducing disaster risk or responding to climate change, it is thus vital to recognize the subjective understanding of winners and losers.

Much depends upon an individual, group, or society's dominant values, perspectives, and access to information. While some regard winners and losers as a natural and inevitable outcome of ecological changes and/or economic development, others suggest that winners and losers are deliberately generated by unequal political and social conditions (O'Brien and Leichenko, 2003; Wisner, 2003). Lurking behind discourses about winners and losers are issues of liability and compensation for losses: that is, if a population or an area experiences severe losses due to an extreme event (at least partly) attributed to climate change, can fault be prescribed? Does responsibility lie with those who have generated local environmental change through settling a hazard-exposed area, those who have promoted or permitted such settlement, or those who have failed to mitigate local hazard or global environmental change? 
Issues of equity, justice, and compensation are emerging in climate change adaptation, but few have begun to deal with questions of liability for disaster risk production beyond the local scale (Kent, 2001; Mitchell, 2001; Wisner, 2001; 0'Brien et al., 2010b). It seems that efforts to assign responsibility will emerge as an issue for both governments and courts at a range of scales (Farber, 2007).

\subsubsection{Potential Implications for Human Security}

Changes in extreme climate and weather events threaten human security, and both disaster risk management and climate change adaptation represent strategies that can improve human security while also avoiding disasters. Human security addresses the combined but related challenges of upholding human rights, meeting basic human needs, and reducing social and environmental vulnerability (UNDP, 1994; Sen, 2003; Bogardi and Brauch, 2005; Brauch 2005a,b, 2009; Fuentes and Brauch, 2009). It also emphasizes equity, ethics, and reflexivity in decisionmaking and a critical questioning and contestation of the drivers of climate change (O'Brien et al., 2010b) and local impacts (Pelling, 2010a). Human security is realized through the capacity of individuals and communities to respond to threats to their environmental, social, and human rights (GECHS, 2000; Barnett et al., 2010). A number of studies have assessed the relationship between climate change and human security, demonstrating that the linkages are often both complex and context-dependent (Barnett, 2003; Barnett and Adger, 2007; Brauch et al., 2008, 2009, 2011; Buhaug et al., 2008; O'Brien et al., 2010a). Among the most likely human security threats are impacts felt through damage to health, food, water, or soil conditions (Oswald Spring, 2009a, 2011b).

Among the most widely discussed humanitarian and human security issues related to climate change are the possibilities of increased migration and/or violent conflict resulting from the biophysical or ecological disruptions associated with climate change (Reuveny, 2007; 0'Brien et al., 2008; Raleigh et al., 2008; Warner et al., 2010). There are indications that migration conditions followed disasters in the distant past, as well as in current situations (see, e.g., Le Roy Ladurie, 1971; Kinzig et al., 2006; Peeples et al., 2006). Migration is a key coping mechanism for poor rural households, not only in extreme circumstances (e.g., during a prolonged drought, as with the 20th-century US Dustbowl period and Sahelian droughts) but also as a means of diversifying and increasing income (Harrington et al., 2009; Oswald Spring, 2011a; Scheffran, 2011). The opportunities that population movement opens for risk reduction are seen in international remittance flows from richer to poorer countries. These are estimated to have exceeded US\$ 318 billion in 2007, of which developing countries received US\$240 billion (World Bank, 2008).

Disasters linked to extreme events often lead to forced displacement of people, as well as provoke voluntary migration among the less poor. The relationship between climate risk and displacement is a complex one and there are numerous factors that affect migration (UNDP, 2009). Nonetheless, recent research suggests that adverse environmental impacts associated with climate change have the potential to trigger displacement of an increased number of people (Kolmannskog, 2008; Feng et al., 2010). Studies suggest that most migration will take place internally within individual countries; that in most cases when climatic extremes occur in developing countries they will not lead to net outmigration because people tend to return to re-establish their lives after a disaster; and that while long-term environmental changes may cause more permanent migration this will also tend to be internal (Piguet, 2008; UNDP, 2009). More negatively, forced land abandonment is stressful for migrants whose culture and sense of identity are affected (Mortreux and Barnett, 2009; Brauch and Oswald Spring, 2011). The social dislocation provoked by migration can lead to a breakdown in traditional rural institutions and associated coping mechanisms, for example, in the erosion of traditional community-based water management committees in central and west Asia (Birkenholtz, 2008). Local collective coping and adaptive capacity can also be limited by increases in the number of female-headed households as men migrate (Oswald Spring, 1991, 2009a).

Attention has been mainly focused on population displacement associated with large disasters. Pakistan's 2010 floods have to date left an estimated 6 million people in need of shelter; India's 2008 floods also uprooted roughly 6 million people; Hurricane Katrina displaced more than half a million people in the United States; and Cyclone Nargis uprooted 800,000 people in Myanmar and South Asia. However, the compound effect of smaller, more frequent events can also contribute to displacement. Hazards such as floods, although often causing relatively low mortality, destroy many houses and hence cause considerable displacement. Between 1970 and 2009 in Colombia, for example, 24 disaster loss reports detailed floods that killed fewer than 10 people but destroyed more than 500 houses. In total, around 26,500 houses were destroyed, potentially displacing more than 130,000 people. In the Indian state of Orissa, 265 floods with similar low mortality rates destroyed more than half a million houses. It is estimated that such extensive disasters account for an additional 19\% displacement of people who are typically less visible than those displaced in larger events that attract international media and humanitarian assistance (UNISDR, 2011).

Despite the opportunities to enhance development, disaster response is often better at meeting basic needs than securing or extending human rights. Indeed, the political neutrality that underpins the humanitarian imperative makes any overt actions to promote human rights by humanitarian actors difficult. In this way, disaster response and reconstruction can to only a partial extent claim to enhance human security (Pelling and Dill, 2009). Work at the boundaries between humanitarian and development actors, new partnerships, the involvement of government, and meaningful local participation are all emerging as ways to resolve this challenge. One successful case has been the reconstruction process in Aceh, Indonesia, following the Indian Ocean tsunami, where collaboration between government and local political interests facilitated by international humanitarian actions on the ground and through politicallevel peace-building efforts have increased rights locally, contained armed conflict, and provided an economic recovery plan (Le Billon and Waizenegger, 2007; Gaillard et al., 2008; Törnquist et al., 2010). 
Coping with the new and unprecedented threats to human security posed by climate change has raised questions about whether existing geopolitics and geo-strategies have become obsolete (Dalby, 2009). The concepts, strategies, policies, and measures of the geopolitical and strategic toolkits of the past as well as the short-term interests dominating responses to climate change have been increasingly questioned, while the potential for unprecedented disasters has led to a consideration of the security implications of climate change (UNSC, 2007; EU, 2008; UNGA, 2009; UNSG, 2009). Concerns range from increased needs for humanitarian assistance to concerns over environmental migration, emergent diseases for humans or in food chains, potentials for conflict between nations or localities over resources, and potential for political/ governmental destabilization due to climate-related stresses in combination with other stresses, along with efforts to assign blame (Ahmed 2009; Brauch and Oswald Spring, 2011).

Climate change is generally regarded to act as a threat multiplier for instability in some of the most volatile regions of the world (CNA Corporation, 2007). Even in stable polities, adaptation planning that seeks long-term resilience is confronted by political instability directly after disasters (Drury and Olson, 1998; Olson, 2000; UNDP, 2004; Pelling and Dill, 2009). When disasters strike across national boundaries or within areas of conflict, they can provide a space for rapprochement, but effects are usually short-lived unless the underlying political and social conditions are addressed (Kelman and Koukis, 2000; Kelman, 2003). New interest in disaster and climate change as a security concern has brought in lessons from international law (Ammer et al., 2010) and security policy (Campbell et al., 2007) on planning for relatively lowprobability, high-consequence futures. Although during times of stress it is easy for polities to drift toward militarization and authoritarianism for managing disaster risk (Albala-Bertrand, 1993), there are alternatives, such as inclusive governance, that can meet the goals of sustainable development and human security over the long term (Olson and Gawronski, 2003; Brauch, 2009; Pelling and Dill, 2009; Bauer, 2011).

\subsubsection{Implications for Achieving Relevant International Goals}

Addressing - or failing to address - disaster risk reduction and climate change adaptation can influence the success of international goals, particularly those linked to development. Successive reports have noted the potential for climate change to derail the Millennium Development Goals (MDGs). In 2003, the Asian Development Bank and nine other development organizations first highlighted that climate change may impact on progress toward the MDGs and in particular constrain progress beyond 2015, underlying the importance of managing climate risks within and across development sectors. The UK Department for International Development (DFID, 2004, 2006) and UNDP (2004) show how each of the MDGs is dependent on some aspect of disaster risk for success. Disaster impacts on the MDG targets are both direct and indirect. For example, MDG 1 (to eradicate extreme poverty and hunger) is impacted directly by damage to productive and reproductive assets of the poor and less poor (who may remain in poverty or slip into poverty as a result of disaster loss), and indirectly affected by negative macroeconomic impacts. The 2007 UN Human Development Report noted that enhanced adaptation is required to protect the poor, with climate change potentially acting as a brake on development beyond 2015 .

The UNISDR Hyogo Framework for Action 2005-2015: Building the Resilience of Nations and Communities to Disasters (HFA) explicitly recognizes that climate variability and change are important contributors to disaster risk and includes strong support for better linking disaster management and climate change adaptation efforts (Sperling and Szekely, 2005; see also Section 7.3.1). The HFA priorities for action have proven foresightful in including resilience explicitly as a component. Priority Three calls for "knowledge, innovation and education to build a culture of safety and resilience at all levels." This provides a strong justification for international actors to support investment in institutional and human capacity for national and local resilience building, and one that does not require the addition of new international agreements to start work. Frameworks for such action exist, for example, in Common Country Assessments, United Nations Development Assistance Frameworks, National Adaptation Plans of Action, and Poverty Reduction Strategies, but limited progress has been made on this to date (DFID, 2004). Some have proposed integrating climate change and disaster risk management into any equivalent of the MDGs post-2015 (Tribe and Lafon, 2009; Gostin et al., 2011).

\subsection{Interactions among Disaster Risk Management, Adaptation to Climate Change Extremes, and Mitigation of Greenhouse Gas Emissions}

\subsubsection{Thresholds and Tipping Points as Limits to Resilience}

Recent literature suggests that climate change could trigger large-scale, system-level regime shifts that could significantly alter climatic and socioeconomic conditions (MEA, 2005; Lenton et al., 2008; Hallegatte et al., 2010; see Section 3.1.7). Examples of potential system changes include dieback of the Amazon rainforest, decay of the Greenland ice sheet, and changes in the Indian summer monsoon (Lenton et al., 2008). At smaller scales, also, climate change is exacerbating well-established examples of environmental regime shifts, such as freshwater eutrophication (Carpenter, 2003), shifts to algae-dominated coral reefs (Hughes et al., 2003), and woody encroachment of savannas (Midgley and Bond, 2001). The abruptness and persistence of such changes in social and ecological systems, coupled with the fact that they can be difficult and sometimes impossible to reverse, means that they can have substantial impacts on human well-being (Scheffer et al., 2001; MEA, 2005; Scheffer, 2009). The notion of regimes shifting once thresholds or tipping points are crossed contrasts with discussions of climate thresholds (see Section 3.1.1) and traditional thinking about gradual, linear, and more predictable changes in ecological and social-ecological systems, and emphasizes 
the possibility of multiple futures determined by the crossing of critical thresholds (Levin, 1998; Gunderson and Holling, 2002). Similar discussion on socioeconomic systems has, for example, identified profitability limits in economic activities as critical thresholds that can bring about sudden collapse and regime change (Schlenker and Roberts, 2006; OECD, 2007).

The metaphor of tipping points, or points at which a system shifts from one state to another, can also be applied to disaster events. Disasters themselves are threshold-breaching events, where coping capacities of communities are overwhelmed (e.g., Blaikie et al., 1994; Sperling et al., 2008). Disasters may lead to secondary hazards, for example, when the impacts from one disaster breach the coping capacities of related systems, as when hurricane impacts trigger landslides or when different disasters produce concatenated impacts over time (Biggs et al., 2011). For example, losses associated with droughts and fires during the 1997/1998 El NiñoSouthern Oscillation event in Central America increased landslide and flood hazard during Hurricane Mitch in 1998 (Villagrán de León, 2011). Critical social thresholds may be crossed as disaster impacts spread across society. Disaster response is as much about containing such losses as assisting those hurt by the initial disaster impact.

For the poor, life and health are immediately at risk; for those living in societies that take measures to protect infrastructure and economic and physical assets, the lives and health of the population are less at risk. However, a threshold can be crossed when hazards exceed anticipated limits, are novel or unexpected in a specific risk management domain (Beniston, 2004; Schär et al., 2004; Salagnac, 2007), or when vulnerability has increased or resilience decreased due to spillover from market and other shocks (Wisner, 2003).

In 2010, for example, western Russia experienced the hottest summer since the beginning of systematic weather data recording 130 years ago. Lack of rainfall in early 2010 and July temperatures almost $8^{\circ} \mathrm{C}$ above the long-term average led to parched fields, forests, and peatlands that posed a high wildfire risk. During and after the wildfires, Russia's mortality rate increased by $18 \%$. In August alone, 41,300 more people died as compared to August 2009, due to both the extreme heat and smoke pollution. Social and economic change had greatly increased the risk posed by wildfires. Traditional agricultural livelihoods have declined, accompanied by out-migration and reduced management of surrounding forests, arguably exacerbated by the decentralization of national management and increased exploitation by the private sector (UNISDR, 2011).

The recognition of nonlinearity and the importance of thresholds as limiting points for existing systems has led climate scientists to increase their attention to the 'tails' of impact probability density functions (Weitzman, 2009). This is in contrast to the disasters research community, which, after focusing on major extremes, is now recognizing the importance of small or local disasters and the secondary disasters that make up concatenated events (UNDP, 2004; UNISDR, 2009). Both lenses are valuable for a comprehensive understanding of the interaction of disaster impact with development.
Tipping points in natural and human systems are more likely to arise with relatively severe and/or rapid climate change than with moderate levels and rates (Wilbanks et al., 2007). Because of this, less success with climate change mitigation implies greater challenges for adaptation and disaster risk management. Not only does adaptation need to consider incremental change in hazard and vulnerability, but the possibility of threshold breaching, systems-wide changes. The nonlinear changes associated with breaching thresholds may exceed adaptation capacity to avoid serious disruptions. Examples of ecological system changes of this kind and social impacts include the disappearance of glaciers currently feeding urban and agricultural water supply (Orlove, 2009), effects of climate change on traditional livelihoods for the sustainability of indigenous cultures (Turner and Clifton, 2009), widespread loss of corals in acidifying oceans and fisher livelihoods (Reaser et al., 2000), and profitability limits for important economic activities like agriculture, fisheries, and tourism. When socioeconomic systems are already under stress (e.g., fisheries in many countries), sustainability thresholds may be more easily passed. Responses to potential thresholds or tipping points include efforts to improve the information available to decisionmakers, for example, through monitoring systems to provide early warning of an impending system collapse (Biggs et al., 2009; Scheffer et al., 2009), but also initiatives researching the balance of risks associated with geoengineering (Royal Society, 2009) aiming to avoid such tipping points (Virgoe, 2002; Kiehl, 2006).

\subsubsection{Adaptation, Mitigation, and Disaster Risk Management Interactions}

As indicated above, the extent to which future adaptation and disaster risk reduction action will be required is likely to be dependent on the extent and rapidity with which climate change mitigation actions may be taken and resulting risk unfolds for any given development context. This section assesses the ways in which mitigation, disaster risk reduction, and adaptation interact with development in urban and rural contexts.

In many instances, climate change mitigation and adaptation may be synergistic, such as land use planning to reduce transport-related energy consumption and limit exposure to floods, or building codes to reduce heating energy consumption and enhance robustness to heat waves (McEvoy et al., 2006). There is an emerging literature exploring the linkages between climate change mitigation and adaptation, and the possibility of approaches that address both objectives simultaneously (Wilbanks and Sathaye, 2007; Hallegatte, 2009; Bizikova et al., 2010; Wilbanks, 2010; Yohe and Leichenko, 2010). In this section we enlarge the scope of the interactions to include disaster risk management. This builds on experience within the disaster management community that has recently sought to integrate risk modeling (UNDP, 2004; UNISDR, 2009,2011 ) and planning to consider multi-hazard contexts. An important lesson from this is that avoiding superficial integration means seeking out and addressing shared root causes of exposure and vulnerability to hazards, and not just addressing the surface expressions of risk (Wisner, 2011). The extent of adaptation required will depend on the climate 
change mitigation efforts undertaken, and it is possible that these requirements could increase drastically if levels of climate change exceed systemic thresholds - whether in geophysical or socioeconomic systems.

Practical integration of climate change mitigation and adaption into a development context is complicated because of a differential distribution in costs and benefits (e.g., mitigation benefits are distributed and accrue globally; adaptation benefits, like disaster risk management, are often easier to measure locally). In addition, the research and policy discourses of these three policy domains are quite separated and in areas technically unrelated, and the constituencies and decisionmakers are often different (Wilbanks et al., 2007). In many cases, the challenge of bringing the entire range of issues and options into focus - seeking synergies and avoiding conflicts - is most likely to occur in discussions of climate change responses and development objectives in particular places: localities and small regions where compliance with national or international mitigation agendas provides a logic for local action (Wilbanks, 2003). The following subsections present the urban and rural contexts as examples.

\subsubsection{Urban}

In an increasingly urbanized world, global sustainability in the context of a changing climate will depend on achieving sustainable and climateresilient cities. Urban spatial form is critical for energy consumption, emission patterns, and disaster risk management (Desplat et al., 2009), and it influences where and how residents live and the modes of transport that they use. Urban planning is a tool that can be used to pursue climate change mitigation, adaptation, and disaster risk reduction as part of the everyday development process (Newman and Kenworthy, 1989; Bento et al., 2005; Handy et al., 2005; Ewing and Rong, 2008; Grazi et al., 2008; Brownstone and Golob, 2009; Glaeser and Kahn, 2010). Urban form also influences the spatial and social inequalities that largely shape vulnerability, coping, and adaptive capacity (Pelling, 2003; Gusdorf et al., 2008; Leichenko and Solecki, 2008). The historical failure of urban planning in most developing country cities has had tremendous environmental and social consequences (UN-HABITAT, 2009; World Bank, 2010a). Also in richer countries, where planning is not comprehensive, maladaptation can take place rather than synergistic risk reduction, for example, where urban heat wave risk management results in increased private air conditioning without decarbonized energy available (Lindley et al., 2006). Similarly, a denser city may reduce greenhouse gas emissions but increase heat wave vulnerability (Hamin and Gurran, 2009). However, since urban forms influence both greenhouse gas emissions and vulnerability (McEvoy et al., 2006), scope for synergistic planning and action can also be found. For example, managing car use may contribute to decreased greenhouse gas emissions, but also lower local particulate pollution and reduce the health impacts of urban heat waves (Dennekamp and Carey, 2010).

As yet there is only limited evidence that opportunities for synergistic planning offered by urbanization are being realized, especially for those most marginalized and vulnerable. More typically, urbanization compounds environmental problems. As countries urbanize, the risks associated with economic asset loss tend to increase through rapid growth in infrastructure and productive and social assets, while mortality risk tends to decrease (Birkmann, 2006). As cities grow, they also modify the surrounding rural environment, and consequently may generate a significant proportion of the hazard to which they are also exposed. For example, as areas of hinterland are paved over, runoff increases during storms, greatly magnifying flood hazards (Mitchell, 1999; Pelling, 1999). As mangroves are destroyed in coastal cities, storm-surge hazard can increase (Hardoy et al., 2001). Likewise, within urban areas (though often beyond the reach of urban planning), the expansion of informal settlements can lead to increased local population exposure to landslide and flood hazards (Satterthwaite, 1997; UNDP, 2004). Global risk models indicate that expansion of urban risk is primarily due to rapidly increasing exposure, which outpaces improvements in capacity to reduce vulnerability (such as through improvements legislating and applying building standards and land use planning), at least in rapidly growing low- and middle-income nations (UNISDR, 2009, 2011). As a consequence, risk is becoming increasingly urbanized (Mitchell, 1999; Pelling, 2003; Leichenko and O'Brien, 2008). There are dramatic differences, nonetheless, between developed and developing countries. In most developed countries (and increasingly in a number of cities in middle-income countries, e.g., Bogota, Mexico City), risk-reducing capacities exist that can manage increases in exposure. In contrast, in much of the developing world (and particularly in the poorest leastdeveloped countries where large proportions of the urban population live in unplanned settlements) such capacities are greatly restricted, while population growth drives exposure. Financial and technical constraints matter for risk management, but differences in wealth alone do not explain differences in risk reduction investments, which also depend on risk perceptions and political choice (e.g., Satterthwaite, 1998; Hardoy et al., 2001; Hanson et al., 2011).

Urban planning can be a vehicle for synergy, but it takes time to produce significant effects. Synergy in planning requires anticipation of future climate change, taking into account how climate will change over many decades, the uncertainty of this information, the vulnerability of urban systems, and the capacity of social agents. The Asian Cities Climate Change Resilience Network found that catalyzing city-level actors to assess these plans are essential, rather than depending on external experts or national agencies to prepare urban plans (Tyler et al., 2010). Built forms are difficult to change because they exhibit strong inertia and irreversibility: when a low-density city is created, transforming it into a high-density city is a long, expensive, and difficult process (Gusdorf et al., 2008). This point is crucial in the world's most rapidly growing cities, where urban forms of the future are being decided based on actions taken in the present, and where current trends indicate that low-density, automobile-dependent forms of suburban settlement are rapidly expanding (Solecki and Leichenko, 2006). Some work has started to investigate these aspects of climate change adaptation and mitigation (Newman et al., 1996). At the same time, there are specific opportunities when cities enter periods of large-scale transformation. This is happening 
in Delhi, Mumbai, and other cities in India as private capital redevelops low-income city neighborhoods into commercial districts and middleand high-income housing areas with associated low-income housing. There is rare scope here to promote disaster risk reduction, climate change adaptation, and mitigation alongside existing demands for market profitability and social justice in urban and building design. There are also growing numbers of large-scale slum/informal settlement upgrading programs that aim to improve housing and living conditions for lowincome households (Boonyabancha, 2005; Satterthwaite, 2010).

Disaster reconstruction also creates opportunities for synergistic development planning. For example, reconstruction after the 2005 Hurricane Katrina disaster in New Orleans, Louisiana, included rebuilding to Green Building Council 'Leadership in Energy and Environmental Design' (LEED) standards (USGBC, 2010). Similarly, in May 2007, Greensburg, Kansas, was virtually destroyed by a tornado and LEED standards have been applied (Harrington, 2010). Echoing the tradeoffs between speed and sustainability presented in Section 8.2.5, the actions in Greensburg have also slowed rebuilding of the town, leading in this instance to an erosion in community and associated aspects of resilience in the short run, while attempting to create a model 'green' community in the long run.

In short, despite the many opportunities for building synergy into urban development planning and practice, examples of success are not plentiful. Lack of synergy is more the norm, to take just one example of urbanization in central Dhaka, Bangladesh. These flood-prone areas had until recently been occupied by natural water bodies and drains, vital to the regulation of floods. The Dhaka Metropolitan Development Plan restricts development in many of these areas, but despite the Plan, infilling continues with both private- and public-sector projects. Destruction of retention ponds and drains increases risks of flooding and building in the drained wetlands generates new risks of liquefaction following earthquakes (UNISDR, 2011).

\subsubsection{Rural}

Rural areas are the primary site for climate change mitigation. Rural areas have considerable experience in disaster risk management and more recently in climate change adaptation (UNDP, 2007b). Nonetheless, as for urban areas, the evidence base is limited for consciously synergistic development projects and policies that consider climate change mitigation, adaptation, and disaster management together. There are, however, several important opportunities where climate change mitigation and adaptation or risk management have shown scope for integration and opportunities are being explored, for example in agroforestry (Verchot et al., 2007).

Any scope for synergy needs to be seen within the context of contemporary development pressures (Goklany, 2007). For small farms in particular, pressures are strong for diversification into non-farm activities, where such opportunities exist, but strong support is needed to enable transitions in economic activity (Roshetko et al., 2007). Climate change affects the range of choices available, for example, in low-lying coastal zones where saltwater intrusion and coastal flooding are already making traditional agriculture marginal and leading to the adoption of saltwater tolerant crops or a shift from agriculture to aquaculture (Adger, 2000). While urban areas have expanded in size and influence, the majority of the poor continue to reside in rural areas in many countries, particularly in Africa, and are among the most resource-scare and capacity-limited population groups (UNDP, 2009). For populations that may also be isolated from markets and communication networks, even small increases in the frequency or severity of hazard can cause local livelihoods to collapse, though recent developments in communication technology may bridge this gap (Aker and Mbiti, 2010). Where political and economic systems disrupt food distribution and market functioning, vulnerability to food insecurity escalates (Misselhorn, 2005).

Hard choices also have to be made between expanding rural populations or economies and natural capital. Too often, local natural assets are exploited not by local actors to build local capacities but by external agents, such that resources are extracted with little benefit accruing locally. The balance and implementation of controls on natural resource exploitation is both a potential damper on current capacity building and a critical mechanism for ensuring long-term sustainability of rural livelihoods and ecosystem services (Chouvy and Laniel, 2007). Non-farm income now represents a substantial proportion of total income for many rural households and can, in turn, increase resilience to weatherand climate-related shocks (Brklacich et al., 1997; Smithers and Smit, 1997; Wandel and Smit, 2000). The implications of these transitions for local rural risk, and how far they may provide scope for mitigation, has not been fully explored in the literature.

While urban sites offer opportunities for mitigation through diversified (household) production and energy conservation, rural areas are a focus for concentrated low- or no-carbon energy production ranging from hydroelectric power (HEP) to solar and wind farms, biofuel crops, and carbon sink functions associated with forestry in particular and REDD+ projects. These investments can have significant local impacts on disaster risk through changes in land use and land cover that may influence hydrology, or through economic effects and consequences for livelihoods. There is scope for synergy, for example, through small HEP/flood or water conservation dams, and some have gone as far to say that this joined-up approach is part of a transformed development policy for meeting combined energy and water demands in vulnerable rural communities, most particularly in sub-Saharan Africa (Foster and BriceñoGarmendia, 2011). Some impacts can even go beyond local places. Recent impacts of biofuel production on rural livelihoods and global food security indicate the interdependence of vulnerability in rural and urban systems, and the care required in transformations of this kind where impacts can quickly spread and be amplified through global markets (Dufey, 2006; de Fraiture et al., 2008).

Flows of investment, remittances, migration, and material transfers through trade and also in the movement of resources (water, food, 
waste, and energy) intimately connect rural and urban economies and societies, and the local with the global, such that the sustainability of one will influence the other. The existence of multiple, intersecting stressors in rural and urban contexts draws attention to the importance of addressing the underlying drivers of risk as a means of both disaster risk management and adaptation, and of promoting climate change mitigation.

\subsection{Options for Proactive, Long-Term Resilience to Future Climate Extremes}

Considering the broad challenges described previously, it is important to assess the range of existing planning tools and the ways they are used, who uses them, and how they interact or change over time. Pursuing sustainable and resilient development pathways requires integrated and ambitious policy that is science-based and knowledgedriven, and that is capable of addressing issues of heterogeneity and scale. The latter issues are particularly vexing, as the consequences of, and responses to, extreme climate and weather events are local, but these responses need to be supported and enabled by actions at regional, national, and global scales.

This section first considers the challenges of planning for the future, then assesses the literature pertaining to tools and practices that can help address these issues. As the preceding sections in this chapter and other chapters in the report have argued, achieving a sustainable and resilient future draws attention to the need for both incremental and transformational changes. Based on an assessment of the literature, the final section discusses why such changes may involve a combination of adaptive management, learning, innovation, and leadership.

\subsubsection{Planning for the Future}

Disaster risk management and climate change adaptation are fundamentally about planning for an uncertain future, a process that involves combining one's own aspirations (individual and collective) with perspectives on what is to come (Stevenson, 2008). Planning for the future is challenging when the stakes are high, values disputed, and decisions urgent, and these factors often create tensions among different visions of development. Typically, decisionmakers (representing households, local or national governments, international institutions, etc.) look to the future partly by remembering the past (e.g., projections of the near future are often derived from recent experiences with extreme events) and partly by projecting how the future might be different (using forecasts, scenarios, visioning processes, or story lines - either formal or informal) (Miller, 2007). Projections further into the future are necessarily shrouded in larger uncertainties. The most common approach for addressing these uncertainties is to develop multiple visions of the future (quantitative scenarios or narrative storylines), that in early years can be compared with actual directions of change (Boulanger et al., 2006a,b; Moss et al., 2010).
Scenario development has become an established research tool both in the natural sciences (e.g., Nakicenovic et al., 2000; Lobell et al., 2008) and in the social sciences (e.g., Wack, 1985; Davis, 1998; Robinson, 2003; Galer, 2004; Kahane, 2004; Rosegrant et al., 2011). Scenarios can be based on different spatial (e.g., global, national, and local) and temporal scales (e.g., from a few years to several decades or centuries). The challenges for integrated disaster risk management and climate change adaptation scenarios are to generate climate data that can be downscaled to at least regional and sub-national scales, while extending disaster risk projections to longer time scales (see Gaffin et al., 2004; Theobald, 2005; Bengtsson et al., 2006; van Vuuren et al., 2006; Grübler et al., 2007; Moss et al., 2010; Hallegatte et al., 2011a).

Scenario development has traditionally been carried out in a sequential manner (Moss et al., 2010). For example, a first step in developing climate change scenarios has typically involved structural projections of key determinants of greenhouse gas emissions (e.g., population changes, urbanization, etc.). These have been used to estimate concentrations and radiative forcing from emissions, leading to climate projections that can be used in impacts research. One difficulty in using climate scenarios for disaster risk management and climate change adaptation has been the uncertainties associated with extreme climate and weather events, including the behavior of local climates (see Section 3.2.3). Future socioeconomic changes (e.g., demography, population preferences, technologies) are also highly uncertain, thus scenarios must consider a wide range of possible futures to design adaptation strategies and analyze tradeoffs (e.g., Hall, 2007; Lempert, 2007; Lempert and Collins, 2007; WGBU, 2008; Dessai et al., 2009a,b; Hallegatte, 2009). Alternative approaches have focused first on scenarios of radiative forcing, followed by an analysis of the combinations of economic, technological, demographic, policy, and institutional factors that can influence such trajectories (Moss et al., 2010). Other approaches are based on robust decisionmaking (e.g., Groves and Lempert, 2007; Lempert and Collins, 2007; Groves et al., 2008); information gap analysis (Hine and Hall, 2010); or on the search for co-benefits, no regrets strategies, flexibility, and reversibility (e.g., Fankhauser et al., 1999; Goodess et al., 2007; Hallegatte, 2009).

Scenario development requires substantial climate, social, environmental, and economic data, which are not equally available or accessible for all parts of the world. Qualitative scenarios can also be produced based on expert judgment (e.g., Delphi exercises) or on storylines designed through consultative processes. Such scenarios often reflect different mindsets or worldviews that represent contrasting visions of the future.

To adapt to changing climate and weather extremes, difficult choices may become increasingly necessary. In many locations, for example, adapting to scenarios of reduced water availability may involve increased investments in water infrastructure to provide enough irrigation to maintain existing agricultural production, or a shift from current production to less water-consuming crops (see Rosenzweig et al., 2004; ONERC, 2009; Gao and Hu, 2011). In considering adaptation to future flood risk in the Thames Estuary, the UK Environment Agency 
(2009) applied four scenarios over three time periods to flood management. Through a wide consultation process, it was determined that improving the current infrastructure continues to be the preferred strategy until 2070, when construction of an outer barrage may become justifiable, especially as economic and climate change conditions change over time.

Evaluating choices among different options depends on how the stakeholders view the region in coming decades, and on adaptation decisions that are informed by political processes. One scenario approach that explicitly acknowledges both social and environmental uncertainties entails identification of flexible adaptation pathways for managing the future risks associated with climate change (Yohe and Leichenko, 2010). Based on principles of risk management (which emphasize the importance of diversification and risk-spreading mechanisms in order to improve social and/or private welfare in situations of profound uncertainty), this approach can be used to identify a sequence of adaptation strategies that are designed to keep society at or below acceptable levels of risk. These strategies, which policymakers, stakeholders, and experts develop and implement, are expected to evolve over time as knowledge of climate change and associated climate hazards progresses. The flexible adaptation or adaptive management approach that underpins this also stresses the connections between adaptation and mitigation of climate change, recognizing that climate change mitigation will be needed in order to sustain society at or below an acceptable level of risk (Yohe and Leichenko, 2010).

In contrast to predictive scenarios and risk management approaches, exploratory and normative approaches can be used to develop scenarios that represent desirable alternative futures. This is particularly important in the case of sustainability, where the most likely futures may not be the most desirable (Robinson, 2003), and where poverty, inequity, and injustice are recognized by many as incompatible with sustainable development (Redclift 1987, 1992; St. Clair, 2010). Pathways that require considerable transformation to reach sustainable futures of this kind can be supported by backcasting techniques. The process of backcasting involves developing normative scenarios that explore the feasibility and implications of achieving certain desired outcomes (Robinson, 2003; Carlsson-Kanyama et al., 2008). It is concerned with how desirable futures can be attained, focusing on policy measures that would be required to reach such conditions. Participatory backcasting, which involves local stakeholders in visionary activities related to sustainable development, can also open deliberative opportunities and inclusiveness in decision framing and making. Where visioning is repeated it can also open possibilities for tracking development and learning processes that make up adaptive strategies for disaster risk management, based on the explicit acknowledgement of the beliefs, values, and preferences of citizens (Robinson, 2003). Changing attitudes and core beliefs, including those on climate change, its causes, and consequences, is a slow process (Volkery and Ribeiro, 2009).

Adding an anticipatory dimension to planning for the future is critical for striving toward transformational actions in the face of multiple and dynamic uncertainties. The literature on anticipatory action learning provides some experience on what this might look like (Stevenson, 2002; Kelleher, 2005). The framing and negotiation of decisionmaking and policy is made inclusive and reflexive through multiple rounds of stakeholder engagement to explore meanings of what different futures may involve, reflect upon unavoidable tradeoffs and the winners and losers, and establish confidence to creatively adapt to new challenges (Inayatullah, 2006). This type of learning stresses the skills, knowledge, and visions of those at risk and aims to support leadership from even the most vulnerable. A combination of local- and global-scale scenarios that link storylines developed at several organizational levels (Biggs et al., 2007), personalizing narratives to create a sense of ownership (Frittaion et al., 2010), and providing safe and repeated learning spaces (Kesby, 2005) can enhance learning.

While scenarios, projections, and forecasts are all useful and important inputs for planning, actual planning and decisionmaking is a complex socio-political process involving different stakeholders and interacting agents. Although much progress has been made by employing scenario building and narrative creation to explore uncertainties, surprises, extreme events, and tipping points, the transition from envisioning to planning, policymaking, and implementation remains poorly understood (Lempert, 2007). Similarly, more widespread uptake of even scientifically highly robust scenarios may be hampered by conflicting understandings of and practical approaches to uncertainty, different scalar needs, and lack of training among users (Gawith et al., 2009). Experiences in scenario building emphasize their usefulness for raising awareness on climate change (Gawith et al., 2009). However, to move from framing public debates to policymaking and implementation, useful scenario building requires procedural stability, permanent yet flexible institutional and governance structures that build trust, and experience to take advantage of new insights for effective and fair risk management (Volkery and Ribeiro, 2009).

Developing the capacity for adaptive learning to accommodate complexity and uncertainty requires exploratory and imaginative visions for the future that support choices and can accommodate multiple values and aspirations (Miller, 2007). Disaster risk management and climate change adaptation, and synergies between the two, can contribute toward planning for a sustainable and resilient future, but this involves expanding the diversity of futures that are considered and identifying those that are desirable, as well as the short- and long-term values and actions that are consistent with them (Lempert, 2007).

\subsubsection{Approaches, Tools, and Integrating Practices}

As discussed above, scenarios, narrative storylines (Tschakert and Dietrich, 2010) and simulations (Nicholls et al., 2007) can help to project and facilitate discussion of possible futures. This section considers the tools that are available for helping decisionmakers and planners think about and plan for the future in the context of extreme climate and weather events. Past experiences with enhancing resilience to climate extremes 
include examples of both specific decision support tools and the governance and institutional contexts in which these tools are used and subsequent decisions are made (OECD, 2009b; Burch et al., 2010; Whitehead et al., 2010). Tools include those that enable information gathering, monitoring, analysis, and assessment; simulate threats; develop projections of possible impacts; and explore implications for response. Effective approaches combine understandings of potential stresses from climate extremes, along with possible tipping points for affected social and physical systems, with monitoring systems for tracking changes and identifying emerging threats in time for adaptive responses. This is, of course, challenging, requiring methodologies that can be open to both quantitative and qualitative data and their analysis, including participatory deliberation (NRC, 2010).

Institutional innovations aimed at improving the availability of disaster information to decisionmakers include the creation of national or regional institutions to manage and distribute disaster risk information (von Hesse et al., 2008; Corfee-Morlot et al., 2011), bringing together previously fragmented efforts centered in national meteorological, geological, oceanographic, and other agencies. The World Meteorological Organization and partner organizations have proposed the creation of a Global Framework for Climate Services, a collaborative effort to help the global community to better adapt to climate variability and change by developing and incorporating science-based climate information and prediction into planning, policy, and practice (WCC-3, 2009). New opensource tools for comprehensive probabilistic risk assessment are beginning to offer ways of compiling information at different scales and from different institutions (OECD, 2009b). A growing number of countries are also systematically recording disaster loss and impacts at the local level (DesInventar, 2010) and developing mechanisms to use such information to inform and guide public investment decisions (Comunidad Andina, 2007, 2009; von Hesse et al., 2008) and national planning. Unfortunately, there is as yet only limited experience with the integrated deployment of such tools and institutional approaches, especially in ways that cross scales of risk management strategy development and decisionmaking, and very limited evaluations of such deployment.

\subsubsection{Improving Analysis and Modeling Tools}

Various tools can be used to design environmental and climate policies. Among them, integrated environment-energy-economy models produce long-term projections taking into account demographic, technological, and economic trends (e.g., Edenhofer et al., 2006; Clarke and Weyant, 2009). These models can be used to assess the consequences of various policies. However, most such models are at spatial and temporal scales that do not resolve specific climate extremes or disasters (Hallegatte et al., 2007). At higher spatial resolution, numerical models (e.g., inputoutput models, calculable general equilibrium models) can help to assess disaster consequences and, therefore, balance the cost of disaster risk management actions and their benefits (Rose et al., 1997; Gordon et al., 1998; Okuyama, 2004; Rose and Liao, 2005; Tsuchiya et al., 2007; Hallegatte, 2008b). In particular, they can compare the cost of responding to disasters with the cost of preventing disasters. Since disasters have intangible consequences (e.g., loss of lives, ecosystem losses, cultural heritage losses, distributional consequences) that are difficult to measure in economic terms, the quantitative models are necessary but not sufficient to determine desirable policies and disaster risk management actions. Whether incorporated in models or used in other forms of analysis, CBA is useful to compare costs and benefits; but when intangibles play a large role and when no consensus can be reached on how to value these intangibles, other decisionmaking tools and approaches are needed. Multi-criteria decisionmaking (Birkmann, 2006), robust decisionmaking (e.g., Lempert 2007; Lempert and Collins, 2007), transition management approaches (e.g., Kemp et al., 2007; Loorbach, 2010), and group-process analytic-deliberative approaches (Mercer et al., 2008) are examples of such alternative decisionmaking methodologies.

Also necessary are indicators to measure the successes and failures of policies. For example, climate change adaptation policies often target the enhancement of adaptive capacity. The effects and outcomes of policies are often measured using classical economic indicators such as GDP. The limits of such indicators are well known, and have been summarized in several recent reports (e.g., CMEPSP, 2009; OECD, 2009a). To measure progress toward a resilient and sustainable future, one needs to include additional components, such as measures of stocks, other capital types (natural capital, human capital, social capital), distribution issues, and welfare factors (health, education, etc.). Many alternative indicators have been proposed in the literature, but no consensus exists. Examples of these alternative indicators include the Human Development Index, the Genuine Progress Indicator, the Index of Sustainable Economic Welfare, the Ecological Footprint, the normalized GDP, and various indicators of vulnerability and adaptive capacity (Costanza, 2000; Yohe and Tol, 2002; Lawn, 2003; Costanza et al., 2004; Eriksen and Kelly, 2006; Jones and Klenow, 2010).

\subsubsection{Institutional Approaches}

Among the most successful disaster risk management and adaptation efforts have been those that have facilitated the development of partnerships between local leaders and other stakeholders, including extra-local governments (Bicknell et al, 2009; Pelling and Wisner, 2009; Gero et al, 2011). This allows local strength and priorities to surface in disaster risk management, while acknowledging also that communities (including local government) have limited resources and strategic scope and alone cannot always address the underlying drivers of risk (Bhattamishra and Barrett, 2010). Local programs are now increasingly moving from a focus on strengthening disaster preparedness and response to reducing both local hazard levels and vulnerability (e.g., through slope stabilization, flood control measures, improvements in drainage, etc.) (Lavell, 2009; UNISDR, 2009; Reyos, 2010). Most of the cases where sustainable local processes have emerged are where national governments have decentralized both responsibilities and resources to the local level, and where local governments have become more accountable to their citizens, as for example in cities in Colombia 
such as Manizales (Velásquez, 1998, 2005). In Bangladesh and Cuba, successes in disaster preparedness and response leading to drastic reduction in mortality due to tropical cyclones, built on solid local organization, have relied on sustained support from the national level (Haque and Blair, 1992; Bern et al., 1993; Ahmed et al., 1999; Chowdhury, 2002; Kossin et al., 2007; Elsner et al., 2008; Karim and Mimura, 2008; Knutson et al., 2010; World Bank, 2010b). A growing number of examples now exist of community-driven approaches that are supported by local and national governments as well as by international agencies, through mechanisms such as social funds (Bhattamishra and Barrett, 2010).

Risk transfer instruments, such as insurance, reinsurance, insurance pools, catastrophe bonds, micro-insurance, and other mechanisms, shift economic risk from one party to another and thus provide compensation in exchange for a payment, often a premium (ex-post effect) (see Sections 5.6.3, 6.5.3, and 7.4, and Case Study 9.2.13). In addition, these mechanisms can also help to anticipate and reduce (economic) risk as they reduce volatility and increase economic resilience at the household, national, and regional levels (Linnerooth-Bayer et al., 2005). As one example, with such insurance, drought-exposed farmers in Malawi have been able to access improved seeds for higher yielding and higher risk crops, thus helping them to make a leap ahead in terms of generating higher incomes and the adoption of higher return technologies (World Bank, 2005; Hazell and Hess, 2010). However, many obstacles to such schemes still exist, particularly in low-income and many middle-income countries, including the absence of comprehensive risk assessments and required data, legal frameworks, and the necessary infrastructure, and probably more experience is required to determine the contexts in which they can be effective (Linnerooth-Bayer and Mechler, 2007; Cummins and Mahul, 2009; Mahul and Stutley, 2010).

Disaster risk management and adaptation can also be addressed through the enhancement of generic adaptive capacity alongside hazardspecific response strategies (IFRC, 2010). This capacity includes access to information, the skills and resources needed to reflect upon and apply new knowledge, and institutions to support inclusive decisionmaking. These are cornerstones of both sustainability and resilience. While uncertainty may make it difficult for decisionmakers to commit funds for hazard-specific risk reduction actions, these barriers do not prevent investment in generic foundations of resilient and sustainable societies (Pelling, 2010a). Importantly, from such foundations, local actors may be able to make better-informed choices on how to manage risk in their own lives, certainly over the short and medium terms. For instance, federations formed by slum dwellers have become active in identifying and acting on disaster risk within their settlements and seeking partnerships with local governments to make this more effective and larger scale (IFRC, 2010).

Changes in systems and structures may call for new ways of thinking about social contracts, which describe the balance of rights and responsibilities between different parties. Social contracts that are suitable for technical problems can be limiting and insufficient for addressing adaptive challenges (Heifetz, 2010). Pelling and Dill (2009) describe the ways that current social contracts are tested when disasters occur, and how disasters may open up a space for social transformation, or catalyze transformative pathways building on pre-disaster trajectories. O'Brien et al. (2009) consider how resilience thinking can contribute to new debates about social contracts in a changing climate, drawing attention to tradeoffs among social groups and ecosystems, and to the rights of and responsibilities toward distant others and future generations.

\subsubsection{Transformational Strategies and Actions for Achieving Multiple Objectives}

If extreme climate and weather events increase significantly in coming decades, climate change adaptation and disaster risk management are likely to require not only incremental changes, but also transformative changes in systems and institutions. Transformation can be defined as a fundamental qualitative change, or a change in composition or structure that is often associated with changes in perspectives or initial conditions (see Box 8-1). It often involves a change in paradigm and may include shifts in perception and meaning, changes in underlying norms and values, reconfiguration of social networks and patterns of interaction, changes in power structures, and the introduction of new institutional arrangements and regulatory frameworks (Folke et al., 2009, 2010; Pahl-Wostl, 2009; Smith and Stirling, 2010).

Although transformational policies and measures may be deliberately invoked as a strategy to reduce disaster risk and adapt to climate change, in many cases such strategies are precipitated by an extreme event, sometimes referred to as a 'focusing event' (Birkland, 1996). However, whether an extreme event leads to any change at all is unclear, as processes of policy change are often subtle and complex and linked to learning processes (Birkland, 2006). Exploring the relationship between systematic learning processes and small disasters, Voss and Wagner (2010) find that a failure to learn is the most common prerequisite for future disasters. There are, however, many dimensions to learning (e.g., cognitive, normative, and relational; see Huitema et al., 2010), and learning may be a necessary but insufficient condition for initiating transformational change.

Understanding processes of deliberate change and change management can provide insights on societal responses to extreme climate and weather events. Traditional approaches to managing change successfully in businesses and organizations focus on a series of defined steps (Harvard Business Essentials, 2003). Kotter (1996), for example, identifies an eight-step process for promoting change: (1) create a sense of urgency; (2) pull together the guiding team; (3) develop the change vision and strategy; (4) communicate for understanding and buy in; (5) empower others to act; (6) produce short-term wins; (7) don't let up; and (8) create a new culture. Kotter (1995) also identifies eight errors that are often made when leading change, including, for example, allowing too much complacency, failing to create a sufficiently powerful guiding coalition, and underestimating the power of a sound vision. It is also 


\section{FAQ 8.2 | Are transformational changes desirable and even possible, and if so, who will lead them?}

Transformation in and of itself is not always desirable. It is a complex process that involves changes at the personal, cultural, institutional, and systems levels. Transformation can imply the loss of the familiar, which can create a sense of disequilibrium and uncertainty. In some cases, notable changes in the nature, form, or appearance of a system or process may be inconsistent with the values and preferences of some groups. Transformation can thus be perceived as threatening by some and instrumental by others, as the potential for real or perceived winners and losers at different scales stimulates social unease or tension. Desirable or not, it is important to recognize that transformations are now occurring at an unprecedented rate and scale, influenced by globalization, social and technological development, and environmental change. Climate change itself represents a system-scale transformation that will have widespread consequences for ecology and society, including through changes in climate extremes. Responses to climate change and changes in disaster risk can be both incremental and transformational. Transformational responses are not always radical or monumental - sometimes they simply involve a questioning of assumptions or viewing a problem from a new perspective. Transformational responses are not only possible, but they can be facilitated through learning processes, especially reflexive learning that explores blind spots in current thinking and approaches to disaster risk management and climate change adaptation. However, because there are risks and barriers, transformation also calls for leadership - not only from authority figures who hold positions and power, but from individuals and groups who are able to connect present-day actions with their values, and with a collective vision for a sustainable and resilient future. Considering the balance between incremental and transformative adjustments flags the importance of scale: first, because of the opportunities for enhancing leadership capacity that come from greater involvement of those locally at risk or undertaking adaptive experimentation for risk management; and second, because of the potential for transformation, incremental change, or stability at one systems level or sector (e.g., administrative, social, technical) to provoke or restrict adjustments in other systems and scales. Inter-scale and inter-sectoral communication therefore become important tools for managing adaptive disaster risk management.

important to recognize that many change initiatives create uncertainty and disequilibria, and are considered disruptive or disorienting (Heifetz et al., 2009). Furthermore, vested interests seldom choose transformation, particularly when there is much to lose from change (Christensen, 1997). As discussed in Section 8.5.2, there are winners and losers not only from extreme climate and weather events, but also from responses. Consequently, fundamental change is often resisted by the people that it affects the most (Kotter, 1996; Kegan and Lahey, 2009). Helping people, groups, organizations, and governments to manage the resulting disequilibria is seen as essential to successful transformation.

Many of the recent approaches to change and transformation focus on learning organizations, and the importance of changing individual and collective mindsets or mental models (Senge, 1990; Heifetz et al., 2009; Kegan and Lahey, 2009; Scharmer, 2009). This transformational change literature distinguishes between technical problems that can be addressed through management based on existing organizational and institutional structures and cultural norms, and adaptive challenges that require a change in mindsets, including changes in assumptions, beliefs, priorities, and loyalties (Heifetz et al., 2009; Kegan and Lahey, 2009). Treating disaster risk management and climate change adaptation as technical problems may focus attention only on improving technologies, reforming institutions, or managing displaced populations, whereas viewing them as an adaptive challenge shifts attention toward gaps between values and behaviors (e.g., values that promote human security versus policies or behaviors that undermine health and livelihoods), beliefs (e.g., a belief that disasters are inevitable or that adaptation will occur autonomously), and competing commitments (e.g., a commitment to maintaining aid dependency or preserving social hierarchies).
Although most problems have both technical and adaptive elements, treating an adaptive challenge only as a technical problem limits successful outcomes (Heifetz et al., 2009).

Transformative changes that move society towards the path of openness and adaptability depend not only on changes in mindsets, but also on changes in systems and structures. Case studies of socialecological systems suggest that there are three phases involved in systems transformations. The first phase includes being prepared, or preparing the system, for change. The second phase calls for navigating the transition by making use of a sudden crisis as an opportunity for change, whether the crisis is real or perceived. The third phase involves building resilience of the new system (Olsson et al., 2004; Chapin et al., 2010). Traditional management approaches emphasize the reduction of uncertainties, with the expectation that this will lead to systems that can be predicted and controlled. However, in the case of climate change, future projections of climate variables and extremes will contain uncertainty (see Section 3.2.3). Consequently, there is a need for management approaches that are adaptive and robust in the presence of large and irreducible uncertainties.

\subsubsection{Facilitating Transformational Change}

Adapting to climate and weather extremes associated with rapid and severe climate change, such as a warming beyond $4^{\circ} \mathrm{C}$ within this century, without transformational policy and social change will be difficult: if not chosen through proactive policies, forced transformations and crises are likely to result (New et al., 2011). Adaptation that is 
transformative marks a shift from emphasizing finite projects with linear trajectories and readily identifiable, discrete strategies and outcomes (Schipper, 2007) toward an approach that includes adaptive management, learning, innovation, and leadership, among other elements. These aspects of adjustment are increasingly seen as being embedded in ongoing socio-cultural and institutional learning processes. This can be observed in the many adaptation projects that emphasize learning about risks, evaluating response options, experimenting with and rectifying options, exchanging information, and making tradeoffs based on public values using reversible and adjustable strategies (McGray et al., 2007; Leary et al., 2008; Hallegatte, 2009; Hallegatte et al., 2011b).

Transformational adaptations are likely to be enabled by a number of factors. Some of the factors arise from external drivers such as focal events that catalyze attention to vulnerabilities or the presence of other sources of stress that also encourage considerations of major changes. Supportive social contexts such as the availability of understandable and socially acceptable options, access to resources for action, and the presence of incentives may also be important. Other factors are related to effective institutions and organizations, including those described in the following subsections.

\subsubsection{Adaptive Management}

In general terms, adaptive management can be defined as a structured process for improving management policies and practices by systemic learning from the outcomes of implemented strategies, and by taking into account changes in external factors in a proactive manner (PahlWostl et al., 2007; Pahl-Wostl, 2009; Section 6.6.2). Principles of adaptive management can contribute to a more process-oriented approach to disaster risk management, and have already shown some success in promoting sustainable natural resource management under conditions of uncertainty (Medema et al., 2008). Adaptive management is often associated with 'adaptive' organizations that are not locked into rigid agendas and practices, such that they can consider new information, new challenges, and new ways of operating (Berkhout et al., 2006; Pelling et al., 2007). Organizations that can monitor environmental, economic, and social conditions and changes, respond to shifting policies and leadership changes, and take advantage of opportunities for innovative interventions are a key to resilience, especially with respect to conceivable but long-term and/or relatively low-probability events. Those social systems that appear most adept at adapting are able to integrate formal organizational roles with cross-cutting informal social spaces for learning, experimentation, communication, and for trust-based and speedy disaster response that is nonetheless accountable to beneficiaries (Pelling et al., 2007).

Adaptive management is a challenge for those organizations that perceive reputational risk from experimentation and the knowledge that some local experiments may fail (Fernandez-Gimenez et al., 2008). Where this approach works best, outcomes have gone beyond specific management goals to include trust-building among stakeholders - a resource that is fundamental to any policy environment facing an uncertain future, and which also has benefits for quality of life and market competitiveness (Fernandez-Gimenez et al., 2008). It requires revisiting the relationship between the state and local actors concerning facilitation of innovation, particularly when experiments go wrong. Investing in experimentation and innovation necessarily requires some tolerance for projects that may not be productive or cost effective, or at least not in the short term or under existing risk conditions. However, it is exactly the existence of this diversity of outcomes that makes societies fit to adapt once risk conditions change, particularly in unexpected and nonlinear directions.

\subsubsection{Learning}

The dynamic notion of adaptation calls for learning as an iterative process in order to build resilience and enhance adaptive capacity now, rather than targeting adaptation in the distant future (see Section 1.4.2). Social and collective learning includes support for joint problem solving, power sharing, and iterative reflection (Berkes, 2009). The need to take into account the arrival of new information in the design of response strategies has also been mentioned for mitigation policies (Ha Duong et al., 1997; Ambrosi et al., 2003). Adaptive management is an incremental and iterative learning-by-doing process, whereby participants make sense of system changes, engage in actions, and finally reflect on changes and actions. Lessons from learning theories, including experiential learning (Kolb, 1984) and transformative learning (Mezirow, 1995), stress the importance of learning-by-doing in concrete learning cycles, problemsolving actions, and the reinterpretation of meanings and values associated with learning activities.

Learning is a key component for living with uncertainty and extreme events, and is nurtured by building the right kind of social/institutional space for learning and experimentation that allows for competing worldviews, knowledge systems, and values, and facilitates innovative and creative adaptation (Thomas and Twyman, 2005; Armitage et al., 2008; Moser, 2009; Pettengell, 2010). Examples include promoting shared platforms for dialogs and participatory vulnerability assessments that include a wide range of stakeholders (see ISET, 2010). It is equally important to acknowledge that abrupt and surprising changes may surpass existing skills and memory (Batterbury, 2008). Adaptation projects have demonstrated that fostering adaptive capacity and managing uncertainty in real-time, by adjusting as new information, techniques, or conditions emerge, especially among populations exposed to multiple risks and stressors, is more effective than more narrowly designed planning approaches that target a given impact and are dependent on particular future climate information (McGray et al., 2007; Pettengell, 2010). In the humanitarian sector, institutionalized processes of learning have contributed to leadership innovation (see Box 8-3).

Action research and learning provide a powerful complement to resilience thinking, as they focus explicitly on iterative or cyclical learning through reflection of successes and failures in experimental 


\section{Box 8-3 | Institutionalized Research and Learning in the Humanitarian Sector}

An important attribute of the humanitarian sector is its readiness to learn. Research and learning unfolds at multiple levels, including sector-wide reviews of performance and practice such as those undertaken by the Active Learning Network for Accountability and Performance in Humanitarian Action. Research and learning is also structured around the internal needs of organizations (e.g., Red Cross and Red Crescent Societies) or the outcomes of individual events (e.g., the landmark report on humanitarian sector practice following the Indian Ocean tsunami (Telford et al., 2006). Organizations have different methodologies, target audiences, and frames of reference, making cross-sector learning difficult (Amin and Goldstein, 2008), but they all have led to practical and procedural changes. Less welldeveloped is active experimentation in the field of practice, with a view of proactive learning (Corbacioglu and Kapucu, 2006). This is difficult in the humanitarian sector, where stakes are high and rapid action has typically made it difficult to implement learning-while-doing experiments. Where experimentation may be more observable, for example, in disaster prevention and risk reduction or reconstruction activities, there are significant gaps in documentation that have slowed down the transferring of learning outcomes between organizations. Hierarchical models of governance have fostered a lack of cooperation and generated competition between agencies within the humanitarian and development sectors, partly explaining why there is more learning based on the sharing of experience inside organizations than across sectors (Kapucu, 2009). But the increasing scale and diversity of risk associated with climate change, and compounded by other development trends such as growing global inequality and urbanization, puts more pressure on donors to promote cross-sector communication of productive innovations and of the research and experimentation such innovation builds upon.

action, transfer of knowledge between learning cycles, and the next learning loop that will lead to new types of action (List, 2006; Ramos, 2006). Referring to the learning processes described in Section 1.4.2, critical reflection is paramount to triple-loop learning; it also constitutes the key pillar of double-loop learning, or the questioning of what works and why that is fundamental to shifts in reasoning and behavior (Kolb and Fry, 1975; Argyris and Schön, 1978; Keen et al., 2005). Allowing time for reflection in this iterative learning process is important because it provides the necessary space to develop and test theories and strategies under ever-changing conditions. It is through such learning processes that individual and collective empowerment can emerge and potentially be scaled up to trigger transformation (Kesby, 2005).

\subsubsection{Innovation}

The transformation of society toward sustainability and resilience involves both social innovations and technological innovations incremental as well as radical. Innovation can refer to non-material changes related to knowledge, cognition, communication, or intelligence, or it can refer to any kind of material resources. In some cases, small adjustments in practices or technologies may represent innovative steps toward sustainability, while in other cases there is a strong need for more radical transformations. Some of the literature on innovation focuses on ensuring economic competitiveness for firms in an increasingly globalized economy (Fløysand and Jakobsen, 2010), and some concentrates on the relationship between environment on the one hand and the competitiveness of firms on the other (Mol and Sonnenfeld, 2000). In addition, there is a body of social science literature on innovation that has emerged during the last 15 years, motivated by the need for transforming society as a whole in more sustainable directions. Recent literature has brought out new ideas and frameworks for understanding and managing technology and innovation-driven transitions, such as the Multi Level Perspective (MLP) (Rip and Kemp, 1998; Geels, 2002; Geels and Schot, 2007; Markard and Truffer, 2008). Combining insights from evolutionary theory and sociology of technology, MLP conceptualizes major transformative change as the product of interrelated processes occurring at the three levels of niches, regimes, and landscape. The model emphasizes the incremental nature of innovation in socio-technical regimes. Transitions - that is, shifts from one stable socio-technical regime to another - occur when regimes are destabilized through landscape pressures, which provide breakthrough opportunities for niche innovations.

In this field of research, there is a strong focus on systems innovation and transformation of socio-technical systems, with the potential of facilitating transitions from established systems for transport, energy supply, agriculture, housing, etc., to alternative, sustainable systems (Geels, 2002; Hoogma et al., 2002; Smith et al., 2005; Raven et al., 2010). The systems innovation literature analyzes the emergence and dynamics of large-scale, long-term socio-technical transformations (Kemp et al., 1998).

Though not directly dependent on changes in technology, technological and social innovations are often closely interrelated, not the least in that they involve changes in social practices, institutions, cultural values, knowledge systems, and technologies (Rohracher, 2008). Box 8-4 describes such innovation in water management. A central, basic insight established within this research is that social and technological change is an interactive process of co-development between technology and society (Kemp, 1994; Hoogma et al., 2002; Rohracher, 2008). Throughout history, new socio-technical systems have emerged and replaced old ones in so-called technological revolutions, and an important characteristic of such transitions is the interactions and conflicts between new, emerging systems and established and dominating socio-technical regimes, with strong actors defending business as usual (Kemp, 1994; Perez, 2002). 


\section{Box 8-4 | Innovation and Transformation in Water Management}

The impacts of climate change in many regions are predominantly linked to the water system, in particular through increased exposure to floods and droughts (Lehner et al., 2006; Smith and Barchiesi, 2009; see Section 2.5). Considering water as a key structuring element or guiding principle for landscape management and land use planning requires technology, integrated systems thinking, and the art of thinking in terms of attractiveness and mutual influence, or even mutual consent, between different authorities, experts, interest groups, and the public. One of the most pronounced changes can be observed in The Netherlands, where the government has requested a radical rethinking of water management in general and flood management in particular. The resulting policy stream, initiated through the 'Room for the River' (Ruimte voor de Rivier) policy, has strongly influenced other areas of government policy. Greater emphasis is now given to the integration of water management and spatial planning, with the regulating services provided by landscapes with natural flooding regimes being highly valued. This requires a revision of land use practices and reflects a gradual movement toward integrated landscape planning, whereby water is recognized as a natural, structural element. The societal debate about the plans to build in deep-lying polders and other hydrologically unfavorable spots, and new ideas on floating cities, indicate a considerable social engagement of both public and private parties with the issue of sustainable landscapes and water management. However, although such innovative ideas have been adopted in policy, they take time to implement, as there is considerable social resistance (Wolsink, 2006).

\subsubsection{Leadership}

Leadership can be critical for disaster risk management and climate change adaptation, particularly in initiating processes and sustaining them over time (Moser and Ekstrom, 2010). Change processes are shaped both by the action of individual champions (as well as by those resisting change) and their interactions with organizations, institutional structures, and systems. Leadership can be a driver of change, providing direction and motivating others to follow, thus the promotion of leaders by institutions is considered an important component of adaptive capacity (Gupta et al., 2010), although knowledge about how to create and enable leadership remains elusive. Leadership and leaders often do not develop independent of the institutional context, which includes institutional rules, resources, and organizational culture (Kingdon, 1995).

Leaders who facilitate transformation have the capacity to understand and communicate a wide set of technical, social, and political perspectives related to a particular issue or problem. They are also able to reframe meanings, overcome contradictions, synthesize information, and create new alliances that transform knowledge into action (Folke et al., 2009). Leadership also involves diagnosing the kinds of losses that some people, groups, organizations, or governments may experience through transformative change, such as the loss of status, wealth, security, loyalty, or competency, not to mention loved ones (Heifetz, 2010). Leaders help individuals and groups to take action to mobilize 'adaptive work' in their communities, such that they and others can thrive in a changing world by managing risk and creating alternative development pathways or engaging and directing people during times of choice and change (Heifetz, 2010).

\subsection{Synergies between Disaster Risk Management and Climate Change Adaptation for a Resilient and Sustainable Future}

Drawing on the assessment presented in this chapter, it becomes clear that there are many potential synergies between disaster risk management and climate change adaptation that can contribute to social, economic, and environmental sustainability and a resilient future. There is, however, no single approach, framework, or pathway to achieve this. Responding to a diversity of extremes in the present and under varying social and environmental conditions can contribute to future resilience in situations of uncertainty. Nonetheless, some important contributing factors have been identified and discussed in this chapter, and are confirmed by the wider literature (e.g., Lemos et al., 2007; Tompkins et al., 2008; Pelling, 2010a; Wisner, 2011). Eight critical factors stand out as important:

1) A capacity to reconcile short- and long-term goals

2) A willingness to reconcile diverse expressions of risk in multi-hazard and multi-stressor contexts

3) The integration of disaster risk reduction and climate change adaptation into other social and economic policy processes

4) Innovative, reflexive, and transformative leadership (at all levels)

5) Adaptive, responsive, and accountable governance

6) Support for flexibility, innovation, and learning, locally and across sectors

7) The ability to identify and address the root causes of vulnerability

8) A long-term commitment to managing risk and uncertainty and promoting risk-based thinking.

Lessons learned in climate change adaptation and disaster risk management illustrate that managing uncertainty through adaptive management, anticipatory learning, and innovation can lead to more flexible, dynamic, and efficient information flows and adaptation plans, while creating openings for transformational action. Reducing vulnerability has been identified in many contemporary disaster studies as the most important prerequisite for a resilient and sustainable future. Research has consistently found that for long-term sustainability, disaster risk management is most impactful when combined with structural reforms that address underlying causes of vulnerability and the structural 


\section{FAQ 8.3 | What practical steps can we take to move toward a sustainable and resilient future?}

The disruptions caused by disaster events often reveal development failures. They also provide an opportunity for reconsidering development through reconstruction and disaster risk reduction. Practical steps can address both the root causes of risk found in development relations, including enhancing human rights, gender equity, and environmental integrity, and more proximate causes expressed most commonly through a need for extending land and property rights, access to critical services and basic needs, including social safety nets and insurance mechanisms, and transparent decisionmaking, especially at the local level. Identifying the drivers of hazard and vulnerability in ways that empower both those at risk and risk managers to take action is key. This can be done best where local and scientific knowledge is combined in the generation of risk maps or risk management plans. Greater use of local knowledge when coupled with local capacity can initiate enhanced accountability in integrated risk decisionmaking that helps to break unsustainable development relations.

The uncertainty that comes with climatic variability and extremes reinforces arguments for better coordination and accountability within governance hierarchies and across sectors, as well as between generations and for non-human species in development. Local, national, and international actors bring different strengths and tools to questions of environmental change and its relationship to trends in human development. While offering a range of specific practical measures, both local and national approaches to risk management can better meet the flexibility demands of adaptation and resilience when they have strong, accountable leadership, and are enhanced by systematic experimentation and support for innovation in the development of tools as part of planned adaptive risk management approaches. International actors can help by providing an institutional framework to support experimentation, innovation, and flexibility. This can be part of national and local strategies to move development away from incentives that promote short-term gain and toward those that promote longer-term sustainability and flexibility.

inequalities that create and sustain poverty and constrain access to resources (Hewitt, 1983; Wisner et al., 2004; Lemos et al., 2007; Collins, 2009; Pelling, 2010b).

Engaging possible and desirable futures and options for decisionmaking fosters knowledge generation essential for adaptive risk management as well as iterative change processes. Zooming in on uncertain elements and their potential impacts (e.g., changes in rainfall and variability) and identifying factors that currently limit adaptive capacity (e.g., marginalization, lack of access to resources, or information gaps) allows for more robust decisionmaking that also integrates local contexts (asset portfolios, spreading and managing risks) with the climate context (current trends, likely futures, and uncertainties) to identify the most feasible, appropriate, and equitable response strategies, policies, and external interventions (Pettengell, 2010). Creating space and recognizing a diversity of voices often means reframing what counts as knowledge, engaging uncertainties, nourishing the capacity for narrative imagination, and articulating agency and strategic adaptive responses in the face of already experienced changes and to anticipate and prepare for future disturbances and shocks (Tschakert and Dietrich, 2010).

Challenges remain with respect to anticipating low-probability, highimpact events and potentially catastrophic tipping points that represent futures too undesirable to imagine, especially under circumstances where exposure and vulnerability are high and adaptive capacity low (Volkery and Ribeiro, 2009). At a practical level, there are many gaps and barriers to realizing synergies for integration to foster a sustainable and resilient future. For example, overcoming the current disconnect between local risk management practices and national institutional and legal frameworks, policy, and planning can be considered key to reconciling short- and long-term goals for vulnerability reduction. Even where capacity is present, it can take effort to shift into more critical, learning modes of governance (Corbacioglu and Kapucu, 2006). Moreover, anticipating vulnerabilities as well as feasible and fair actions may also reveal limits of adaptation and risk management, and thus raise the potential need for transformation. Because transformative changes open up questions about the values and priorities shaping development and risk futures, who wins and loses, and the balance of tradeoffs, decisions about when and where to facilitate transformative change and to whose benefit are inherently normative and political. Transformation cannot be approached without understanding related ethical and governance dimensions. At the same time, incremental changes, in supporting many aspects of business-as-usual, also possess implicit ethical and normative aspects. At heart, it is perhaps in failing to fully reveal and question these normative positions that current disaster risk management practice and policy has remained outside of development planning and policy processes, inhabiting a long acknowledged, but still present 'disasters archipelago' in the policy world (Hewitt, 1983, p. 12).

Disasters often require urgent action and represent a time when everyday processes for decisionmaking are disrupted. Although it is a useful approach in responding to emergency events and disaster relief, such top-down command and control frameworks work less well in disaster risk reduction and this is likely to be the case too in integrated adaptive risk management. In such systems, it is often the most vulnerable to hazards that are left out of decisionmaking processes (Pelling, 2003, 2007; Cutter, 2006; Mercer et al., 2008), whether it is within households 
(where the knowledge of women, children, or the elderly may not be recognized), within communities (where divisions among social groups may hinder learning), or within nations (where marginalized groups may not be heard, and where social division and political power influence the development and adaptation agenda). Disaster periods are frequently the times when the development visions and aspirations for the future of those most affected are not recognized. This reflects a widespread limitation on the quality and comprehensiveness of local participation in disaster risk reduction and its integration into everyday development planning. Instead, the humanitarian imperative, limited-term reconstruction budgets, and an understandable desire for rapid action over deliberation means that too often international social movements and humanitarian nongovernmental organizations, government agencies, and local relief organizations impose their own values and visions, often with the best of intentions. It is also important to recognize the potential for some people or groups to prevent sustainable decisions by employing their veto power or lobbying against reforms or regulations based on shortterm political or economic interests (Klein, 2007). The distribution of power in society and who has the responsibility or right to shape the future through decisionmaking today is thus significant, and includes the role of international as well as national and local actors. Within the international humanitarian community, efforts such as the Sphere Standards and the Humanitarian Accountability Partnership are steps toward addressing this challenge.

Actions to reduce disaster risk and responses to climate change invariably involve tradeoffs with other societal goals, and conflicts related to different values and visions for the future. Innovative and successful solutions that combine multiple perspectives, differing worldviews, and contrasting ways of organizing social relations have been described by Verweij et al. (2006) as 'clumsy solutions.' Such solutions, they argue, depend on institutions in which all perspectives are heard and responded to, and where the quality of interactions among competing viewpoints foster creative alternatives. Drawing on the development ethics literature, St. Clair (2010) notes that when conflict and broadbased debate arise, alternatives often flourish and many potential spaces for action can be created, tapping into people's innovation and capacity to cope, adapt, and build resilience. Pelling (2010a) stresses the importance of social learning for transitional or transformational adaptation, and points out that it requires a high level of trust, a willingness to experiment and accept the possibility of failure in processes of learning and innovation, transparency of values, and active engagement of civil society. Committing to such a learning process is, as Tschakert and Dietrich $(2010$, p. 17) argue, preferable to alternatives because "learning by shock is neither an empowering nor an ethically defensible pathway."

The conjuncture of hazard and vulnerability, realized through disasters, forces coping and adaptation on individuals and society. Climate change and ongoing development place more people and assets at risk. Noteworthy progress in disaster risk management has been made, especially through the action of early warning on reducing mortality, but underlying vulnerability remains high (as indicated by increasing numbers of people affected and economic losses from disaster) and demographic and economic development trends continue to raise the stakes and present a choice: risk can be denied or faced, and adaptation can be forced or chosen. A reduction in the disaster risks associated with climate and weather extremes is therefore a question of political choice that involves addressing issues of equity, rights, and participation at all levels.

\section{References}

A digital library of non-journal-based literature cited in this chapter that may not be readily available to the public has been compiled as part of the IPCC review and drafting process, and can be accessed via either the IPCC Secretariat or IPCC Working Group II web sites.

AAG, 2003: Global Change and Local Places: Estimating, Understanding, and Reducing Greenhouse Gases. Association of American Geographers, Cambridge University Press, Cambridge, UK, $290 \mathrm{pp}$.

Adger, W.N., 1996: Approaches to Vulnerability to Climate Change. CSERGE Working Paper \#GEC 96-05, University of East Anglia, Norwich, UK, 66 pp.

Adger, W.N., 2000: Social and ecological resilience: are they related? Progress in Human Geography, 24(3), 347-364.

Adger, W.N., 2003: Social capital, collective action, and adaptation to climate change. Economic Geography, 79(4), 387-404.

Adger, W.N., 2004: The right to keep cold. Environment and Planning A, 36(10), 1711-1715.

Adger, W.N., S. Huq, K. Brown, D. Conway, and M. Hulme, 2003: Adaptation to climate change in the developing world. Progress in Development Studies, 3(3), 179-195.

Adger, W.N., T.P. Hughes, C. Folke, S.R. Carpenter, and J. Rockstrom, 2005: Socialecological resilience to coastal disasters. Science, 309, 1036-1039.

Adger,W.N., S. Agrawala, M.M.Q. Mirza, C. Conde, K. O'Brien, J. Pulhin, R. Pulwarty, B. Smit, and K. Takahashi, 2007: Assessment of adaptation practices, options, constraints and capacity. In: Climate Change 2007: Impacts, Adaptation and Vulnerability. Contribution of Working Group II to the Fourth Assessment Report of the Intergovernmental Panel on Climate Change [Parry, M.L., O.F. Canziani, J.P. Palutikof, P.J. van der Linden and C.E. Hanson (eds.)], Cambridge University Press, Cambridge, UK, pp. 717-743.

Adger, W.N., J. Barnett, and H. Ellemor, 2010: Unique and valued places. In: Climate Change Science and Policy [Schneider, S. H., A. Rosencranz, M. Mastrandrea, and K. Kuntz-Duriseti (eds.)]. Island Press, Washington, DC, pp. 131-138.

Adger, W.N., K. Brown, D. Nelson, F. Berkes, H. Eakin, C. Folke, K. Galvin, L. Gunderson, M. Goulden, K. O'Brien, J. Ruitenbeek, and E. Tompkins, 2011: Resilience implications of policy responses to climate change. WIRES Climate Change, doi:10.1002/WCC.133.

Adly, E. and T. Ahmed, 2009: Water and food security in the river Nile basin: Perspectives of the government and NGOs in Egypt. In: Facing Global Environmental Change: Environmental, Human, Energy, Food, Health and Water Security Concepts [Brauch, H.G., N.C. Behera, P. Kameri-Mbote, J. Grin, Ú. Oswald Spring, B. Chourou, C. Mesjasz, and H. Krummenacher (eds.)]. Springer, Berlin, Germany, pp. 645-654.

Agarwal, B., 1991: Social security and the family: Coping with seasonality and calamity in rural India. In: Social Security in Developing Countries [Ahmad, E., J. Dreze, J. Hills, and A. Sen (eds.)]. Clarendon Press, Oxford, UK, pp. 171-244.

Agrawala, S. (ed.), 2005: Bridge over Troubled Waters: Linking Climate Change and Development. Organisation for Economic Co-operation and Development, Paris, France, 153 pp. 
Ahmed, A.U., M. Alam, and A.A. Rahman, 1999: Adaptation to climate change in Bangladesh: future outlook. In: Vulnerability and Adaptation to Climate Change for Bangladesh [Huq, S., M. Asaduzzaman, Z. Karim, and F. Mahtab (eds.)]. J. Kluwer Academic Publishers, Dordrecht, The Netherlands, pp. 125-143.

Ahmed, I., 2009: Environmental refugees and environmental distressed migration as a security challenge for India and Bangladesh. In: Facing Global Environmental Change: Environmental, Human, Energy, Food, Health and Water Security Concepts [Brauch, H.G., Ú. Oswald Spring, J. Grin, C. Mesjasz, P. Kameri-Mbote, N. Chadha Behera, B. Chourou, and H. Krummenacher (eds.)]. Springer, Berlin, Germany, pp. 295-308.

Ahrens, J. and P.M. Rudolph, 2006: The importance of governance in risk reduction and disaster management. Journal of Contingencies and Crisis Management, 14(4), 207-220.

Aker, J.C. and I.M. Mbiti, 2010: Mobile phones and economic development in Africa. The Journal of Economic Perspectives, 24(3), 207-232.

Albala-Bertrand, J.M., 1993: The Political Economy of Large Natural Disasters with Special Reference to Developing Countries. Clarendon Press, Oxford, UK, $259 \mathrm{pp}$.

Alderman, H., J. Hodditnott, and B. Kinsey, 2006: Long-term consequences of early childhood malnutrition. Oxford Economic Papers, 58(3), 450-474.

Altieri, M.A. and P. Rosset, 1999: Ten reasons why biotechnology will not ensure food security, protect the environment, and reduce poverty in the developing world. AgBioForum, 2(3/4), 155-162.

Alves, D., 2002: An analysis of the geographical patterns of deforestation in Brazilian Amazonia in the 1991-1996 period. In: Patterns and Processes of Land Use and Forest Change in the Amazon [Wood, C. and R. Porro (eds.)]. University of Florida Press, Gainesville, Florida, pp. 95-105.

Ambrosi, P., J.-C. Hourcade, S. Hallegatte, P. Lecocq, P. Dumas, and M. Ha Duong, 2003: Optimal control models and elicitation of attitudes towards climate damages. Environmental Modeling and Assessment, 8(3), 133-147.

Amin, S. and M. Goldstein (eds.), 2008: Data against Natural Disasters: Establishing Effective Systems for Relief, Recovery and Reconstruction. World Bank, Washington, DC, $342 \mathrm{pp}$.

Ammer, M., M. Nowak, L. Stadlmayr, and G. Hafner, 2010: Legal Status and Legal Treatment of Environmental Refugees. Federal Environment Ministry, DessauRoßlau, Germany, $16 \mathrm{pp}$.

Argyris, C. and D. Schön, 1978: Organizational Learning: A Theory of Action Perspective. Addison Wesley, Reading, MA.

Armitage, D., 2005: Adaptive capacity and community-based natural resource management. Environmental Management, 35(6), 703-715.

Armitage, D., M. Marschke, and R. Plummer, 2008: Adaptive co-management and the paradox of learning. Global Environmental Change, 18(1), 86-98.

ASCE, 2010: Report Card for America's Infrastructure: Dams. American Society of Civil Engineers, Reston, VA.

Back, E., C. Cameron, and T.M. Tanner, 2009: Children and Disaster Risk Reduction: Taking Stock and Moving Forward. Children in a changing climate report, Institute of Development Studies, Brighton, UK, 44 pp.

Baghel, R. and M. Nusser, 2010: Discussing large dams in Asia after the World Commission on Dams: is a political ecology approach the way forward. Water Alternatives, 3(2), 231-248.

Bahadur, A.V., M. Ibrahim, and T. Tanner, 2010: The Resilience Renaissance? Unpacking of Resilience for Tackling Climate Change and Disasters. Strengthening Climate Resilience Discussion Paper, 1, Institute of Development Studies, Brighton, UK , 43 pp.

Balaban, V., 2006: Psychological assessment of children in disasters and emergencies. Disasters, 30(2), 178-198

Bangay, C. and N. Blum, 2010: Education responses to climate change and quality: two parts of the same agenda? International Journal of Educational Development, 30(4), 359-368.

Barnett, J., 2003: Security and climate change. Global Environmental Change, 13(1), 7-17.

Barnett, J. and W.N. Adger, 2007: Climate change, human security and violent conflict. Political Geography, 26(6), 639-655.
Barnett, J. and S. O'Neill, 2010: Maladaptation. Global Environmental Change, 20 211-213.

Barnett, J., R. Matthew, and K. O'Brien, 2010: Global environmental change and human security: An introduction. In: Global Environmental Change and Human Security [Matthew, R.A., B. McDonald, J. Barnett, and K. O'Brien (eds.)]. MIT Press, Cambridge, MA, pp. 3-32.

Bartlett, S., 2008: After the tsunami in Cooks Nagar: The challenges of participatory rebuilding. Children, Youth and Environments, 18(1), 470-484.

Batterbury, S., 2008: Anthropology and global warming: the need for environmental engagement. Australian Journal of Anthropology, 19(1), 62-68.

Bauer, S., 2011: Stormy weather: International security in the shadow of climate change. In: Coping with Global Environmental Change, Disaster and Security [Brauch, H.G., Ú. Oswald Spring, C. Mesjasz, J. Grin, P. Kameri-Mbote, B. Chourou, P. Dunay, and J. Birkmann (eds.)]. Springer, Berlin, Germany, pp. 719-734.

Beck, U., 2007: World at Risk. Polity, Cambridge, UK, 269 pp.

Beckman, M., 2011: Converging and conflicting interests in adaptation to env. change in Central Vietnam. Climate and Development, 3(1), 32-41.

Bengtsson, M., Y. Shen, and T. Oki, 2006: A SRES-based gridded global population dataset for 1990-2100. Population and Environment, 28(2), 113-131.

Beniston, M., 2004: The 2003 heat wave in Europe: a shape of things to come? An analysis based on Swiss climatological data and model simulations. Geophysical Research Letters, 31(2), L02202.

Benson, C. and E. Clay, 2004: Understanding the Economic and Financial Impact of Natural Disasters. International Bank for Reconstruction and Development, Disaster Risk Management Series 4, World Bank, Washington, DC, 134 pp.

Bento, A.M., M.L. Cropper, A.M. Mobarak, and K. Vinha, 2005: The effects of urban spatial structure on travel demand in the United States. Review of Economics and Statistics, 87(3), 466-478.

Berke, P.R., J. Kartez, and D. Wenger, 1993: Recovery after disaster: achieving sustainable development, mitigation and equity. Disasters, 17(2), 93-109.

Berkes, F., 2007: Understanding uncertainty and reducing vulnerability: Lessons from resilience thinking. Natural Hazards, 41(2), 283-295.

Berkes, F., 2009: Evolution of co-management: role of knowledge generation, bridging organizations and social learning. Journal of Environmental Management 90(5), 1692-1702.

Berkes, F., J. Colding, and C. Folke (eds.), 2003: Navigating Social-ecological Systems: Building Resilience for Complexity and Change. Cambridge University Press, Cambridge, UK, 398 pp.

Berkes, F., T.P. Hughes, R.S. Stenech, J.A. Wilson, D.R. Bellwood, B. Crona, C. Folke, L.H. Gunderson, H.M. Leslie, J. Norberg, M. Nyström, P. Olsson, H. Österblom, M. Scheffer, and B. Worm, 2006: Globalization, roving bandits, and marine resources. Science, 311(5767), 1557-1558.

Berkhout, F., J. Hertin, and D.M. Gann, 2006: Learning to adapt: Organisational adaptation to climate change impacts. Climatic Change, 78(1), 135-156.

Bern, C., J. Sniezek, G.M. Mathbor, M.S. Siddiqi, C. Ronsmans, A.M. Chowdhury, A.E. Chowdhury, K. Islam, M. Bennish, E. Noji, and R.I. Glass, 1993: Risk factors for mortality in the Bangladesh Cyclone 1991. Bulletin of the World Health Organization, 71(1), 73-78.

Bhattamishra, R. and C.B. Barrett, 2010: Community-based risk management arrangements: A review. World Development, 38(7), 923-932.

Bicknell, J., D. Dodman, and D. Satterthwaite (eds.), 2009: Adapting Cities to Climate Change: Understanding and Addressing the Development Challenges. Earthscan Publications, London, p. 384.

Biggs, D., R. Biggs, V. Dakos, R.J. Scholes, and M.L. Schoon, 2011: One crisis after another: Are we entering an era of concatenated global shocks? Ecology and Society, 16(2), 27.

Biggs, R., C. Raudsepp-Hearne, C. Atkinson-Palombo, E. Bohensky, E. Boyd, G. Cundill, H. Fox, S. Ingram, K. Kok, S. Spehar, M. Tengö, D. Timmer, and M. Zurek, 2007: Linking futures across scales: a dialog on multiscale scenarios. Ecology and Society, 12(1), 17

Biggs, R., S.R. Carpenter, and W.A. Brock, 2009: Turning back from the brink: detecting an impending regime shift in time to avert it. Proceedings of the National Academy of Sciences, 106(3), 826-831. 
Birkenholtz, T., 2008: Irrigated landscapes, produced scarcity and adaptive social institutions in Rajasthan, India. Annals of the Association of American Geographers, 99(1), 118-137.

Birkland, T.A., 1996: Natural disasters as focusing events: Policy communities and political response. International Journal of Mass Emergencies and Disasters, 14(2), 221-243.

Birkland, T.A., 2006: Lessons of Disaster: Policy Change after Catastrophic Events. Georgetown University Press, Washington, DC, 224 pp.

Birkmann, J., (ed.), 2006: Measuring Vulnerability to Natural Hazard: Towards Disaster Resilient Societies. UNU Press, Tokyo, Japan, 400 pp.

Bizikova, L., S. Burch, S. Cohen, and J. Robinson, 2010: Linking sustainable development with climate change adaptation and mitigation. In: Climate Change, Ethics and Human Security [O'Brien, K., A. St. Clair, and B. Kristoffersen (eds.)]. Cambridge University Press, Cambridge, UK, pp. 157-179.

Blaikie, P., T. Cannon, I. Davis and B. Wisner, 1994: At Risk: Natural Hazards, People's Vulnerability and Disaster. 1st ed. Routledge, London, UK, 286 pp.

Bogardi, J. and H.G. Brauch, 2005: Global environmental change: A challenge for human security - Defining and conceptualizing the environmental dimension of human security. In: UNEO - Towards an International Environmental Organisation - Approaches to a Sustainable Reform of Global Environmental Governance [Rechkemmer, A. (ed.)]. Nomos, Baden-Baden, Germany, pp. 85-109.

Bohle, H.G., 2009: Sustainable livelihood security. Evolution and application. In: Facing Global Environmental Change: Environmental, Human, Energy, Food, Health and Water Security Concepts [Brauch, H.G., Ú. Oswald Spring, J. Grin, C. Mesjasz, P. Kameri-Mbote, N. Chadha Behera, B. Chourou, and H. Krummenacher (eds.)]. Springer, Berlin, Germany, pp. 521-528.

Bohle, H.G., B. Etzold, and M. Keck, 2009: Resilience as agency. IHDP Update, 2, 8-13.

Boonyabancha, S., 2005: Baan Mankong; going to scale with 'slum' and squatter upgrading in Thailand. Environment and Urbanization, 2(2), 309-329.

Boulanger, J.-P., F. Martinez, and E.C. Segura, 2006a: Projection of future climate change conditions using IPCC simulations, neural networks and Bayesian statistics. Part 1. Temperature mean state and seasonal cycle in South America. Climate Dynamics, 27, 233-259.

Boulanger, J.-P., F. Martinez, and E.C. Segura, 2006b: Projection of future climate change conditions using IPCC simulations, neural networks and Bayesian statistics. Part 2. Precipitation mean state and seasonal cycle in South America. Climate Dynamics, 28, 255-271.

Bradley, R.S., M. Vuille, H. Diaz, and W. Vergara, 2006: Threats to water supplies in the tropical Andes. Science, 312, 1755-1756.

Brand, F.S. and K. Jax, 2007: Focusing the meaning(s) of resilience: resilience as a descriptive concept and a boundary object. Ecology and Society, 12(1), 23.

Brauch, H.G., 2005a: Environment and Human Security. Towards Freedom from Hazard Impact. InterSecTions No. 2, United Nations University-Institute for Environment and Human Security, Bonn, Germany, $60 \mathrm{pp}$.

Brauch, H.G., 2005b: Threats, Challenges, Vulnerabilities and Risks in Environmental and Human Security. Source No. 1, United Nations University-Institute for Environment and Human Security, Bonn, Germany, 100 pp.

Brauch, H.G., 2009: Introduction: facing global environmental change and sectorialization of security. In: Facing Global Environmental Change: Environmental, Human, Energy, Food, Health and Water Security Concepts [Brauch, H.G., Ú. Oswald Spring, J. Grin, C. Mesjasz, P. Kameri-Mbote, N. Chadha Behera, B. Chourou, and H. Krummenacher (eds.)]. Springer, Berlin, Germany, pp. 21-42.

Brauch, H.G. and Ú. Oswald Spring, 2011: Introduction: coping with global environmental change in the anthropocene. In: Coping with Global Environmental Change, Disaster and Security [Brauch, H.G., Ú. Oswald Spring, C. Mesjasz, J. Grin, P. Kameri-Mbote, B. Chourou, P. Dunay, and J. Birkmann (eds.)]. Berlin, Springer, Germany, pp. 31-60.

Brauch, H.G., Ú. Oswald Spring, C. Mesjasz, J. Grin, P. Dunay, N. Chadha Behera, B. Chourou, P. Kameri-Mbote, and P.H. Liotta (eds.), 2008: Globalization and Environmental Challenges: Reconceptualizing Security in the 21 st Century. Springer, Berlin, Germany, 1148 pp.
Brauch, H.G., Ú. Oswald Spring, J. Grin, C. Mesjasz, P. Kameri-Mbote, N. Chadha Behera, B. Chourou, and H.Krummenacher (eds.), 2009: Facing Global Environmental Change: Environmental, Human, Energy, Food, Health and Water Security Concepts. Springer, Berlin, Germany, 1588 pp.

Brauch, H.G., Ú. Oswald Spring, C. Mesjasz, J. Grin, P. Kameri-Mbote, B. Chourou, P. Dunay, and J. Birkmann (eds.), 2011: Coping with Global Environmental Change, Disasters and Security - Threats, Challenges, Vulnerabilities and Risks. Springer, Berlin, Germany, 1815 pp.

Bressers, H.T.A. and W.A. Rosenbaum (eds), 2003: Achieving Sustainable Development: the Challenge of Governance Across Social Scales. Praeger Publishers, Westport, CT.

Brklacich, M., D. McNabb, C. Bryant, and J. Dumanski, 1997: Adaptability of agriculture systems to global climate change: A Renfrew county, Ontario, Canada pilot study. In: Agricultural Restructuring and Sustainability: A Geographical Perspective [Illbery, B., Q. Chiotti, and T. Rickard (eds.)]. CABI, Wallingford, UK, pp. 351-364.

Brock, W.A. and S.R. Carpenter, 2007: Panaceas and diversification of environmental policy. Proceedings of the National Academy of Sciences, 104(39), 15206-15211.

Brown, K., 2011: Sustainable adaptation: an oxymoron? Climate and Development, 3(1), 21-31.

Brownstone, D. and T.F. Golob, 2009: The impact of residential density on vehicle usage and energy consumption. Journal of Urban Economics, 65(1), 91-98.

Bruner, A.G., R.E. Gullison, R.E. Rice, and G.A.B. da Fonseca, 2001: Effectiveness of parks in protecting tropical biodiversity. Science, 291, 125-128.

Buhaug, H., N.P. Gleditsch, and O.M. Theisen, 2008: Implications of Climate Change for Armed Conflict. World Bank, Washington DC, 52 pp.

Bunyavanich, S., C.P. Landrigan, A.J. McMichael, and P.R. Epstein, 2003: The impact of climate change on child health. Ambulatory Pediatrics, 3(1),44-52.

Burby, R.J., 2006: Hurricane Katrina and the paradoxes of government disaster policy: bringing about wise governmental decisions for hazardous areas. The Annals of the American Academy of Political and Social Science, 604(1), 171-191.

Burby, R.J., B.A. Cigler, S.P. French, E.J. Kaiser, J. Kartez, D. Roenigk, D. Weist, and D. Whittington, 1991: Sharing Environmental Risks: How to Control Governments' Losses in Natural Disasters. Westview, Boulder, CO, 280 pp.

Burby, R.J., A.C. Nelson, D. Parker, and J. Handmer, 2001: Urban containment policy and exposure to natural hazards: is there a connection? Journal of Environmental Planning and Management, 44(4), 475-490.

Burby, R.J., A.C. Nelson, and T.W. Sanchez, 2006: The problem of containment and the promise of planning. In: Rebuilding Urban Places After Disaster, Lessons from Hurricane Katrina [Birch, E.L. and S.M. Wachter (eds.)]. University of Pennsylvania Press, Philadelphia, PA, pp. 47-65.

Burch, S., S.R.J. Sheppard, A. Shaw, and O. Flanders, 2010: Planning for climate change in a flood-prone community: municipal barriers to policy action and the use of visualizations as decision-support tools. Journal of Flood Risk Management, 3(2), 126-139.

Burton, I., R.W. Kates, and G.F. White: 1993: The Environment as Hazard. 2nd ed. Guildford Press, London, UK, 290 pp.

Camerer, C. and H. Kunreuther, 1989: Decision processes for low probability events: policy implications. Journal of Policy Analysis and Management, 8(4), 565-592.

Campbell, B.M., J.A. Sayer, and B. Walker, 2010: Navigating trade-offs: working for conservation and development outcomes. Ecology and Society, 15(2), 16.

Campbell, K.M., J. Gulledge, J.R. McNeill, J. Podesta, P. Ogden, L. Fuerth, R.J. Woolsey, A.T.J. Lennon, J. Smith, R. Weitz, and D. Mix, 2007: The Age of Consequences: The Foreign Policy and National Security Implications of Global Climate Change. Center for Strategic and International Studies, Washington, DC, 124 pp.

Cannon, T., 2002: Gender and climate hazards in Bangladesh. Gender and Development, 10(2), 45-50.

Cardona, 0., 1999: Environmental management and disaster prevention: Two related topics. In: Cities at Risk: Environmental Degradation, Urban Risks and Disaster in Latin America [Fernandez, M.A. (ed.)]. La Red/USAID, Quito, Ecuador, pp. 79-102.

Carlsson-Kanyama, A., K.H. Dreborg, H.C. Moll, and D. Padovan, 2008: Participative backcasting: a tool for involving stakeholders in local sustainability planning. Futures, 40(1), 34-46. 
Carpenter, S.R., 2003: Regime Shifts in Lake Ecosystems: Pattern and Variation Excellence in Ecology Series, 15, Ecology Institute, Oldendorf/Luhe, Germany.

Carpenter, S.R., B.H. Walker, J.M. Anderies, and N. Abel, 2001: From metaphor to measurement: resilience of what to what? Ecosystems, 4(8), 765-781.

Carter, M., P.D. Little, T. Mogues, and W. Negatu, 2007: Poverty traps and natural disasters in Ethiopia and Honduras. World Development, 35(5), 835-856.

Cash, D.W., W. Adger, F. Berkes, P. Garden, L. Lebel, P. Olsson, L. Pritchard, and 0. Young, 2006: Scale and cross-scale dynamics: governance and information in a multilevel world. Ecology and Society, 11(2), 8.

Cavallo, E. and I. Noy, 2009: The Economics of Natural Disasters: A Survey. IDB Working Paper Series 124, Inter-American Development Bank, Washington, DC, $50 \mathrm{pp}$.

CCSP, 2008: Weather and Climate Extremes in a Changing Climate. Regions of Focus: North America, Hawaii, Caribbean, and U.S. Pacific Islands [Karl, T.R., G.A. Meehl, C.D. Miller, S.J. Hassol, A.M. Waple, and W.L. Murray (eds.)]. A report by the U.S. Climate Change Science Program and the Subcommittee on Global Change Research, Department of Commerce, NOAA National Climatic Data Center, Washington, DC, $164 \mathrm{pp}$.

Chakrabarti, P.G.D. and M.R. Bhatt (eds.), 2006: Micro-finance and Disaster Risk Reduction. Knowledge World, New Delhi, India.

Chambers, R., 2006: Vulnerability, coping and policy. IDS Bulletin, 37(4), 33-40.

Chapin III, F.S., S.R. Carpenter, G.P. Kofinas, C. Folke, N. Abel, W.C. Clark, P. Olsson, D.M. Stafford Smith, B.H. Walker, O.R. Young, F. Berkes, R. Biggs, J.M. Grove, R.L. Naylor, E. Pinkerton, W. Steffen, and F.J. Swanson, 2010: Ecosystem stewardship: sustainability strategies for a rapidly changing planet. Trends in Ecology and Evolution, 25(4), 241-249.

Chouvy, P.-A. and L.R. Laniel, 2007: Agricultural drug economies: cause or alternative to intra-state conflicts? Crime, Law, Social Change, 48, 133-150.

Chowdhury, K.M.M.H., 2002: Cyclone preparedness and management in Bangladesh. In: Improvement of Early Warning System and Responses in Bangladesh Towards Total Disaster Risk Management Approach. Bangladesh Public Administration Training Centre, Dhaka, Bangladesh, pp. 97-106.

Christensen, C. M., 1997: The Innovator's Dilemma: When New Technologies Cause Great Firms to Fail. Harvard Business School Press, Boston, MA, 256 pp.

Christoplos, I., 2006: Links between Relief, Rehabilitation and Development in the Tsunami Response. Tsunami Evaluation Coalition, London, UK, 102 pp.

Christoplos, I., S. Anderson, M. Arnold, V. Galaz, M. Hedger, R.J.T. Klein, and K. Le Goulven, 2009: The Human Dimension of Climate Adaptation: The Importance of Local and Institutional Issues. Commission on Climate Change and Development, Edita Sverige AB, Stockholm, Sweden, 38 pp.

Clarke, L. and J. Weyant, 2009: Introduction to the EMF 22 special issue on climate change control scenarios. Energy Economics, 31(2), 63.

CMEPSP, 2009: Report of the Commission on the Measurement of Economic Performance and Social Progress. Commission on the Measurement of Economic Performance and Social Progress, France, $292 \mathrm{pp}$.

CNA Corporation, 2007: National Security and the Threat of Climate Change. CNA Corporation, Alexandria, VA, $63 \mathrm{pp}$

Cohen, S., D. Demeritt, J. Robinson, and D. Rothman, 1998: Climate change and sustainable development: towards dialogue. Global Environmental Change, 8(4), 341-371.

Collins, A.E., 2009: Disaster and Development. Routledge Perspectives on Development, Routledge, London, UK.

Comunidad Andina, 2007: Agenda Ambiental Andina 2006-2010 (Andean Environmental Agenda 2006-2010). Secretary General, San Isidro, Perú, 12 pp.

Comunidad Andina, 2009: Articulando la gestión del riesgo y la adaptación al cambio climático en el sector agropecuario (Articulating risk assessment and adaptation to climate change in agriculture and livestock). Secretary General, San Isidro, Perú, 128 pp.

Conde, J.E., 2001: The Orinoco River Delta Venezuela. In: Coastal Marine Ecosystems of Latin America [Seeliger, U. and B. Kjerfve (eds.)]. Springer, Berlin, Germany, pp. $61-70$

Corbacioglu, S. and N. Kapucu, 2006: Organisational learning and self adaptation in dynamic disaster environments. Disasters, 30(2), 212-233.
Corfee-Morlot, J., I. Cochran, P.-J. Teasdale, and S. Hallegatte, 2011: Multilevel governance and deliberative practice to support local climate action. Climatic Change, 104(1), 169-197.

Costanza, R., 2000: The dynamics of the ecological footprint concept. Ecological Economics, 32, 341-345

Costanza, R., J. Erickson, K. Fligger, A. Adams, C. Adams, G. Altschuler, S. Balter, B. Fisher, J. Hike, J. Kelly, T. Kerr, M. McCauley, K. Montone, M. Rauch, K. Schmiedeskamp, D. Saxton, L. Sparacino, W. Tusinski, and L. Williams, 2004: Estimates of the Genuine Progress Indicator (GPI) for Vermont, Chittenden County and Burlington, from 1950 to 2000. Ecological Economics, 51(1-2), 139-155.

Costello, A., M. Abbas, A. Allen, S. Ball, S. Bell, R. Bellamy, S. Friel, N. Groce, A. Johnson, M. Kett, M. Lee, C. Levy, M. Maslin, D. McCoy, B. McGuire, H. Montgomery, D. Napier, C. Pagel, J. Patel, J. Antonio, P. de Oliveira, N. Redclift, H. Rees, D. Rogger, J. Scott, J. Stephenson, J. Twigg, J. Wolff, and C. Patterson, 2009: Managing the health effects of climate change. The Lancet, 373, 1693-1733.

Cummins, J.D. and O. Mahul, 2009: Catastrophe Risk Financing in Developing Countries: Principles for Public Intervention. World Bank, Washington, DC, 268 pp.

Cutter, S.L., 1995: The forgotten casualties: women, children, and environmental change. Global Environmental Change, 5(3), 181-194.

Cutter, S.L., 2006: Hazards, Vulnerability and Environmental Justice. Earthscan, London, UK, $418 \mathrm{pp}$.

Cutter, S.L., L. Barnes, M. Berry, C. Burton, E. Evans, E. Tate, and J. Webb, 2008: A place-based model for understanding community resilience to natural disasters. Global Environmental Change, 18(4), 598-606.

Dalby, S., 2009: Security and Environmental Change. Polity, Cambridge, UK, 199 pp.

Davidson, F., M. Zaaijer, M. Peltenburg, and M. Rodell, 1993. Relocation and Resettlement Manual: A Guide to Managing and Planning Relocation. Institute for Housing and Urban Development Studies, Rotterdam, The Netherlands, 69 pp.

Davies, M., B. Guenther, J. Leavy, T. Mitchell, and T.M. Tanner, 2008: Adaptive social protection: synergies for poverty reduction. IDS Bulletin, 39(4), 105-112.

Davies, S., 1993: Are coping strategies a cop-out? IDS Bulletin, 24(4), 60-72.

Davis, G., 1998: Creating Scenarios for Your Company's Future. The 1998 Conference on Corporate Environmental, Health, and Safety Excellence, Bringing Sustainable Development Down to Earth, New York, USA, 5 pp.

Davis, M., 2001: Late Victorian Holocausts. El Niño Famines and the Making of the Third World. Verso, London, UK, $464 \mathrm{pp}$.

de Fraiture, C., M. Giordano, and Y. Liao, 2008: Biofuels and implications for agricultural water use: blue impacts of green energy. Water Policy, 10(S1), 67-81.

de la Fuente, A., A. Revi, F. Lopez-Calva, J. Serje, F. Ramirez, C. Rosales, A. Velasquez, and S. Dercan, 2009: Deconstructing disaster: Risk patterns and poverty trends at the local level. In: Global Assessment Report on Disaster Risk Reduction. United Nations International Strategy for Disaster Reduction, Geneva, Switzerland, pp. 59-85.

del Ninno, C. and M. Lindberg, 2005: Treading water: the long-term impact of the 1998 flood on nutrition in Bangladesh. Economics and Human Biology, 3(1), 67-96.

Dennekamp, M. and M. Carey, 2010: Air quality and chronic disease: why action on climate change is also good for health. New South Wales Public Health Bulletin, 21(6), 115-121.

Dercon, S. and I. Outes, 2009: Income Dynamics in Rural India: Testing for Poverty Traps and Multiple Equilibria. Background paper for the U.N.-World Bank Assessment on the Economics of Disaster Risk Reduction, Washington, DC, $40 \mathrm{pp}$.

DesInventar, 2010: online.desinventar.org/desinventar/

Desplat, J., J-L. Salagnac, R. Kounkou, A. Lemonsu, M. Colombert, M. Lauffenburger, and V. Masson, 2009: Multidisciplinary study of the impacts of climate change on the scale of Paris. In: Proceedings of the Seventh International Conference on Urban Climate, Yokohama, Japan, June 2009, 5 pp.

Dessai, S., M. Hulme, R. Lempert, and R. Pielke, Jr., 2009a: Climate prediction: a limit to adaptation? In: Adapting to Climate Change: Thresholds, Values, Governance [Adger, W.N., I. Lorenzoni, and K.L. O'Brien (eds.)]. Cambridge University Press, Cambridge, UK, pp. 64-78. 
Dessai, S., M. Hulme, R. Lempert, and R. Pielke, Jr., 2009b: Do we need better predictions to adapt to a changing climate? Eos, 90(13), 111-112.

DFID, 2004: Disaster Risk Reduction: a Development Concern. Department for International Development, London, UK, 74 pp.

DFID, 2006: Eliminating World Poverty: Making Governance Work for the Poor. A White Paper on International Development, Department for International Development, London, UK, $132 \mathrm{pp}$.

Dodman, D., J. Hardoy, and D. Satterthwaite, 2008: Urban Development and Intensive and Extensive Risk. Contribution to the Global Assessment Report on Disaster Risk Reduction (2009), International Institute for Environment and Development, London, UK, $67 \mathrm{pp}$.

Drury, A.C. and R.S. Olson, 1998: Disasters and political unrest: an empirical investigation. Journal of Contingencies and Crisis Management, 6(3), 153-161.

Dufey, A., 2006: Biofuels Production, Trade and Sustainable Development: Emerging Issues. Sustainable Markets Discussion Paper 2, International Institute for Environment and Development, London, UK, 62 pp.

Eakin, H. and M. Webbe, 2008: Linking local vulnerability to system sustainability in a resilience framework: Two cases from Latin America. Climatic Change, 93, 355-377.

ECA, 2009: Shaping Climate-Resilient Development: A Framework for DecisionMaking. A report of the Economics of Climate Adaptation Working Group. ClimateWorks Foundation, Global Environment Facility, European Commission, McKinsey and Company, The Rockefeller Foundation, Standard Chartered Bank, and Swiss Re, $164 \mathrm{pp}$.

Edenhofer, O., K. Lessmann, C. Kemfert, M. Grubb, and J. Köhler, 2006: Induced technological change: exploring its implications for the economics of atmospheric stabilization: synthesis report from innovation modeling comparison project. The Energy Journal, 27(S1), 57-107.

Edenhofer, O., R. Pichs-Madruga, Y. Sokona, K. Seyboth, P. Matschoss, S. Kadner, T. Zwickel, P. Eickemeier, G. Hansen, S. Schlömer, and C. von Stechow (eds.), 2011: IPCC Special Report on Renewable Energy Sources and Climate Change Mitigation. Cambridge University Press, Cambridge, UK, 1544 pp.

Elmqvist, T., C. Folker, M. Nyström, G. Peterson, J. Bengtsson, B. Walker, and J. Norberg, 2003: Response diversity, ecosystem change, and resilience. Frontiers in Ecology and the Environment, 1(9), 488-494.

Elsner, J.B., J.P. Kossin, and T.H. Jagger, 2008: The increasing intensity of the strongest tropical cyclones. Nature, 455, 92-95.

Enfors, E. I., L.J. Gordon, G.D. Peterson, and D. Bossio, 2008: Making investments in dryland development work: participatory scenario planning in the Makanya catchment, Tanzania. Ecology and Society, 13(2), 42.

Eriksen, S. and K. Brown, 2011: Sustainable adaptation to climate change. Climate and Development, 3(1), 3-6.

Eriksen, S.H. and P.M. Kelly, 2006: Developing credible vulnerability indicators for climate adaptation policy assessment. Mitigation and Adaptation Strategies for Global Change, 12(4), 495-524.

Eriksen, S. and K. O'Brien, 2007: Vulnerability, poverty and the need for sustainable adaptation measures. Climate Policy, 7(4), 337-352.

Eriksen, S., P. Aldunce, C.S. Bahinipati, R. Martins, J.I. Molefe, C. Nhemachena, K. O'Brien, F. Olorunfemi, J. Park, L. Sygna, and K. Ulsrud, 2011: When not every response to climate change is a good one: identifying principles for sustainable adaptation. Climate and Development, 3(1), 7-20.

EU, 2008: Climate Change and International Security. Paper from the High Representative and the European Commission to the European Council, European Commission, Brussels, Belgium, $11 \mathrm{pp}$.

Evans, L. and J. Oehler-Stinnett, 2006: Children and natural disasters: a primer for school psychologists. School Psychology International, 27(1), 33-55.

Ewing, R. and F. Rong, 2008: The impact of urban form on US residential energy use. Housing Policy Debate, 19(1), 1-30.

Fankhauser, S., J.B. Smith, and R.S.J. Tol, 1999: Weathering climate change: some simple rules to guide adaptation decisions. Ecological Economics, 30(1), 67-78.

Farber, D., 2007: Basic compensation for victims of climate change. University of Pennsylvania Law Review, 155(6), 1605-1656.
Fargione, J.E., T.R. Cooper, D.J. Flaspohler, J. Hill, C. Lehman, T. McCoy, S. Mcleod, E.J. Nelson, K.S. Oberhauser, and D. Tilman, 2009: Bioenergy and wildlife: threats and opportunities for grassland conservation. BioScience, 59(9), 767-777.

Fearnside, P.M., 2001: Status of South American natural ecosystems. In: Encyclopedia of Biodiversity [Levin, S.A. (ed.)]. Academic Press, San Diego, CA, pp. 345-359.

FEMA, 2009: Dam Safety in the United States: A Progress Report on the National Dam Safety Program Fiscal Years 2006 and 2007. Federal Emergency Management Agency, Washington, DC, 60 pp.

Feng, S., A.B. Krueger, and M. Oppenheimer, 2010: Linkages among climate change, crop yields and Mexico-US cross-border migration. Proceedings of the National Academy of Sciences, 107(32), 14257-14262.

Fernandez-Gimenez, M.E., H.L. Ballard, and V.E. Sturtevant, 2008: Adaptive management and social learning in collaborative and community-based monitoring: a study of five community-based forestry organizations in the western USA. Ecology and Society, 13(2), 4.

Ferris, E., 2011: Protecting Civilians in Disasters and Conflicts. Brookings Policy Brief 182, Brookings Institute, Washington, DC, 4 pp.

Fløysand, A. and S.-E. Jakobsen, 2010: The complexity of innovation: A relational turn. Progress in Human Geography, 35(1), 328-344.

Foley, J.A., R. DeFries, G.P. Asner, C. Barford, G. Bonan, S.R. Carpenter, F.S. Chapin, M.T. Coel, G.C. Daily, H.K. Gibbs, T. Helkowski, E.A. Howard, C.J. Kucharik, C. Monfreda, J.A. Patz, I.C. Prentice, N. Ramankutty, and P.K. Snyder, 2005: Global consequences of land use. Science, 309, 570-574.

Folke, C., 2006: Resilience: The emergence of a perspective for social-ecological systems analyses. Global Environmental Change, 16(3), 253-267.

Folke, C., S. Carpenter, B. Walker, M. Scheffer, T. Elmqvist, L. Gunderson, and C.S. Holling, 2004: Regime shifts, resilience, and biodiversity in ecosystem management. Annual Review of Ecology, Evolution and Systematics, 35, 557-581.

Folke, C., F.S. Chapin III, and P. Olsson, 2009: Transformations in ecosystem stewardship. In: Principles of Ecosystem Stewardship: Resilience-Based Natural Resource Management in a Changing World [Chapin III, F.S., G.P. Kofinas, and C. Folke (eds.)]. Springer, New York, NY, pp. 103-125.

Folke, C., S.R. Carpenter, B.H. Walker, M. Scheffer, F.S. Chapin III, and J. Rockström, 2010: Resilience thinking: integrating resilience, adaptability and transformability. Ecology and Society, 15(4), 20.

Ford, J.D. and L.B. Ford (eds.), 2011: Climate Change Adaptation in Developed Nations: From Theory to Practice. Springer, Dordrecht, The Netherlands, $295 \mathrm{pp}$.

Foster, V. and C. Briceño-Garmendia (eds.), 2011: Africa's Infrastructure. A Time for Transformation. World Bank and French Development Agency, Washington, DC, $44 \mathrm{pp}$.

Frittaion, C., P.N. Duinker, and J. Grant, 2010: Suspending disbelief: Influencing engagement in scenarios of forest futures. Technological Forecasting and Social Change, 78(3), 421-436.

Fuentes, C.J. and H.G. Brauch, 2009: The human security network: A global NorthSouth coalition. In: Facing Global Environmental Change: Environmental, Human, Energy, Food, Health and Water Security Concepts [Brauch, H.G., Ú. Oswald Spring, J. Grin, C. Mesjasz, P. Kameri-Mbote, N. Chadha Behera, B. Chourou, and H. Krummenacher (eds.)]. Springer, Berlin, Germany, pp. 991-1001.

Gachathi, F. and S. Eriksen, 2011: Gums and resins: the potential for supporting sustainable adaptation in Kenya's drylands. Climate and Development, 3(1), 59-70.

Gaffin, S, X. Xing, and G. Yetman, 2004: Downscaling and geospatial gridding of socio-economic projections from the IPCC special report on emissions scenarios (SRES). Global Environmental Change, 14, 105-123.

Gaillard, J.C., E. Clavé, and I. Kelman, 2008: Wave of peace? Tsunami disaster diplomacy in Aceh, Indonesia. Geoforum, 39(1), 511-526.

Galer, G., 2004: Preparing the ground? Scenarios and political change in South Africa. Development, 47(4), 26-34.

Gao, Z. and Y. Hu, 2011: Coping with population growth, climate change, water scarcity and growing food demand in China in the 21st century. In: Coping with Global Environmental Change, Disaster and Security [Brauch, H.G., Ú, Oswald Spring, C. Mesjasz, J. Grin, P. Kameri-Mbote, B. Chourou, P. Dunay, and J. Birkmann (eds.)] Springer, Berlin, Germany, pp. 957-968. 
Gardiner, S. 2010: Climate change: a global test for contemporary political institutions and theories. In: Climate Change, Ethics and Human Security [O'Brien, K., A. Lera St. Clair, and B. Kristoffersen (eds.)]. Cambridge University Press, Cambridge, UK, pp. 131-153.

Garg, A., R.C. Dhiman, S. Bhattacharya, and P.R. Shukla, 2009: Development, malaria and adaptation to climate change: A case study from India. Environmental Management Journal, 43(5), 779-789.

Gawith, M., R. Street, R. Westaway, and A. Steynor, 2009: Application of the UKCIP02 climate change scenarios: reflections and lessons learnt. Global Environmental Change, 19(1), 113-121.

GECHS, 2000: Science Plan: Global Environmental Change and Human Security Project. IHDP Report 11, International Human Dimensions Programme, Bonn, Germany, 60 pp.

Geels, F.W., 2002: Technological transitions as evolutionary reconfiguration processes: A multi-level perspective and a case-study. Research Policy, 31(8/9), 1257-1274.

Geels, F.W. and J.W. Schot, 2007: Typology of sociotechnical transition pathways. Research Policy, 36(3), 399-417.

Gero, A., K. Méheux, and D. Dominey-Howes, 2011: Integrating community based disaster risk reduction and climate change adaptation: examples from the Pacific. Natural Hazards and Earth Systems Science, 11, 101-113.

Ghesquiere, F., L. Jamin, and O. Mahul, 2006: Earthquake Vulnerability Reduction Program in Colombia: A Probabilistic Cost-Benefit Analysis. Policy Research Working Paper 3939, World Bank, Washington, DC, 22 pp.

Gilbert, A. and P. Ward, 1984: Community participation in upgrading irregular settlements: the community response. World Development, 12(9), 913-922.

Glaeser, E.L. and M.E. Kahn, 2010: The greenness of cities: Carbon dioxide emissions and urban development. Journal of Urban Economics, 67(3), 404-418.

Goklany, I.M., 2007: Integrated strategies to reduce vulnerability and advance adaptation, mitigation, and sustainable development. Mitigation and Adaptation Strategies for Global Change, 12(5), 755-786.

Goldstein, B.E., 2009: Resilience to surprises through communicative planning. Ecology and Society, 14(2), 33.

Goodess, C.M., J.W. Hall, M. Best, R. Betts, L. Cabantous, P.D. Jones, C.G. Kilsby, A. Pearman, and C.J. Wallace, 2007: Climate scenarios and decision making under uncertainty. Built Environment, 33(1), 10-30.

Gordon, P., H. Richardson, and B. Davis, 1998: Transport related impacts of the Northridge earthquake. Journal of Transportation and Statistics, 1, 21-36.

Gostin, L.O., E.A. Friedman, G. Ooms, T. Gebauer, N. Gupta, D. Sridhar, W. Chenguang, J-A. Røttingen, and D. Sanders, 2011: The joint action and learning initiative: towards a global agreement on national and global responsibilities for health. PLoS Medicine, 8(5), e1001031.

Grasso, M., 2009: An ethical approach to climate adaptation finance. Global Environmental Change, 20(1), 74-81.

Grasso, M., 2010: Justice in Funding Adaptation Under the International Climate Change Regime. Springer, Dordrecht, The Netherlands, 184 pp.

Grazi, F., J.C.J.M. van den Bergh, and J. N van Ommeren, 2008: An empirical analysis of urban form, transport, and global warming. The Energy Journal, 29(4), 97-122.

Groves, D.G. and R.J. Lempert, 2007: A new analytic method for finding policyrelevant scenarios. Global Environmental Change, 17(1), 73-85.

Groves, D.G., D. Knopman, R.J. Lempert, S.H. Berry, and L. Wainfan, 2008: Presenting Uncertainty about Climate Change to Water-Resource Managers. A Summary of Workshops with the Inland Empire Utilities Agency. Technical Reports 505, Rand Corporation, Santa Monica, CA, $100 \mathrm{pp}$.

Grubb, M., C. Vrolijk, and D. Brack, 1999: The Kyoto Protocol: A Guide and Assessment. Royal Institute of International Affairs and Earthscan, London, UK, $342 \mathrm{pp}$.

Grübler, A., B. O'Neill, K.Riahi, V. Chirkov, A. Goujon, P. Kolp, I. Prommer, S. Scherbov, and E. Slentoe, 2007: Regional, national, and spatially explicit scenarios of demographic and economic change based on SRES. Technological Forecasting and Social Change, 74(7), 980-1029.

Gunderson, L., 2009: Comparing Ecological and Human Community Resilience. CARRI Research Paper 5, Community and Regional Resilience Initiative, National Security Directorate, Oak Ridge, TN, 35 pp.
Gunderson, L.H. and C.S. Holling (eds.), 2002: Panarchy: Understanding Transformations in Human and Natural Systems. Island Press, Washington, DC, $450 \mathrm{pp}$.

Guojie, C., 2003: Ecological reconstruction of the upper reaches of the Yangtze River. In: Natural Disasters and Development in a Globalizing World [Pelling, M. (ed.)] Routledge, London, UK, pp. 214-230.

Gupta, J., C. Termeer, J. Klostermann, S. Meijerink, M. van den Brink, P. Jong, S. Nooteboom, and E. Mbergsma, 2010: The adaptive capacity wheel: a method to assess the inherent characteristics of institutions to enable the adaptive capacity of society. Environmental Science and Policy, 13(6), 459-471.

Gusdorf, F., S. Hallegatte, and A. Lahellec, 2008: Time and space matter: how urban transitions create inequality. Global Environment Change, 18(4), 708-719.

Ha Duong, M., M.J. Grubb, and J.-C. Hourcade, 1997: Influence of socioeconomic inertia and uncertainty on optimal $\mathrm{CO}_{2}$-emission abatement. Nature, $\mathbf{3 9 0}$ 270-274.

Haines, A., R.S. Kovats, D. Campbell-Lendrum, and C. Corvalan, 2006: Climate change and human health: impacts, vulnerability and public health. Public Health, 120, 585-596.

Hall, J.W., 2007: Probabilistic climate scenarios may misrepresent uncertainty and lead to bad adaptation decisions. Hydrological Processes, 21(8), 1127-1129.

Hallegatte, S., 2006: A Cost-Benefit Analysis of the New Orleans Flood Protection System. Regulatory Analysis 2, American Enterprise Institute-Brookings Joint Center, Washington, DC, $18 \mathrm{pp}$.

Hallegatte, S., 2008a: An adaptive regional input-output model and its application to the assessment of the economic cost of Katrina. Risk Analysis, 28(3), 779-799.

Hallegatte, S., 2008b: A Note on Including Climate Change Adaptation in an International Scheme. Idées pour le Débat 18, Institut du Développement Durable et des Relations Internationals, Paris, France, $15 \mathrm{pp}$

Hallegatte, S., 2009: Strategies to adapt to an uncertain climate change. Global Environmental Change, 19(2), 240-247.

Hallegatte, S. and P. Dumas, 2008: Can natural disasters have positive consequences? Investigating the role of embodied technical change. Ecological Economics, 68(3), 777-786.

Hallegatte, S. and V. Przyluski, 2010: The Economics of Natural Disasters: Concepts and Methods. Policy Research Working Paper 5507, World Bank, Washington, DC, $29 \mathrm{pp}$

Hallegatte, S., J.-C. Hourcade, and P. Dumas, 2007: Why economic dynamics matter in assessing climate change damages: illustration on extreme events. Ecological Economics, 62(2), 330-340.

Hallegatte, S., P. Dumas, and J.-C. Hourcade, 2010: A Note on the Economic Cost of Climate Change and the Rationale to Limit it Below $2^{\circ} \mathrm{C}$. Background Paper to the 2010 World Development Report, Policy Research Working Paper 5179, World Bank, Washington, DC, 19 pp.

Hallegatte, S., F. Henriet, and J. Corfee-Morlot, 2011a: The economics of climate change impacts and policy benefits at city scale: A conceptual framework. Climatic Change, 104(1), 51-87.

Hallegatte, S., F. Lecocq, and C. De Perthuis, 2011b: Designing Climate Change Adaptation Policies: An Economic Framework. Policy Research Working Paper 5568, World Bank, Washington, DC, 41 pp.

Hamin, E.M. and N. Gurran, 2009: Urban form and climate change: Balancing adaptation and mitigation in the U.S. and Australia. Habitat International, 33(3), 238-245

Handy, S., X. Cao, and P. Mokhtarian, 2005: Correlation or causality between the built environment and travel behavior? Evidence from Northern California. Transportation Research Part D: Transport and Environment, 10(6), 427-444.

Hanson, S., R. Nicholls, N. Ranger, S. Hallegatte, J. Corfee-Morlot, C. Herweijer, and J. Chateau, 2011: A global ranking of port cities with high exposure to climate extremes. Climatic Change, 104(1), 89-111.

Haque, C.E. and D. Blair, 1992: Vulnerability to tropical cyclones: evidence from the April 1991 cyclone in coastal Bangladesh. Disasters, 16(3), 217-229.

Harberger, A.C., 1978: On the use of distributional weights in social cost benefit analysis. Journal of Political Economy, 86(2), 87-120. 
Harberger, A.C., 1984: Basic needs versus distributional weights in social costbenefit analysis. Economic Development and Cultural Change, 32(3), 455-474.

Hardoy, J.E., D. Mitlin, and D. Satterthwaite, 2001: Environmental Problems in an Urbanizing World. Earthscan, London, UK.

Harrington, L.M.B., 2005: Vulnerability and sustainability concerns for the US High Plains. In: Rural Change and Sustainability: Agriculture, the Environment and Communities [Essex, S.J., A.W. Gilg, R.B. Yarwood, J. Smithers, and R. Wilson (eds.)]. CABI, Wallingford, UK, pp. 169-184.

Harrington, L.M.B., 2010: The U.S. Great Plains, change, and place development. In: The Next Rural Economies: Constructing Rural Place in Global Economies [Halseth, G., S. Markey, and D. Bruce (eds.)]. CABI, Wallingford, UK, pp. 32-44.

Harrington, L.M.B., M. Lu, and J.A. Harrington, Jr., 2009: Fossil water and agriculture in southwestern Kansas. In: Sustainable Communities on a Sustainable Planet: The Human-Environment Regional Observatory Project [Yarnal, B., C. Polsky, and J. O'Brien (eds.)]. Cambridge University Press, Cambridge, UK, pp. 269-291.

Harvard Business Essentials, 2003: Managing Change and Transition. Harvard Business School Press, Boston, MA.

Harvey, D., 2010: The Enigma of Capital: And the Crisis of Capitalism. Profile, London, UK.

Hazell, P. and U. Hess, 2010: Drought insurance for agricultural development and food security in dryland areas. Food Security, 2(4), 395-405.

Hedlund-de Witt, A., 2011: The rising culture and worldview of contemporary spirituality: A sociological study of potentials and pitfalls for sustainable development. Ecological Economics, 70, 1057-1065.

Hedrén, J. and B.O. Linnér, 2009: Utopian thought and the politics of sustainable development. Futures, 41(4), 210-219.

Heifetz, R., 2010: Leadership. In: Political and Civic Leadership: A Reference Handbook [Couto, R.A. (ed.)]. Sage Publications, London, UK, pp. 12-23.

Heifetz, R., A. Grashow, and M. Linsky, 2009: The Practice of Adaptive Leadership: Tools and Tactics for Changing Your Organization and the World. Harvard Business Press, Boston, MA.

Hewitt, K. (ed.), 1983: Interpretations of Calamity. Allen and Unwin, London, UK, $304 \mathrm{pp}$.

Hewitt, K., 1997: Regions of Risk: Geographical Introduction to Disasters. Longman, London, UK, $389 \mathrm{pp}$.

Heyd, T. and N. Brooks, 2009: Exploring cultural dimensions of adaptation to climate change. In: Adapting to Climate Change: Thresholds, Values, Governance [Adger, W.N., I. Lorenzoni, and K. O'Brien (eds.)]. Cambridge University Press, Cambridge, UK, pp. 269-282.

Hine, D. and J.W. Hall, 2010: Information gap analysis of flood model uncertainties and regional frequency analysis. Water Resources Research, 46, W01514.

Hochrainer, S., 2009: Assessing Macroeconomic Impacts of Natural Disasters: Are There Any? Policy Research Working Paper 4968, World Bank, Washington, DC, 43 pp.

Hogarth, R. and H. Kunreuther, 1995: Decision making under ignorance: arguing with yourself. Journal of Risk and Uncertainty, 10(1), 15-36.

Holling, C.S., 1973: Resilience and stability of ecological systems. Annual Review of Ecology and Systematics, 4, 1-23.

Hoogma, R., R. Kemp, J. Schot, and B. Truffer, 2002: Experimenting for Sustainable Transport: The Approach of Strategic Niche Management. Routledge, London, New York.

Hopwood, B., M. Mellor, and G. O'Brien, 2005: Sustainable development: mapping different approaches. Sustainable Development, 13(1), 38-52.

Hughes, D., 2001: Cadastral politics: The making of community-based resource management in Zimbabwe and Mozambique. Development and Change, 32(4), 741-768.

Hughes, T., A.H. Baird, D.R. Bellwood, M. Card, S.R. Connolly, C. Folke, R. Grosberg, O. Hoegh-Guldberg, J.B.C. Jackson, J. Kleypas, J.M. Lough, P. Marshall, M. Nystro, S.R. Palumbi, J.M. Pandolfi, B. Rosen, and J. Roughgarden, 2003: Climate change, human impacts, and the resilience of coral reefs. Science, 301, 929-933.

Huitema, D., C. Cornelisse, and B. Ottow. 2010. Is the jury still out? Toward greater insight in policy learning in participatory decision processes - the case of Dutch citizens' juries on water management in the Rhine Basin. Ecology and Society, 15(1), 16
Hunt, A. and T. Taylor, 2009: Values and cost-benefit analysis: economic efficiency criteria in adaptation. In: Adapting to Climate Change: Thresholds, Values, Governance [Adger, W.N., I. Lorenzoni, and K.L. O'Brien (eds.)]. Cambridge University Press, Cambridge, UK, pp. 197-211.

Hunter, L.M., 2005: Migration and environmental hazards. Population and Environment, 26(4), 273-302.

ICOMOS, 1998: Report on Economics of Conservation: An Appraisal of Theories, Principles and Methods. International Economics Committee, International Council on Monuments and Sites, Paris, France, 123 pp.

ICSU, 2002: Science and Technology for Sustainable Development. Consensus Report and Background Document, Mexico City Synthesis Conference, May 2002. ICSU Series on Science for Sustainable Development 9, International Council for Science, Paris, France, $37 \mathrm{pp}$.

IFRC, 2002: World Disasters Report: Focus on Reducing Risk. International Federation of Red Cross and Red Crescent Societies, Eurospan, London, UK, 239 pp.

IFRC, 2005: World Disasters Report: Focus on Information in Disasters. International Federation of Red Cross and Red Crescent Societies, Eurospan, London, UK, 246 pp.

IFRC, 2010: World Disasters Report 2010: Focus on Urban Risk. International Federation of Red Cross and Red Crescent Societies, Geneva, Switzerland, 220 pp.

Inayatullah, S., 2006: Anticipatory action learning: Theory and practice. Futures, 38(6), 656-666.

IOM, 2007: Discussion Note: Migration and the Environment. MC/ING/288, 94th Session, International Organization for Migration, Geneva, Switzerland, 9 pp.

IOM, 2009a: Migration, Climate Change and the Environment. IOM Policy Brief, International Organization for Migration, Geneva, Switzerland, 9 pp.

IOM, 2009b: Compendium of IOM's Activities on Migration, Climate Change and the Environment. International Organization for Migration, Geneva, Switzerland, $311 \mathrm{pp}$.

IRGC, 2009: Risk Governance Deficits: An Analysis and an Illustration of the Most Common Deficits in Risk Governance. International Risk Governance Council, Geneva, Switzerland, $92 \mathrm{pp}$.

ISET, 2010: The Shared Learning Dialogue: Building Stakeholder Capacity and Engagement for Resilience Action. Climate Resilience in Concept and Practice, Working Paper 1, Institute for Social and Environmental Transition, Boulder, CO, $29 \mathrm{pp}$.

Jabry, A. (ed.), 2003: Children in Disasters: After the Cameras Have Gone. Plan UK, London, UK, 68 pp.

Jackson, T., 2009: Prosperity without Growth: Economics for a Finite Planet. Earthscan, London, UK, 278 pp.

Jaramillo, C.R.H., 2009: Do Natural Disasters have Long-Term Effects on Growth? Manuscript, Universidad de los Andes, Bogota, Colombia, 44 pp.

Jones, C. and P. Klenow, 2010: Beyond GDP? Welfare across Countries and Time. NBER Working Paper No. 16352, National Bureau of Economic Research, Cambridge, MA, $52 \mathrm{pp}$.

Jonkman, S.N., A. Lentz, and J.K. Vrijling, 2010: A general approach for the estimation of loss of life due to natural and technological disasters. Reliability Engineering and System Safety, 95(11), 1123-1133.

Kahane, A., 2004: Colombia: speaking up. Development, 47(4), 95-98.

Kahl, C.H., 2003: The political ecology of violence: lessons for the Mediterranean. In: Security and Environment in the Mediterranean. Conceptualising Security and Environmental Conflicts [Brauch, H.G., P.H. Liotta, A. Marquina, P.F. Rogers, and M. El-Sayed Selim (eds.)]. Springer, Berlin, Germany, pp. 465-476.

Kahl, C.H., 2006: States, Scarcity and Civil Strife in the Developing World. Princeton University Press, Princeton, NJ, $352 \mathrm{pp}$.

Kameri-Mbote, P. and K. Kindiki, 2009: Water and food security in the Nile River Basin: perspectives of governments and NGOs of upstream countries. In: Facing Global Environmental Change: Environmental, Human, Energy, Food, Health and Water Security Concepts [Brauch, H.G., Ú. Oswald Spring, J. Grin, C. Mesjasz, P. Kameri-Mbote, N. Chadha Behera, B. Chourou, and H. Krummenacher (eds.)]. Springer, Berlin, Germany, pp. 655-664.

Kapucu, N., 2009: Interorganizational coordination in complex environments of disasters: the evolution of intergovernmental disaster response systems. Journal of Homeland Security and Emergency Management, 6(1), 47. 
Karim, M.F. and N. Mimura, 2008: Impacts of climate change and sea level rise on cyclonic storm surge floods in Bangladesh. Global Environmental Change, 18(3), 490-500.

Keen, M., V.A. Brown, and R. Dyball, 2005: Social Learning in Environmental Management: Towards a Sustainable Future. Earthscan, London, UK, 270 pp.

Keenan, H.T., S.W. Marshall, M.A. Nocera, and D.K. Runyan, 2004: Increased incidence of inflicted traumatic brain injury in children after a natural disaster. American Journal of Preventive Medicine, 26(3), 189-193.

Kegan, R. and L.L. Lahey, 2009: Immunity to Change: How to Overcome It and Unlock the Potential in Yourself and Your Organization. Harvard Business Press, Boston, $341 \mathrm{pp}$.

Kelleher, A., 2005: A personal philosophy of anticipatory action-learning. Journal of Future Studies, 10(1), 85-90.

Kelman, I., 2003: Beyond disaster, beyond diplomacy. In: Natural Disasters and Development in a Globalizing World [Pelling, M. (ed.)]. Routledge, London, UK, pp. 110-123.

Kelman, I. and T. Koukis, 2000: Disaster diplomacy. Cambridge Review of International Affairs, 14(1), 214-294.

Kemp, R., 1994: Technology and the transition to environmental sustainability. The problems of technological regime shifts. Futures, 26(10), 1023-1046.

Kemp, R., J. Schot, and R. Hoogma, 1998: Regime shifts to sustainability through processes of niche formation: The approach of strategic niche management. Technology Analysis \& Strategic Management, 10(2), 175-195.

Kemp, R., D. Loorbach, and R. Rotmans, 2007: Transition management as a model to manage processes of co-evolution towards sustainable development. International Journal of Sustainable Development and World Ecology, 14(1), 78-91.

Kent, G., 2001: The human right to disaster mitigation and relief. Environmental Hazards, 3(3-4), 137-138.

Kesby, M., 2005: Retheorizing empowerment-through-participation as a performance in space: beyond tyranny to transformation. Signs: Journal of Women in Culture and Society, 30(4), 2037-2065.

Kiehl, J.T., 2006: Geoengineering climate change: Treating the symptom over the cause? Climatic Change, 77(3-4), 227-228.

Kingdon, J.W., 1995: Agendas, Alternatives and Public Policies. 2nd ed. HarperCollins, New York, NY, 273 pp.

Kinzig, A.P., P. Ryan, M. Etienne, H. Allison, T. Elmqvist, and B.H. Walker, 2006: Resilience and regime shifts: assessing cascading effects. Ecology and Society, 11(1), 20

Klein, N., 2007: The Shock Doctrine: The Rise of Disaster Capitalism. Penguin, London, UK, $701 \mathrm{pp}$.

Klein, R.J.T., E.L.F. Schipper, and S. Dessai, 2005: Integrating mitigation and adaptation into climate and development policy: three research questions. Environmental Science \& Policy, 8(6), 579-588.

Klein, R.J.T., S.E.H. Eriksen, L.O. Næss, A. Hammill, T.M. Tanner, C. Robledo, and K.L. O'Brien, 2007: Portfolio screening to support the mainstreaming of adaptation to climate change into development assistance. Climatic Change, 84(1), 23-44.

Knutson, T.R., J.L. McBride, J. Chan, K. Emanuel, G. Holland, C. Landsea, I. Held, J.P. Kossin, A.K. Srivastava, and M. Sugi, 2010: Tropical cyclones and climate change. Nature Geoscience, 3, 157-163.

Kolb, D.A., 1984: Experiential Learning. Englewood Cliffs, Prentice Hall, NJ, 256 pp.

Kolb, D.A. and R. Fry, 1975: Toward an applied theory of experiential learning. In: Theories of Group Process [Cooper, C. (ed.)]. John Wiley, London, UK, pp. 33-57.

Kolmannskog, V., 2008: Future Floods of Refugees: A Comment on Climate Change, Conflict and Forced Migration. Report by the Norwegian Refugee Council, Oslo, Norway, $44 \mathrm{pp}$.

Kossin, J.P., K.R. Knapp, D.J. Vimont, R.J. Murnane, and B.A. Harper, 2007: A globally consistent reanalysis of hurricane variability and trends. Geophysical Research Letters, 34, L04815.

Kotter, J.P., 1995: Leading change: Why transformation efforts fail. Harvard Business Review OnPoint, March-April, 1-10.

Kotter, J.P., 1996: Leading Change. Harvard Business School Press, Boston, MA, $200 \mathrm{pp}$.
Kovats, S., D. Campbell-Lendrum, and F. Matthies, 2005: Climate change and human health: estimating avoidable deaths and disease. Risk Analysis, 25(6), 1409-1418.

Kristjanson, P., R.S. Reid, N. Dickson, W.C. Clark, D. Romney, R. Puskur, S. MacMillan, and D. Grace, 2009: International agricultural research knowledge with action for sustainable development. Proceedings of the National Academy of Sciences, 106(13), 5047-5052.

Kunreuther, H., R. Ginsberg, L. Miller, P. Sagi, P. Slovic, B. Borkan, and N. Katz, 1978: Disaster Insurance Protection: Public Policy Lessons. John Wiley and Sons, New York, NY.

Kwa, E., 2009: Climate change and indigenous peoples in the South Pacific: the need for regional and local strategies. In: Climate Law and Developing Countries: Legal and Policy Challenges for the World Economy [Richardson, B.J., Y. le Bouthillier, H. McLeod-Kilmurray, and S. Wood (eds.)]. Edward Elgar, Cheltenham, UK, pp. 102-124.

La Trobe, S. and I. Davis, 2005: Mainstreaming Disaster Risk Reduction: A Tool for Development Organizations. Tearfund, London, $20 \mathrm{pp}$.

Lacambra, C. and K. Zahedi, 2011: Climate change, natural hazards and coastal ecosystems in Latin-America: A framework for analysis. In: Coping with Global Environmental Change, Disaster and Security [Brauch, H.G., Ú. Oswald Spring, C. Mesjasz, J. Grin, P. Kameri-Mbote, B. Chourou, P. Dunay, and J. Birkmann (eds.)]. Springer, Berlin, Germany, pp. 585-602.

Larsen, P., S. Goldsmith, 0. Smith, M. Wilson, K. Strzepek, P. Chinowsky, and B. Saylor, 2007: Estimating Future Costs for Alaska Public Infrastructure at Risk from Climate Change. Institute of Social and Economic Research, University of Alaska, Anchorage, AK, 108 pp.

Last, M., 1994: Putting children first. Disasters, 18(3), 192-202.

Lauten, A.W. and K. Lietz, 2008: A look at the standards gap: comparing child protection responses in the aftermath of hurricane Katrina and the Indian Ocean tsunami. Children, Youth and Environments, 18(1), 158-201.

Lavell, A., 1999: Desastres en América Latina:Avences Teóricos y Prácticos: 1990-1999. Anuario Social y Politico de América Latina y el Caribe, FLACSO-Nueva Sociedad, Caracas, Venezuela, 34 pp.

Lavell, A., 2009: Unpacking Climate Change Adaptation and Disaster Management: Searching for the Links and Differences: A Conceptual and Epistemological Critique and Proposal. FLACSO, Caracas, Venezuela.

Lawn, P., 2003: A theoretical foundation to support the Index of Sustainable Economic Welfare (ISEW), Genuine Progress Indicator (GPI), and other related indexes. Ecological Economics, 44, 105-118.

Le Billon, P. and A. Waizenegger, 2007: Peace in the wake of disaster? Secessionist conflicts and the 2004 Indian Ocean tsunami. Transactions of the Institute of British Geographers, 32(3), 411-427.

Le Roy Ladurie, E., 1971: Times of Feast, Times of Famine:A History of Climate Since the Year 1000. Doubleday, New York, NY.

Leary, N., J. Adequwon, V. Barros, I. Burton, J. Kukarni, and R. Lasco (eds.), 2008: Climate Change and Adaptation. Earthscan, London, UK.

Lebel, L., J.M. Anderies, B. Campbell, C. Folke, S. Hatfield-Dodds, T.P. Hughes, and J. Wilson, 2006: Governance and the capacity to manage resilience in regional social-ecological systems. Ecology and Society, 11(1), 19.

Lebel, L., B.T. Sinh, P. Garden, S. Seng, L.A. Tuan, and D. Van Truc, 2009: The promise of flood protection: dykes and dams, drains and diversions. In: Contested Waterscapes in the Mekong Region: Hydropower, Livelihoods and Governance [Molle, F., T. Foran, and M. Kakonen (eds.)]. Earthscan Publications, London, UK, pp. 283-306.

Lee, E.K.O., C. Shen, and T.V. Tran, 2009: Coping with Hurricane Katrina: psychological distress and resilience among African Americans evacuees. Journal of Black Psychology, 35(1), 5-23.

Lehner, B., P. Döll, J. Alcamo, T. Henrichs, and F. Kaspar, 2006: Estimating the impact of global change on flood and drought risks in Europe: A continental, integrated analysis. Climatic Change, 75(3), 273-299.

Leichenko, R.M. and K.L. O'Brien, 2008: Environmental Change and Globalization: Double Exposures. Oxford University Press, New York, NY, 192 pp.

Leichenko, R. and W. Solecki, 2008: Consumption, inequity, and environmental justice: the making of new metropolitan landscapes in developing countries. Society and Natural Resources, 21(7), 611-624. 
Leiserowitz, A., 2006: Climate change risk perception and policy preferences: the role of affect, imagery, and values. Climatic Change, 77(1-2), 45-72.

Leiserowitz, A.A., R.W. Kates, and T.M. Parris. 2005: Do global attitudes and behaviors support sustainable development? Environment, 47(9), 22-38.

Leiserowitz, A.A., R. Kates, and T. M. Parris. 2006: Sustainability values, attitudes, and behaviors: A review of multinational and global trends. Annual Review of Environment and Resources, 31, 413-444.

Lemos, M.C., E. Boyd, E.L. Tompkins, H. Osbahr, and D. Liverman, 2007: Developing adaptation and adapting development. Ecology and Society, 12(2), 26.

Lempert, R., 2007: Can scenarios help policymakers be both bold and careful? In: Blindside: How to Anticipate Forcing Events and Wild Cards in Global Politics [Fukuyama, F. (ed.)]. Brookings Institution Press, Washington, DC, pp. 109-179.

Lempert, R.J. and M.T. Collins, 2007: Managing the risk of uncertain thresholds responses: comparison of robust, optimum, and precautionary approaches. Risk Analysis, 27(4), 1009-1026.

Lenton, T.M., H. Held, E. Kriegler, J.W. Hall, W. Lucht, S. Rahmstorf, and H.J. Schellnhuber, 2008: Tipping elements in the Earth's climate system. Proceedings of the National Academy of Sciences, 105(6), 1786-1793.

Levin, S.A., 1998: Ecosystems and the biosphere as complex adaptive systems. Ecosystems, 1(5), 431-436.

Lin, J., 2009: Supporting adaptation in developing countries at the national and global levels. In: Climate Law and Developing Countries: Legal and Policy Challenges for the World Economy [Richardson, B.J., Y. le Bouthillier, H. McLeodKilmurray, and S. Wood (eds.)]. Edward Elgar, Cheltenham, UK, pp. 127-150.

Lindley, S., D. McEvoy, and J. Handley, 2006: Adaptation and mitigation in urban areas: synergies and conflicts. Municipal Engineer, 159(4), 185-191.

Linnenluecke, M. and A. Griffiths, 2010: Beyond adaptation: resilience for business in light of climate change and weather extremes. Business \& Society, 49(3), 477-511.

Linnerooth-Bayer, J. and R. Mechler, 2007: Disaster safety nets for developing countries: extending public-private partnerships. Environmental Hazards, 7(1), 54-61.

Linnerooth-Bayer, J., R. Mechler, and G. Pflug, 2005: Refocusing Disaster Aid. Science, 309(5737), 1044-1046.

List, D., 2006: Action Research cycles for multiple futures perspectives. Futures, 38(6), 673-684

Loayza, N., E. Olaberria, J.Rigolini, and L. Christiansen, 2009: Natural Disasters and Growth - Going Beyond the Averages. World Bank Policy Research Working Paper 4980, World Bank, Washington, DC, 42 pp.

Lobell, D.B., M.B. Burke, C. Tebaldi, M.D. Mastrandrea, W.P. Falcon, and R.L. Naylor, 2008: Prioritizing climate change adaptation needs for food security in 2030. Science, 319(5863), 607-610.

Locatelli, B., V. Evans, A. Wardell, A. Andrade, and R. Vignola, 2010: Forests and Climate Change in Latin America Linking Adaptation and Mitigation in Projects and Policies. CIFOR Infobrief No. 31, Center for International Forestry Research, Bogor, Indonesia, 8 pp.

Loorbach, D., 2010: Transition management for sustainable development: a prescriptive, complexity-based governance framework. Governance, 23(1), 161-183.

Loorbach, D., R. van der Brugge, and M. Taanman, 2008: Governance in the energy transition: practice of transition management in the Netherlands. International Journal of Environmental Technology and Management, 9(2/3), 294-315.

López, R., 2009: Natural Disasters and the Dynamics of Intangible Assets. Policy Research Working Paper 4874, Background paper for the UN-World Bank Assessment on the Economics of Disaster Risk Reduction, World Bank, Washington, DC, $79 \mathrm{pp}$.

Lovins, A. and H. Lovins, 1982: Brittle Power: Energy Strategy for National Security. Brick House, Andover, MA, 486 pp.

Lyons, M., T. Schilderman, and C. Boano (eds.), 2010: Building Back Better: Delivering People-Centred Reconstruction at Scale. Practical Action Publishing, Rugby, UK, $380 \mathrm{pp}$

Magat, W., K.W. Viscusi, and J. Huber, 1987: Risk-dollar tradeoffs, risk perceptions, and consumer behaviour. In: Learning About Risk [Viscusi, W. and W. Magat (eds.)]. Harvard University Press, Cambridge, MA, pp. 83-97.
Mahul, O. and C.J. Stutley, 2010: Government Support to Agricultural Insurance: Challenges and Options for Developing Countries. World Bank, Washington, DC, $19 \mathrm{pp}$.

Markard, J, and B. Truffer, 2008: Technological innovation systems and the multi-level perspective: towards an integrated framework. Research Policy, 37(4), 596-615.

Marulanda, M.C., O.D. Cardona, and A.H. Barbat, 2010: Revealing the socioeconomic impact of small disasters in Colombia using the DesInventar database. Disasters, 34(2), 552-570.

Maskrey, A., 1989: Disaster Mitigation: A Community Based Approach. Oxfam, Oxford, UK, $114 \mathrm{pp}$.

Maskrey, A., 1994: Comunidad y desastres en América Latina: Estrategias de Intervención. In: Viviendo en Riesgo: Comunidades vulnerables y prevención de desastres en América Latina [Lavell, A. (ed.)]. Red de Estudios Sociales en Prevención de Desastres en América Latina, Bogota, Colombia, pp. 14-38.

Maskrey, A. (ed.), 1996: Terremotos en el tropico humedo:La gestion de los desastres del Alto Mayo, Peru (1990-1991), Limon, Costa Rica (1991) y Atrato Medio, Colombia (1992). LA RED, Tercer Mundo, Bogota, Colombia, 256 pp.

Maskrey, A., 2011: Revisiting community-based disaster risk management. Environmental Hazards, 10(1), 42-52.

McCool, D., 2005: The river commons: a new era in U.S. water policy. Texas Law Review, 83(7), 1903-1927.

McEvoy, D., S. Lindley, and J. Handley, 2006: Adaptation and mitigation in urban areas: synergies and conflict. Municipal Engineer, 159(4), 185-191.

McGray, H., A. Hammill, R. Bradley, E.L. Schipper, and J.-E. Parry, 2007: Weathering the Storm: Options for Framing Adaptation and Development. World Resources Institute, Washington, DC, $57 \mathrm{pp}$.

MEA, 2005: Ecosystems and Human Well-being A Framework for Assessment. Millennium Ecosystem Assessment Series, Island Press, Washington, DC, 266 pp.

Meadowcroft, J., 1997: Planning for sustainable development: insights from the literatures of political science. European Journal of Political Research, 31(4), 427-454.

Medema, W., B.S. McIntosh, and P.J. Jeffrey, 2008: From premise to practice: a critical assessment of integrated water resources management and adaptive management approaches in the water sector. Ecology and Society, 13(2), 29.

Mercer, J., I. Kelman, K. Lloyd, and S. Suchet-Pearson, 2008: Reflections on use of participatory research for disaster risk reduction. Area, 40(2), 172-183.

Metcalf \& Eddy, 2005: Water Reuse: Issues, Technologies and Applications. Mcgraw-Hill, New York, NY, 1570 pp.

Mezirow, J., 1995: Transformation theory in adult learning. In: In Defense of the Life World [Welton, M.R. (ed.)]. State University of New York Press, Albany, NY, pp. 39-70.

Mgbako, C. and L.A. Smith, 2010: Sex work and human rights in Africa. Fordham International Law Journal, 33(4), 1178-1220.

Michel-Kerjan, E., 2008: Disasters and public policy: Can market lessons help address government failures? In: Proceedings of the 99th National Tax Association Conference, Boston, MA, 16-18 Nov. 2006, 15 pp.

Midgley, J. J. and W. J. Bond, 2001: A synthesis of the demography of African acacias. Journal of Tropical Ecology, 17(6), 871-886.

Miller, R., 2007: Futures literacy: A hybrid strategic scenario method. Futures, 39(4), 341-362.

Milligan, J., T. O'Riordan, S.A. Nicholson-Cole, and A.R. Watkinson, 2009: Nature conservation for future sustainable shorelines: lessons from seeking to involve the public. Land Use Policy, 26(2), 203-213.

Misselhorn, A.A., 2005: What drives food insecurity in southern Africa? A metaanalysis of household economy studies. Global Environmental Change $A, 15(1)$, 33-43.

Mitchell, J.K., 1999: Crucibles of Hazard: Mega-Cities and Disasters in Transition. UNU Press, New York, NY, 535 pp.

Mitchell, J.K., 2001: Policy forum: human rights to disaster assistance and mitigation. Environmental Hazards, 3(3-4), 123-124.

Mitchell, T., K. Haynes, N. Hall, W. Choong, and K. Oven, 2008: The role of children and youth in communicating disaster risk. Children, Youth and Environments, 18(1), 254-279. 
Moench, M. and A. Dixit, 2007: Working with the Winds of Change: Toward Strategies for Responding to the Risks Associated with Climate Change and other Hazards. Institute for Social and Environmental Transition, Kathmandu, Nepal, 296 pp.

Moench, M., A. Dixit, S. Janakarajan, M.S. Rathore, and S. Mudrakartha, 2003: The Fluid Mosaic: Water Governance in the Context of Variability, Uncertainty and Change. Institute for Social and Environmental Transition, Boulder, CO, $71 \mathrm{pp}$.

Mol, A.P.J. and D.A. Sonnenfeld (eds.), 2000: Ecological Modernization around the World. Frank Cass Publishers, Portland, OR, $312 \mathrm{pp}$.

Montgomery, S., M. Lucotte, and I. Rheault, 2000: Temporal and spatial influences of flooding on dissolved mercury in boreal reservoirs. The Science of the Total Environment, 260(1-3), 147-157.

Moreno, A. and O.D. Cardona, 2011: Efectos de los desastres naturales sobre el crecimiento, el desempleo, la inflación y la distribución del ingreso: Una evaluación de los casos de Colombia y México. Background Paper prepared for the 2011 Global Assessment Report on Disaster Risk Reduction, United Nations International Strategy for Disaster Reduction, Geneva, Switzerland, $30 \mathrm{pp}$.

Mortreux, C. and J. Barnett, 2009: Climate change, migration and adaptation in Funafuti, Tuvalu. Global Environmental Change, 19(1), 105-112.

Moser, S., 2009: Now more than ever: The need for more socially relevant research on vulnerability and adaptation to climate change. Applied Geography, 30(4), 464-474.

Moser, S. and J.A. Ekstrom, 2010: A framework to diagnose barriers to climate change adaptation. Proceedings of the National Academy of Sciences, 107(51), 22026-22031.

Moss, R.H., J.A. Edmonds, K.A. Hibbard, M.R. Manning, S.K. Rose, D.P. van Vuuren, T.R. Carter, S. Emori, M. Kainuma, T. Kram, G.A. Meehl, J.F.B. Mitchell, N. Nakicenovic, K. Riahi, S.J. Smith, R.J. Stouffer, A.M. Thomson, J.P. Weyant and T.J. Wilbanks, 2010: A new paradigm for the next generation of climate change scenarios. Nature, 463, 747-756.

Murray, C. and A. Lopez (eds.), 1996: The Global Burden of Disease. Harvard University Press, Cambridge, MA, 1022 pp.

Mustafa, D., 2005: The production of an urban hazardscape in Pakistan: modernity, vulnerability and the range of choice. The Annals of the Association of American Geographers, 95(3), 566-586.

Nakicenovic, N., J. Alcamo, G. Davis, B. de Vries, J. Fenhann, S. Gaffin, K. Gregory, A. Grübler, T.Y. Jung, T. Kram, E.L. La Rovere, L. Michaelis, S. Mori, T. Morita, W. Pepper, H. Pitcher, L. Price, K. Riahi, A. Roehrl, H-H. Rogner, A. Sankovski, M. Schlesinger, P. Shukla, S. Smith, R. Swart, S. van Rooijen, N. Victor, and Z. Dadi, 2000: Special Report on Emissions Scenarios: A Special Report of Working Group III of the Intergovernmental Panel on Climate Change. Cambridge University Press, Cambridge, UK, 599 pp.

Nelson, D.R., 2009: Conclusions: transforming the world. In: Adapting to Climate Change: Thresholds, Values, Governance [Adger, W.N., I. Lorenzoni, and K.L. O'Brien (eds.)]. Cambridge University Press, Cambridge, UK, pp. 491-500.

Nelson, D.R., W.N. Adger, and K. Brown, 2007: Adaptation to environmental change: contributions of a resilience framework. Annual Review of Environment and Resources, 32, 395-419.

Nelson, R. and S. Winter, 1982: An Evolutionary Theory of Economic Change. Harvard University Press, Cambridge, MA, $454 \mathrm{pp}$.

Nemarundwe, N., 2003: Negotiating Resource Access; Institutional Arrangement for Woodlands and Water Use in Southern Zimbabwe. Doctoral Thesis, University of Uppsala, Sweden, 279 pp.

Nepstad, D.C., I.M. Tohver, D. Ray, P. Moutinho, and G. Cardinot, 2007: Mortality of large trees and lianas following experimental drought in an Amazon forest. Ecology, 88(9), 2259-2269.

New, M., D. Liverman, H. Schroeder, and K. Anderson, 2011: Four degrees and beyond: the potential for a global temperature increase of four degrees and its implications. Philosophical Transactions of the Royal Society A, 369, 6-19.

Newman, P. and J.R. Kenworthy, 1989: Cities and Automobile Dependence: $A$ Sourcebook. Gower Publishing Company, Farnham, UK, 388 pp.
Newman, P.W.G., B. Birrell, D. Holmes, C. Mathers, P. Newton, G. Oakley, A. O'Connor, B. Walker, A. Spessa, and D. Tait, 1996: Human settlements. In: Australian State of the Environment Report [Beeton, R.J.S., K.I> Buckley, G.J. Jones, D. Morgan, R.E. Reichelt, and D. Trewin (eds.)]. Department of Environment, Sport and Territories, Canberra, pp. 7-18.

Nicholls, R., A. Watkinson, M. Mokrech, S. Hanson, J. Richards, J. Wright, S. Jude, S. Nicholson-Cole, M. Walkden, J. Hall, R. Dawson, P. Stansby, G.K. Jacoub, M. Rounsvell, C. Fontaine, L. Acosta, J. Lowe, J. Wolf, J. Leake, and M. Dickson, 2007: Integrated coastal simulation to support shoreline management planning. In: Proceedings of the 42nd Flood and Coastal Management Conference, York, UK, 3-5 July 2007, $11 \mathrm{pp}$.

Nicholls, R.J., S. Hanson, C. Herweijer, N. Patmore, S. Hallegatte, J. Chateau, and R. Muir-Wood, 2008: Ranking Port Cities with High Exposure and Vulnerability to Climate Extremes: Exposure Estimates. Environment Working Papers 1, Organisation for Economic Co-operation and Development, Paris, France, 61 pp.

Njuki, J.M., M.T. Mapila, S. Zingore, and R. Delve, 2008: The dynamics of social capital in influencing use of soil management options in the Chinyanja Triangle of southern Africa. Ecology and Society, 13(2), 9.

Nobre, C.A., P. Sellers, and J. Shukla, 1991: Amazonian deforestation model and regional climate change. Journal of Climate, 4, 957-988.

Nobre, C.A., E.D. Assad, and M.D. Oyama, 2005: Mudança ambiental no Brasil: 0 impacto do aquecimento global nos ecossistemas da Amazônia e na agricultura. Scientific American Brasil, Special Issue: A Terra na Estufa, 70-75.

Norris, F.H., 2005: Range, Magnitude, and Duration of the Effects of Disasters on Mental Health: Review Update 2005. Dartmouth Medical School and National Center for PTSD, Hanover, NH, $23 \mathrm{pp}$.

Norris, F., 2010: Behavioral Science Perspectives on Resilience. CARRI Research Paper 10, Community and Regional Resilience Institute, Oak Ridge, TN, 50 pp.

Norris, F.H., M. J. Friedman, P.J. Watson, C.M. Byrne, E. Diaz, and K. Kaniasty, 2002: 60,000 disaster victims speak: Part I. An empirical review of the empirical literature, 1981-2001. Psychiatry, 65(3), 207-239.

Noy, I., 2009: The macroeconomic consequences of disasters. Journal of Development Economics, 88(2), 221-231.

Noy, I. and A. Nualsri, 2007: What do Exogenous Shocks Tell Us about Growth Theories? Working Paper 07-28, University of Hawaii at Manoa, Department of Economics, Manoa, $\mathrm{HI}, 31 \mathrm{pp}$.

Noy, I. and T.B. Vu, 2010: The economics of natural disasters in a developing country: The case of Vietnam. Journal of Asian Economics, 21(4), 345-354.

NRC, 1999: Our Common Journey: A Transition Towards Sustainability. National Research Council, National Academies Press, Washington, DC, 384 pp.

NRC, 2005: Thinking Strategically: The Appropriate Use of Metrics for the Climate Change Science Program. National Research Council, National Academies Press, Washington, DC, $162 \mathrm{pp}$.

NRC, 2008: Disaster Risk Management in an Age of Climate Change. A Summary of the April 3, 2008 Workshop of the Disasters Roundtable [Anderson, W.A. (ed.)] National Research Council, National Academies Press, Washington, DC, 18 pp.

NRC, 2010: Adapting to the Impacts of Climate Change. Panel on Adapting to Impacts of Climate Change, National Research Council, National Academies Press, Washington, DC, $292 \mathrm{pp}$.

O'Brien, G., P. O'Keefe, J. Rose, and B. Wisner, 2006: Climate change and disaster management. Disasters, 30(1), 64-80.

O'Brien, K., 2009: Do values subjectively define the limits to climate change adaptation? In: Adapting to Climate Change: Thresholds, Values, Governance [Adger, W.N., I. Lorenzoni, and K. O'Brien (eds.)]. Cambridge University Press, Cambridge, UK, pp. 164-180.

O'Brien, K. and R. Leichenko, 2003: Winners and losers in the context of global change. Annals of the Association of American Geographers, 93(1), 89-103.

O'Brien, K. and J. Wolf. 2010: A values-based approach to vulnerability and adaptation to climate change. Wiley Interdisciplinary Reviews: Climate Change, 1(2), 232-242.

O'Brien, K.L., R. Leichenko, U. Kelkar, H. Venema, G. Aandahl, H. Tompkins, A. Javed, S. Bhadwal, S. Barg, L. Nygaard, and J. West, 2004: Mapping vulnerability to multiple stressors: climate change and globalization in India. Global Environmental Change, 14(4), 303-313. 
O'Brien, K. L., S. Eriksen, L. Sygna, and L.O. Næss, 2006: Questioning complacency: climate change impacts, vulnerability, and adaptation in Norway. Ambio, 35(2), 50-56.

O'Brien, K., L. Sygna, R. Leichenko, W.N. Adger, J. Barnett, T. Mitchell, L. Schipper, T. Tanner, C. Vogel, and C. Mortreux, 2008: Disaster Risk Reduction, Climate Change Adaptation and Human Security. A Commissioned Report for the Norwegian Ministry of Foreign Affairs, GECHS Report 2008:3, University of Oslo, Oslo, Norway, 76 pp.

O'Brien, K., B. Hayward, and F. Berkes, 2009: Rethinking social contracts: building resilience in a changing climate. Ecology and Society, 14(2), 12.

O'Brien, K., A. St Clair, and B. Kristoffersen (eds.), 2010a: Climate Change, Ethics and Human Security. Cambridge University Press, Cambridge, UK, 246 pp.

O'Brien, K., A. St Clair, and B. Kristoffersen, 2010b: The framing of climate change: Why it matters. In: Climate Change, Ethics and Human Security [0'Brien, K., A. St Clair, and B. Kristoffersen (eds.)]. Cambridge University Press, Cambridge, UK, pp. 3-22.

Obrist, B., C. Pfeiffer, and R. Henley, 2010: Multi-layered social resilience: a new approach in mitigation research. Progress in Development Studies, 10(4), 283-293.

OECD, 2006: Declaration On Integrating Climate Change Adaptation into Development Cooperation. Organisation for Economic Co-operation and Development, Paris, France, 7 pp.

OECD, 2007: Climate Change in the European Alps: Adapting Winter Tourism and Natural Hazards Management [Agrawala, S. (ed.)]. Organisation for Econonomic Co-operation and Development, Paris, France.

OECD, 2009a: Measuring and Fostering the Progress of Societies. Document prepared for OECD Meeting of the Council at Ministerial Level, 27-28 May 2010. C/MIN(2010)13, 12 May 2010, Organisation for Econonomic Co-operation and Development, Paris, France, 17 pp.

OECD, 2009b: Innovation in Country Risk Management. Organisation for Economic Co-operation and Development, Paris, France, $47 \mathrm{pp}$.

Okuyama, Y., 2004: Modeling spatial economic impacts of an earthquake: Inputoutput approaches. Disaster Prevention and Management, 13(4), 297-306.

Oliver-Smith, A., 1994: Peru's five hundred year earthquake: vulnerability in historical context. In: Disasters, Development and Environment [Varley, A. (ed.)]. John Wiley and Sons, London, UK, pp. 31-48.

Oliver-Smith, A., 2007: Communities after catastrophes: reconstructing the material, reconstituting the social. In: Community Building in the Twenty First Century [Hyland, S.E. (ed.)]. School of American Research Press, Santa Fe, NM, pp. 49-75.

Olson, R.S., 2000: Toward a politics of disaster losses, values, agendas, and blame. International Journal of Mass Emergencies and Disasters, 18(2), 265-287.

Olson, R.S. and V. Gawronski, 2003: Disasters as 'critical junctures' Managua, Nicaragua 1972 and Mexico City 1985. International Journal of Mass Emergencies and Disasters, 21(1), 5-35.

Olsson, P., C. Folke, and T. Hahn, 2004: Social-ecological transformation for ecosystem management: the development of adaptive co-management of a wetland landscape in southern Sweden. Ecology and Society, 9(4), 2.

ONERC, 2009: Climate Change: Costs of Impacts and Lines of Adaptation. Report to the Prime Minister and Parliament, Observatoire National sur les Effets du Réchauffement Climatique, Paris, France, 136 pp.

Orlove, B., 2009: Glacier retreat: reviewing the limits of human adaptation to climate change. Environment: Science and Policy for Sustainable Development, 51(3), 22-34.

Oswald Spring, Ú., 1991: Estrategias de Supervivencia en la Ciudad de México. Centro Regional de Investigaciones Multidisciplinarias, Universidad Nacional Autónoma de México, Cuernavaca, México, 219 pp.

Oswald Spring, Ú., 2009a: A HUGE gender security approach: towards human, gender and environmental security. In: Facing Global Environmental Change: Environmental, Human, Energy, Food, Health and Water Security Concepts [Brauch, H.G., Ú. Oswald Spring, J. Grin, C. Mesjasz, P. Kameri-Mbote, N. Chadha Behera, B. Chourou, and H. Krummenacher (eds.)]. Springer, Berlin, Germany, pp.1165-1190.
Oswald Spring, Ú., 2009b: Food as a new human and livelihood security challenge. In: Facing Global Environmental Change: Environmental, Human, Energy, Food, Health and Water Security Concepts [Brauch, H.G., Ú. Oswald Spring, J. Grin, C. Mesjasz, P. Kameri-Mbote, N. Chadha Behera, B. Chourou, and H. Krummenacher (eds.)]. Springer, Berlin, Germany, pp. 471-500.

Oswald Spring, Ú., 2011a: Environmentally-forced migration in rural areas: security risks and threats in Mexico. In: Climate Change, Human Security and Violent Conflict: Challenges for Societal Stability [Scheffran, J., M. Brzoska, H.G. Brauch, P.M. Link, and J. Schilling (eds.)]. Hexagon Series on Human and Environmental Security and Peace 8, Springer, Heidelberg, Germany (in press).

Oswald Spring, Ú. (ed.), 2011b: Retos de la Investigación del Agua en México. Centro Regional de Investigaciones Multidisciplinarias, Universidad Nacional Autónoma de México / Scientific Network on Water - National Council on Science and Technology, Cuernavaca, México.

Oswald Spring, Ú. and H.G. Brauch, 2011: Coping with global environmental change - sustainability revolution and sustainable peace. In: Coping with Global Environmental Change, Disaster and Security [Brauch, H.G., Ú. Oswald Spring, C. Mesjasz, J. Grin, P. Kameri-Mbote, B. Chourou, P. Dunay, and J. Birkmann (eds.)]. Springer, Berlin, Germany, pp. 1487-1504.

Owuor, B., W. Mauta, and S. Eriksen, 2011: Strengthening sustainable adaptation: examining interactions between pastoral and agropastoral groups in dryland Kenya. Climate and Development, 3(1), 42-58.

Oxfam, 2010: Gender, Disaster Risk Reduction and Climate Change Adaptation, A Learning Companion. Oxfam GB, Oxford, UK, 15 pp.

Paavola, J., 2005: Seeking justice: international environmental governance and climate change. Globalizations, 2(3), 309-322.

Paavola, J. and W.N. Adger, 2006: Fair adaptation to climate change. Ecological Economics, 56(1), 594-609.

Paavola, J., W.N. Adger, and S. Huq, 2006: Multifaceted justice in adaptation to climate change. In: Fairness in Adaptation to Climate Change [Adger, W.N., J. Paavola, S. Huq, and M.J. Mace (eds.)]. MIT Press, Cambridge, MA, 263-277.

Pahl-Wostl, C., 2009: A conceptual framework for analysing adaptive capacity and multi-level learning processes in resource governance regimes. Global Environmental Change, 19(3), 354-365.

Pahl-Wostl, C., M. Craps, A. Dewulf, E. Mostert, D. Tabara, and T.Taillieu, 2007: Social learning and water resources management. Ecology and Society, 12(2), 5.

Parry, M.L., O.F. Canziani, J.P. Palutikof and Co-authors, 2007: Technical summary. In: Climate Change 2007: Impacts, Adaptation and Vulnerability. Contribution of Working Group II to the Fourth Assessment Report of the Intergovernmental Panel on Climate Change [Parry, M.L., O.F. Canziani, J.P. Palutikof, P.J. van der Linden, and C.E. Hanson (eds.)]. Cambridge University Press, Cambridge, UK, pp. 23-78.

Patel, P. and K. Pavit, 1995: Patterns of technological activity: their measurement and interpretation. In: Handbook of Economics of Innovation and Technological Change [Stoneman, P. (ed.)]. Wiley-Blackwell, Oxford, UK, pp. 14-51.

Pearce, L., 2003: Disaster management and community planning, and public participation: how to achieve sustainable hazard mitigation. Natural Hazards, 28(2-3), 211-228.

Peek, L., 2008: Children and disasters: understanding vulnerability, developing capacities and promoting resilience - an introduction. Children, Youth and Environments, 18(1), 1-29.

Peeples, M.A., C.M. Barton, and S. Schmich, 2006: Resilience lost: intersecting land use and landscape dynamics in the prehistoric southwestern United States. Ecology and Society, 11(2), 22.

Pelling, M., 1999: The political ecology of flood hazard in urban Guyana. Geoforum, 30, 249-261.

Pelling, M., 2003: Vulnerability of Cities, Natural Disasters and Social Resilience. Earthscan, London, UK, $212 \mathrm{pp}$.

Pelling, M., 2007: Learning from others: scope and challenges for participatory disaster risk assessment. Disasters, 31(4), 373-385.

Pelling, M., 2010a: Adaptation to Climate Change: From Resilience to Transformation. Taylor and Francis, London, UK, 224 pp.

Pelling, M., 2010b: Systematisation Review of Urban Disaster Risk Reduction Projects in the Caribbean Region. Oxfam, Oxford, UK, 90 pp. 
Pelling, M. and K. Dill, 2009: Disaster politics: tipping points for change in the adaptation of socio-political regimes. Progress in Human Geography, 34(1), 21-37.

Pelling, M. and A. Holloway, 2006: Legislation for Mainstreaming Disaster Risk Reduction. Tearfund, London, UK, $36 \mathrm{pp}$.

Pelling, M. and D. Manuel-Navarrete, 2011: From resilience to transformation: the adaptive cycle in two Mexican urban centers. Ecology and Society, 16(2), 11.

Pelling, M. and J.I. Uitto, 2001: Small island developing states: natural disaster vulnerability and global change. Environmental Hazards: Global Environmental Change $B, 3(2), 49-62$.

Pelling, M. and B. Wisner (eds.), 2009: Disaster Risk Reduction: Cases from Urban Africa. Earthscan, London, UK.

Pelling, M., A. Özerdem, and S. Barakat, 2002: The macro-economic impact of disasters. Progress in Development Studies, 2(4), 283-305.

Pelling, M., C. High, J. Dearing, and D. Smith, 2007: Shadow spaces for social learning: a relational understanding of adaptive capacity to climate change within organizations. Environment and Planning A, 40(4), 867-884.

Penrose, A. and M. Takaki, 2006: Children's rights in emergencies and disasters. The Lancet, 367, 698-699.

Perez, C., 2002: Technological Revolutions and Financial Capital. The Dynamics of Bubbles and Golden Ages. Edward Elgar, Cheltenham, UK, 198 pp.

Peterson, G., 2009: Ecological limits of adaptation to climate change. In: Adapting to Climate Change: Thresholds, Values, Governance [Adger, W.N., I. Lorenzoni, and K. O'Brien (eds.)]. Cambridge University Press, Cambridge, UK, pp. 25-41.

Peterson, G., G.A. De Leo, J.J. Hellmann, M.A. Janssen, A. Kinzig, J.R. Malcolm, K.L. O'Brien, S.E. Pope, D.S. Rothman, E. Shevliakova, and R.R.T Tinch, 1997: Uncertainty, climate change, and adaptive management. Conservation Ecology, 1(2), 4.

Pettengell, C., 2010: Climate Change Adaptation: Enabling People Living in Poverty to Adapt. Oxfam International Research Report, Oxfam, Oxford, UK, 48 pp.

Pielke, Jr., R., J. Rubiera, C. Landsea, M. Fernández, and R. Klein, 2003: Hurricane vulnerability in Latin America and the Caribbean: Normalized damage and loss potentials. Natural Hazards Review, 4(3), 101-114.

Pielke, Jr., R., G. Prins, S. Rayner, and D. Sarewitz, 2007: Climate change 2007: lifting the taboo on adaptation. Nature, 445, 597-598.

Pielke, Jr., R.A., J. Gratz, C.W. Landsea, D. Collins, M. Saunders, and R. Musulin, 2008: Normalized hurricane damages in the United States: 1900-2005. Natural Hazards Review, 9(1), $29-42$.

Pigou, A.C., 1920: The Economics of Welfare. Macmillan, London, UK, 976 pp.

Piguet, E., 2008: Climate Change and Forced Migration. Research Paper No 153, Evaluation and Policy Analysis Unit, UN High Commissioner for Refugees, Geneva, Switzerland, $15 \mathrm{pp}$.

Platt, R.H., 1999: Disasters and Democracy: the Politics of Extreme Natural Events. Island Press, Washington, DC, $320 \mathrm{pp}$.

Plummer, R. and D.R. Armitage, 2007: Charting the new territory of adaptive comanagement: a Delphi study. Ecology and Society, 12(2), 10.

Quarantelli, E.L., 1984: Perceptions and reactions to emergency warnings of sudden hazards. Ekistics, 309,511-515.

Quarantelli, E.L., 1995: What is a Disaster? Routledge, London, UK, 312 pp.

Raddatz, C., 2007: Are external shocks responsible for the instability of output in low-income countries? Journal of Development Economics, 84(1), 155-187.

Raleigh, C., L. Jordan, and I. Salehyan, 2008: Assessing the Impact of Climate Change on Migration and Conflict. World Bank, Washington DC, 57 pp.

Ramos, J.M., 2006: Dimensions in the confluences of futures studies and action research. Futures, 38(6), 642-655.

Raven, R.P.J.M., S. van den Bosch, and R. Weterings, 2010: Transitions and strategic niche management: towards a competence kit for practitioners. International Journal of Technology Management, 51(1), 57-74.

Rawls, J., 1971: A Theory of Justice. Harvard University Press, Cambridge, MA, $607 \mathrm{pp}$.

Reaser, J.K., R. Pomerance, and P.O. Thomas, 2000: Coral bleaching and global climate change: scientific findings and policy recommendations. Conservation Biology, 14(5), 1500-1511
Redclift, M., 1987: Sustainable Development: Exploring the Contradictions. Methuen, London, UK, $221 \mathrm{pp}$.

Redclift, M., 1992: The meaning of sustainable development. Geoforum, 25(3), 395-403.

Reeder, T., J. Wicks, L. Lovell, and 0. Tarrant, 2009: Protecting London from tidal flooding: limits to engineering adaptation. In: Adapting to Climate Change: Thresholds, Values, Governance [Adger, W.N., I. Lorenzoni, and K. O'Brien (eds.)]. Cambridge University Press, Cambridge, UK, pp. 54-78.

Reid, H., 2006: Climatic change and biodiversity in Europe. Conservation and Society, 4(1), 84-101.

Repetto, R., 2008: The Climate Crisis and the Adaptation Myth. Working Paper 13, Yale School of Forestry and Environmental Studies, New Haven, CT, 24 pp.

Reuveny, R., 2007: Climate change induced migration and violent conflict. Political Geography, 26(6), 656-673.

Reyos, J., 2010: Community-driven Disaster Intervention: Experiences of the Homeless People's Federation in the Philippines. Homeless Peoples Federation Philippines, Philippines Action for Community-led Shelter Initiatives, and International Institute for Environment and Development, Manila, Philippines and London, UK, $70 \mathrm{pp}$.

Richardson, B.J., Y. Le Bouthillier, H. McLeod-Kilmurray, and S. Wood (eds.), 2009: Climate Law and Developing Countries: Legal and Policy Challenges for the World Economy. Edward Elgar, Cheltenham, UK, 448 pp.

Rip, A. and R. Kemp, 1998: Technological change. In: Human Choice and Climate Change [Rayner, S. and L. Malone (eds.)]. Batelle Press, Washington, DC, pp. 327-399.

Rist, S., 2000: Linking ethics and market - Campesino economic strategies in the Bolivian Andes. Mountain Research and Development, 20(4), 310-315.

Roberts, D., 2008: Thinking globally, acting locally - institutionalizing climate change at the local government level in Durban, South Africa. Environment and Urbanization, 20(2), 521-537.

Roberts, D., 2010: Prioritizing climate change adaptation and local level resilience in Durban, South Africa. Environment and Urbanization, 22(2), 397-413.

Robinson, J., 2003: Future subjunctive: backcasting as social learning. Futures, 35(8), 839-856.

Rodriguez-Oreggia, E., A. de la Fuente, R. de la Torre, H. Moreno, and C. Rodriguez, 2009: The Impact of Natural Disasters on Human Development and Poverty at the Municipal Level in Mexico. CID Working Paper 43, Center for International Development at Harvard University, Cambridge, MA, 35 pp.

Rohan, M.J., 2000: A rose by any name? The values construct. Personal and Social Psychology Review, 4(3), 255-277.

Rohracher, H., 2008: Energy systems in transition: contributions from social sciences. International Journal of Environmental Technology and Management, 9(2-3), 144-161.

Rokeach, M., (ed.), 1979: Understanding Human Values: Individual and Societal. The Free Press, New York, NY, 322 pp.

Rose, A. and S.-Y. Liao, 2005: Modeling regional economic resilience to disasters: A computable general equilibrium analysis of water service disruptions. Journal of Regional Science, 45(1), 75-112.

Rose, A., J. Benavides, S.E. Chang, P. Szczesniak, and D. Lim, 1997: The regional economic impact of an earthquake: Direct and indirect effects of electricity lifeline disruptions. Journal of Regional Science, 37(3), 437-458.

Rosegrant, M.W., T. Zhu, S. Msangi, and T. Sulser, 2011: Global scenarios for biofuels: impacts and implications. Applied Economic Perspectives and Policy, 30(3), 595-505.

Rosenberg, S.W. (ed.), 2007: Deliberation, Participation and Democracy: Can the People Govern? Palgrave Macmillan, New York, NY, 322 pp.

Rosenzweig, C., K.M. Strzepek, D.C. Major, A. Iglesias, D.N. Yates, A. McCluskey, and D. Hillel, 2004: Water resources for agriculture in a changing climate: international case studies. Global Environmental Change, 14(4), 345-360.

Roshetko, J.M., R.D. Lasco, and M.S.D. Angeles, 2007: Smallholder agroforestry systems for carbon storage. Mitigation and Adaptation Strategies for Global Change, 12, 219-242.

Royal Society, 2009: Geoengineering The Climate: Science, Governance and Uncertainty. The Royal Society, London, UK, 98 pp. 
Sacoby, M., R.R. Wilson, J. Lesley, and E. Williams, 2010: Climate change, environmental justice, and vulnerability: an exploratory spatial analysis. Environmental Justice, 3(1), 13-19.

Salagnac, J.-L., 2007: Lessons from the 2003 heat wave: a French perspective. Building Research and Information, 35(4), 450-457.

Santos, I., 2007: Disentangling the Effects of Natural Disasters on Children: 2001 Earthquakes in El Salvador. Doctoral Dissertation, Kennedy School of Government, Harvard University, Cambridge, MA.

Satterthwaite, D., 1997: Sustainable cities or cities that contribute to sustainable development? Urban Studies, 34(10), 1167-1691.

Satterthwaite, D., 1998: Meeting the challenge of urban disasters. In: World Disasters Report 1998. International Federation of Red Cross and Red Crescent Societies, Oxford University Press, Oxford, UK, pp. 9-19.

Satterthwaite, D. (ed.), 2007: The Transition to a Predominantly Urban World and its Underpinnings. International Institute for Environment and Development, London, UK, $91 \mathrm{pp}$.

Satterthwaite, D., 2010: Slum upgrading. Economic and Political Weekly, 45(10), 12-16.

Schär, C., P.L. Vidale, D. Lüthi, C. Frei, C.Häberli, M.A. Liniger, and C. Appenzeller, 2004: The role of increasing temperature variability in European summer heatwaves. Nature, 427, 332-336.

Scharmer, C.0., 2009: Theory U: Leading from the Future as it Emerges. The Society for Organizational Learning, Cambridge, MA, 533 pp.

Scheffer, M., 2009. Critical Transitions in Nature and Society. Princeton University Press, Princeton, NJ, $400 \mathrm{pp}$

Scheffer, M., S.R. Carpenter, J.A. Foley, C. Folke, and B. Walker, 2001: Catastrophic shifts in ecosystems. Nature, 413, 591-596.

Scheffer, M., J. Bascompte, W.A. Brock, V. Brovkin, S.R. Carpenter, V. Dakos, H. Held, E.H. van Nes, M. Rietkerk, and G. Sugihara, 2009: Early-warning signals for critical transitions. Nature, 461, 53-59.

Scheffran, J., 2011: Security risks of climate change: vulnerabilities, threats, conflicts and strategies. In: Coping with Global Environmental Change, Disaster and Security [Brauch, H.G., Ú. Oswald Spring, C. Mesjasz, J. Grin, P. Kameri-Mbote, B. Chourou, P. Dunay, and J. Birkmann (eds.)]. Springer, Berlin, Germany, pp. 735-756.

Schipper, E.L.F., 2007: Climate Change Adaptation and Development: Exploring the Linkages. Working Paper 107, Tyndall Centre for Climate Change Research, Norwich, UK, $20 \mathrm{pp}$.

Schipper, L., 2009: Meeting at the crossroads? Exploring the linkages between climate change adaptation and disaster risk reduction. Climate and Development, 1(1), 16-30.

Schipper, L. and M. Pelling, 2006: Disaster risk, climate change and international development: scope and challenges for integration. Disasters, 30(1), 19-38.

Schlenker, W. and M.J. Roberts, 2006: Nonlinear effects of weather on corn yields. Review of Agricultural Economics, 28(3), 391-398.

Scholze, M., W. Knorr, N.W. Arnell, and I.C. Prentice, 2005: A climate change risk analysis for world ecosystems. Proceedings of the National Academy of Sciences, 103, 13116-13120.

Schumacher, I. and E. Strobl, 2008: Economic Development and Losses due to Natural Disasters: The Role of Risk. Cahiers 2008-32, Département d'Economie, Ecole Polytechnique, Palaiseau, France, 39 pp.

SCBD, 2010: Global Biodiversity Outlook 3. Secretariat of the Convention on Biological Diversity, Montréal, Canada.

Scott, J.C., 2003: The Moral Economy of the Peasant: Rebellion and Subsistence in Southeast Asia. Yale University Press, New Haven, CT, 246 pp.

Sen, A, 2000: Un Nouveau Modèle Économique. Développement, Justice, Liberté. Editions Odile Jacob, Paris, France, $356 \mathrm{pp}$

Sen, A, 2003: Human security now. Soka Gakkai International Quarterly, 33, 1-7.

Senge, P.M., 1990: The Fifth Discipline: The Art and Practice of the Learning Organization. Currency/Doubleday, New York, NY, p. 445.

Silvestri, S. and F. Kershaw (eds.), 2010: Framing the flow: Innovative Approaches to Understand, Protect and Value Ecosystem Services across Linked Habitats. United Nations Environment Programme World Conservation Monitoring Centre, Cambridge, UK, $66 \mathrm{pp}$
Simmie, J. and R. Martin. 2010: The economic resilience of regions: towards an evolutionary approach. Economy and Society, 3(1), 27-43.

Skidmore, M. and H. Toya, 2002: Do natural disasters promote long-run growth? Economic Inquiry, 40(4), 664-687.

Slovic, P., 1987: Perception of risk. Science, 236, 280-285.

Smith, A. and A. Stirling, 2010: The politics of social-ecological resilience and sustainable sociotechnical transitions. Ecology and Society, 15(1), 11.

Smith, A., A. Stirling, and F. Berkhout, 2005: The governance of sustainable sociotechnical transitions: a quasi-evolutionary model. Research Policy, 34(10), 1491-1510.

Smith, D.M. and S. Barchiesi, 2009: Environment as Infrastructure: Resilience to Climate Change impacts on Water through Investments in Nature. International Union for Conservation of Nature, Gland, Switzerland, $13 \mathrm{pp}$.

Smith, S.K. and C. McCarty, 2006: Florida's 2004 Hurricane Season: Demographic Response and Recovery. Bureau of Economic and Business Research, University of Florida, Gainesville, FL, $40 \mathrm{pp}$.

Smithers, J. and B. Smit, 1997: Agricultural system response to environmental stress. In: Agricultural Restructuring and Sustainability: A Geographical Perspective [Ilbery, B., Q. Chiotti, and T. Rickard (eds.)]. CABI, Wallingford, UK, pp. 167-183.

Solecki, W. and R. Leichenko, 2006: Urbanization and the metropolitan environment: lessons from New York and Shanghai. Environment, 48(4), 8-23.

Sperling, F. and F. Szekely, 2005: Disaster Risk Management in Changing Climate. Discussion Paper prepared for the World Conference on Disaster Risk Reduction on behalf of the Vulnerability and Adaptation Resource Group (VARG). Reprint with Addendum on Conference Outcomes, VARG, Washington, DC, 45 pp.

Sperling, F., C. Valdivia, R. Quiroz, R. Valdivia, L. Angulo, A. Seimon, and I. Noble, 2008: Transitioning to Climate Resilient Development: Perspectives from Communities in Peru. World Bank Environment Department Papers 115, World Bank, Washington, DC, 103 pp.

Sphere, 2004: Humanitarian Charter and Minimum Standards in Humanitarian Response. The Sphere Project, Belmont Press Ltd., Northampton, UK, 402 pp.

St. Clair, A., 2010: Global poverty: towards the responsibility to protect. In: Climate Change, Ethics and Human Security [O'Brien, K., A. St. Clair, and B. Kristoffersen (eds.)]. Cambridge University Press, Cambridge, UK, pp. 180-198.

Stafford Smith, M., L. Horrocks, A. Harvey, and C. Hamilton, 2011: Rethinking adaptation for a $4^{\circ} \mathrm{C}$ world. Philosophical Transactions of the Royal Society $A$, 369, 196-216

Stehr, N. and H. Von Storch, 2005: Introduction to papers on mitigation and adaptation strategies for climate change: protecting nature from society or protecting society from nature? Environmental Science Policy, 8(6), 537-540.

Stern, P. and W. Easterling (eds.), 1999: Making Use of Seasonal Climate Forecasts. National Academies Press, Washington, DC, $175 \mathrm{pp}$.

Stevenson, T., 2002: Anticipatory action learning: conversations about the future. Futures, 34(5), 417- 425.

Stevenson, T., 2008: Enacting the vision for sustainable development. Futures, 41(4), 246-252

Strobl, E., 2011: The economic growth impact of hurricanes: evidence from US coastal counties. The Review of Economics and Statistics, 93(2), 575-589.

Swart, R., J. Robinson, and S. Cohen, 2003: Climate change and sustainable development: expanding the options. Climate Policy, 391, 810-849.

Swift, J., 1989: Why are rural people vulnerable to famine? IDS Bulletin, 20(2), 8-15.

Tanner, T.M., 2010: Shifting the narrative: child-led responses to climate change and disasters in El Salvador and the Philippines. Children and Society, 24(4), 339-351.

Tanner, T.M., M. Garcia, J. Lazcano, F. Molina, G. Molina, G. Rodríguez, B. Tribunalo, and F. Seballos, 2009: Children's participation in community-based disaster risk reduction and adaptation to climate change. Participatory Learning and Action, 60, 54-64.

Telford, J., J. Cosgrave, and R. Houghton, 2006: Joint Evaluation of the International Response to the Indian Ocean Tsunami: Synthesis Report. Tsunami Evaluation Coalition, London, UK, $178 \mathrm{pp}$.

Thaler, R., 1999: Mental accounting matters. Journal of Behavioral Decision Making, $12,183-206$ 
Theobald, D., 2005: Landscape patterns of exurban growth in the USA from 1980 to 2020. Ecology and Society, 10(1), 32.

Thomas, D.S.G. and C. Twyman, 2005: Equity and justice in climate change adaptation amongst natural-resource dependent societies. Global Environmental Change Part A, 15(2), 115-124.

Thomas-Slayter, B., R. Polestico, A.L. Esser, O. Taylor, and E. Mutua, 1995: A Manual for Socio-Economic and Gender Analysis: Responding to the Development Challenge. Clark ECOGEN Publication, Worcester, MA, 278 pp.

Thompson, I., B. Mackey, S. McNulty, and A. Mosseler, 2009: Forest Resilience, Biodiversity, and Climate Change. A Synthesis of the Biodiversity/Resilience/ Stability Relationship in Forest Ecosystems. Technical Series no. 43, Secretariat of the Convention on Biological Diversity, Montreal, Canada, $67 \mathrm{pp}$.

Tierney, K. and M. Bruneau, 2007: Conceptualizing and measuring resilience: A key to disaster loss reduction. TR News 250, May-June, 14-17.

Tol, R. and G. Yohe, 2007: The weakest link hypothesis for adaptive capacity: An empirical test. Global Environmental Change, 17(2), 218-227.

Tol, R.S.J., T.E. Downing, O.J. Kuik, and J.B. Smith: 2004. Distributional aspects of climate change impacts. Global Environmental Change, 14(3), 259-272.

Tompkins, E.L., M.C. Lemos, and E. Boyd, 2008: A less disastrous disaster: Managing response to climate-driven hazards in the Cayman Islands and NE Brazil. Global Environmental Change, 18(4), 736-745.

Törnquist, O., S.A. Prasetyo, and T. Birks (eds.), 2010: Aceh: The Role of Democracy for Peace and Reconstruction. PCD Press Indonesia, Jogjakarta, Indonesia, $431 \mathrm{pp}$.

Tran, P., R. Shaw, G. Chantry, and J. Norton, 2009: GIS and local knowledge in disaster management: a case study of flood risk mapping in Viet Nam. Disasters, 33(1), 152-169.

Trawick, P., 2001: The moral economy of water: equity and antiquity in the Andean commons. American Anthropologist, 103(2), 361-379.

Tribe, M. and A. Lafon, 2009: After 2015: Promoting Pro-Poor Policy after the MDGS: The Plenary Presentations and Discussion. Report on the EADI - DSA - IDSActionAid - DIFID High Level Policy Forum, June 2009, 17 pp.

Trope, Y. and N. Liberman, 2003: Temporal construal. Psychological Review, 110(3), 403-421.

Tschakert, P. and K.A. Dietrich, 2010: Anticipatory learning for climate change adaptation and resilience. Ecology and Society, 15(2), 11.

Tschakert, P., R. Sagoe, G. Darko, and S.N. Codjoe, 2010: Floods in the Sahel: an analysis of anomalies, memory, and anticipatory learning. Climatic Change, 103(3-4), 471-502.

Tsuchiya, S., H. Tatano, and N. Okada, 2007: Economic loss assessment due to railroad and highway disruptions. Economic Systems Research, 19(2), 147-162.

Turner, N.J. and H. Clifton, 2009: It's so different today: climate change and indigenous lifeways in British Columbia. Global Environmental Change, 19(2), 180-190.

Tversky, A. and E. Shafir, 1992: Choice under conflict: the dynamics of deferred decision. Psychological Science, 3(6), 358-361.

Twigg, J., 2001: Corporate Social Responsibility and Disaster Reduction: A Global Overview. Benfield Greig Hazard Research Centre, University College London, UK, $84 \mathrm{pp}$.

Tyler, S., S.O. Reed, K. Macclune, and S. Chopde, 2010: Planning for Urban Climate Resilience: Framework and Examples from the Asian Cities Climate Change Resilience Network (ACCCRN). Climate Resilience in Concept and Practice Working Paper Series 3, Institute for Social and Environmental Transition, Boulder, CO, $168 \mathrm{pp}$.

UK Environment Agency, 2009: The Thames estuary is changing. In: Managing Flood Risk through London and the Thames Estuary. TE2100 Plan Consultation Document, Environment Agency, London, UK, pp. 20-23.

Ulsrud, K., L. Sygna, and K.L. O'Brien, 2008: More than Rain, Identifying Sustainable Pathways for Climate Adaptation and Poverty Reduction. Report prepared for the Development Fund, Oslo, Norway, $68 \mathrm{pp}$.

UN, 2002: World Population Ageing 1950 - 2050. Executive Summary. United Nations, Department of Economic and Social Affairs, Population Division, New York, NY.
UN-HABITAT, 2009: Planning Sustainable Cities: Global Report on Human Settlements 2009. Earthscan Publications Ltd., London, UK, 306 pp.

UNDP, 1994: Human Development Report 1994: New Dimensions of Human Security. United Nations Development Programme, Oxford University Press, New York, NY.

UNDP, 2004: Reducing Disaster Risk: A Challenge for Development. United Nations Development Programme, Oxford University Press, New York, NY, 161 pp.

UNDP, 2007a: Thailand Human Development Report 2007: Sufficiency Economy and Human Development. United Nations Development Programme, Bangkok, Thailand, $152 \mathrm{pp}$.

UNDP, 2007b: Human Development Report 2007/2008: Fighting Climate Change: Human Solidarity in a Divided World. United Nations Development Programme, Palgrave Macmillan, New York, NY, 399 pp.

UNDP, 2009: Human Development Report 2009: Overcoming Barriers: Human Mobility and Development. United Nations Development Programme, Oxford University Press, Oxford, UK.

UNFCCC, 2006: Technologies for Adaptation to Climate Change. Adaptation, Technology and Science Programme of the United Nations Framework Convention on Climate Change Secretariat, Bonn, Germany, 40 pp.

UNGA, 2009: General Assembly, Expressing Deep Concern, Invites Major United Nations Organs: to Intensify Efforts in Addressing Security Implications of Climate Change. GA/10830, 3 June 2009, United Nations General Assembly, New York, NY.

UNISDR, 2004: Living with Risk. A Global Review of Disaster Reduction Initiatives. United Nations International Strategy for Disaster Reduction Secretariat, Geneva, Switzerland, $429 \mathrm{pp}$.

UNISDR, 2008: Gender Perspectives: Integrating Disaster Risk Reduction into Climate Change Adaptation. Good practices and Lessons Learned. United Nations International Strategy for Disaster Reduction, Geneva, Switzerland, $87 \mathrm{pp}$.

UNISDR, 2009: Global Assessment Report on Disaster Risk Reduction. United Nations International Strategy for Disaster Reduction Secretariat, Geneva, Switzerland, $207 \mathrm{pp}$.

UNISDR, 2011: Global Assessment Report on Disaster Risk Reduction. United Nations International Strategy for Disaster Reduction, Geneva, Switzerland.

UNSC, 2007: Security Council Holds First-Ever Debate on Impact of Climate Change on Peace, Security, Hearing over 50 Speakers. UN Security Council, 5663rd Meeting, 17 April 2007. UN Security Council, New York, NY.

UNSG, 2009: Climate Change and its Possible Security Implications. Report of the Secretary-General. United Nations, New York, NY.

USGBC, 2010: USGBC Celebrates Five Years of Green Building, Economic \& Educational Progress in New Orleans. Press Release, US Green Building Council, Washington, DC

van den Berg, M., 2010: Household income strategies and natural disasters: dynamic livelihoods in rural Nicaragua. Ecological Economics, 69(3), 592-602.

van Vuuren, D.P., P.L. Lucas, and H. Hilderink, 2006: Downscaling drivers of global environmental change scenarios: enabling use of the IPCC-SRES scenarios at the national and grid level. Global Environmental Change, 17(1), 114-130.

Velásquez, L.S., 1998: Agenda 21: A form of joint environmental management in Manizales, Colombia. Environment and Urbanization, 10(2), 9-36.

Velásquez, L.S., 2005: The bioplan: decreasing poverty in Manizales, Colombia, through shared environmental management. In: Reducing Poverty and Sustaining the Environment [Bass, S., H. Reid, D. Satterthwaite, and P. Steele (eds.)]. Earthscan Publications, London, UK, pp. 44-72.

Verchot, L.V., M. van Noordijk, S. Kandji, T. Tomich, C. Ong, A. Albrecht, J. Mackensen, C. Bantilan, K.V. Anupama, and C. Palm, 2007: Climate change: linking adaptation and mitigation through agroforestry. Mitigation and Adaptation Strategies for Global Change, 12(5), 901-918.

Vergara, W. and S.M. Scholz (eds.), 2011: Assessment of the Risk of Amazon Dieback. World Bank, Washington, DC, 99 pp.

Verweij, M., M. Douglas, R. Ellis, C. Engel, F. Hendriks, S. Lohmann, S. Ney, S. Rayner, and M. Thompson, 2006: Clumsy solutions for a complex world: the case of climate change. Public Administration, 84(4), 817-843. 
Villagrán de León, J.C., 2011: Risks in Central America: bringing them under control. In: Coping with Global Environmental Change, Disaster and Security [Brauch, H.G., Ú. Oswald Spring, C. Mesjasz, J. Grin, P. Kameri-Mbote, B. Chourou, P. Dunay, and J. Birkmann (eds.)]. Springer, Berlin, Germany, pp. 1147-1158.

Viratkapan, V. and R. Perera, 2006: Slum relocation projects in Bangkok: what has contributed to their success or failure? Habitat International, 30(1), 157-174.

Virgoe, J., 2002: International governance of a possible geoengineering intervention to combat climate change. Climatic Change, 95(1-2), 103-119.

Viscusi, W.K. and J. Aldy, 2003: The value of a statistical life: a critical review of market estimates throughout the world. Journal of Risk and Uncertainty, 27(1), 5-76.

Vogel, C., S.C. Moser, R.E. Kasperson, and G. Dabelko. 2007: Linking vulnerability, adaptation, and resilience science to practice: pathways, players, and partnerships. Global Environmental Change, 17(3-4), 349-364.

Volkery, A. and T. Ribeiro, 2009: Scenario planning in public policy: understanding use, impacts and the role of institutional context factors. Technological Forecasting and Social Change, 76(9), 1198-1207.

von Hesse, M., J. Kamiche, and C. de la Torre, 2008: Contribución Temática de America Latina al Informe Bienal de Evaluación Mundial Sobre la Reducción de Riesgo 2009. Contribution to the GTC-UNDP Background Paper prepared for the 2009 Global Assessment Report on Disaster Risk Reduction, United Nations International Strategy for Disaster Reduction, Geneva, Switzerland, 131 pp.

Voss, M. and K. Wagner, 2010: Learning from (small) disasters. Natural Hazards, 55, 657-669.

Wack, P., 1985: Scenarios: shooting the rapids. Harvard Business Review, 63(6), 139-150.

Walker, B. and D. Salt, 2006: Resilience Thinking: Sustaining Ecosystems and People in a Changing World. Island Press, Washington, DC, $176 \mathrm{pp}$

Walker, B., S. Carpenter, J. Anderies, N. Abel, G.S. Cumming, M. Janssen, L. Lebel, J. Norberg, G.D. Peterson, and R. Pritchard, 2002: Resilience management in social-ecological systems: a working hypothesis for a participatory approach. Conservation Ecology, 6(1), 14.

Walker, B., C.S. Holling, S.R. Carpenter, and A. Kinzig, 2004: Resilience, adaptability and transformability in social-ecological systems. Ecology and Society, 9(2), 5.

Wandel, J. and B. Smit, 2000: Agricultural risk management in light of climate variability and change. In: Agricultural and Environmental Sustainability in the New Countryside [Millward, H., K. Beesley, B. Ilbery, and L. Harrington (eds.)]. Hignell Printing Limited, Winnipeg, Canada, pp. 30-39.

Warner, K., M. Hamza, A. Oliver-Smith, F. Renaud, and A. Julca, 2010: Climate change, environmental degradation and migration. Natural Hazards, 55(3), 689-715.

Waterson, T., 2006: Climate change - the greatest crisis for children? Journal of Tropical Pediatrics, 52(6), 383-385.

WCC-3, 2009: Global Framework for Climate Services. Background paper prepared by WMO secretariat, World Climate Conference 3, World Meteorological Organization, Geneva, Switzerland, 6 pp.

WCED, 1987: Our Common Future. World Commission on Environment and Development, Oxford University Press, Oxford, UK.

Weber, E.U., 2010: What shapes perceptions of climate change? Wiley Interdisciplinary Reviews: Climate Change, 1(3), 332-342.

Weissbecker, I., S.E. Sephton, M.B. Martin, and D.M. Simpson, 2008: Psychological and physiological correlates of stress in children exposed to disaster: review of current research and recommendations for intervention. Children, Youth and Environments, 18(1), 30-70.

Weitzman, M.L., 2009: On modeling and interpreting the economics of catastrophic climate change. Review of Economics and Statistics, 91(1), 1-19.

West, C.T. and D.G. Lenze, 1994: Modeling the regional impact of natural disasters and recovery: a general framework and an application to hurricane Andrew. International Regional Science Review, 17(2), 121-150.

WGBU, 2008: Climate Change as a Security Risk. German Advisory Council on Climate Change (WGBU), Earthscan, London, UK, 271 pp.
Whitehead, J., R. Bacon, G.Carbone, K. Dow, J. Thigpen, and D. Tufford, 2010: Using climate extension to assist coastal decision-makers with climate adaptation. In: 22nd International Conference of the Coastal Society, Shifting Shorelines: Adapting to the Future, Wilmington, NC, 13-16 June 2010.

Wilbanks, T.J., 1994: "Sustainable development" in geographic context. Annals of the Association of American Geographers, 84(4), 541-557.

Wilbanks, T., 2003: Integrating climate change and sustainable development in a place-based context. Climate Policy, 3(1), 147-154.

Wilbanks, T., 2007: Scale and sustainability. Climate Policy, 7(4), 278-287.

Wilbanks, T., 2009: How Geographic Scale Matters in Seeking Community Resilience. CARRI Research Report 7, Community and Resilience Research Institute, Oak Ridge, TN, 28 pp.

Wilbanks, T., 2010: Research and development priorities for climate change mitigation and adaptation. In: Dealing with Climate Change: Setting a Global Agenda for Mitigation and Adaptation [Pachauri, R. (ed.)]. The Energy and Resources Institute, New Delhi, India, pp. 77-99.

Wilbanks, T. and R. Kates, 2010: Beyond adapting to climate change: embedding adaptation in responses to multiple threats and stresses. Annals of the Association of American Geographers, 100(4), 719-728.

Wilbanks, T. and J. Sathaye, 2007: Integrating mitigation and adaptation as responses to climate change: a synthesis. Mitigation and Adaptation Strategies for Global Change, 12(5), 957-962

Wilbanks, J. and T. Wilbanks, 2010: Science, open communication, and sustainable development. Sustainability, 2(4), 993-1015.

Wilbanks, T., P. Leiby, R. Perlack, J.T. Ensminger, and S.B. Wright, 2007: Toward an integrated analysis of mitigation and adaptation: Some preliminary findings. Mitigation and Adaptation Strategies for Global Change, 12(5), 713-725.

Wisner, B., 2001: Disasters: what the United Nations and its world can do. Environmental Hazards, 3(3-4), 125-127.

Wisner, B., 2003: Changes in capitalism and global shifts in the distribution of hazard and vulnerability. In: Natural Disasters and Development in a Globalizing World [Pelling, M. (ed.)]. Routledge, London, UK, pp. 43-56.

Wisner, B., 2006: Let Our Children Teach Us! A Review of the Role of Education and Knowledge in Disaster Risk Reduction. Books for Change, Bangalore, India, 148 pp.

Wisner, B., 2011: Are we there yet? Reflections on integrated disaster risk management after ten years. Journal of Integrated Disaster Risk Management, 1(1), doi:10.5595/idrim.2011.0015.

Wisner, B., P. Blaikie, T. Cannon, and I. Davis, 2004: At Risk: Natural Hazards, People's Vulnerability and Disaster. 2nd ed. Routledge, London, UK, 472 pp.

Wolf, J., 2011: Climate change adaptation as a social process. In: Climate Change Adaptation in Developed Nations: From Theory to Practice [Ford, J. and L. Ford Berrang (eds.)]. Springer, Dordrecht, The Netherlands, pp. 21-32.

Wolsink, M., 2006: River basin approach and integrated water management: Governance pitfalls for the Dutch Space-Water-Adjustment Management Principle. Geoforum, 37(4), 473-487.

Woodward, G. (ed.), 2010: Advances in Ecological Research 42: Ecological Networks. Academic Press, London, UK, 454 pp.

World Bank, 2005: Managing Agricultural Production Risk. World Bank, Washington, DC, $129 \mathrm{pp}$.

World Bank, 2008: World Development Report 2009: Reshaping Economic Geography. World Bank, Washington, DC.

World Bank, 2010a: Natural Hazards, Unnatural Disasters, The Economics of Effective Prevention. World Bank and United Nations, Washington, DC, 254 pp.

World Bank, 2010b: Vulnerability of Bangladesh to Cyclones in a Changing Climate. Potential Damages and Adaptation Cost. Policy Research Working Paper 5280. World Bank, Washington, DC, 54 pp.

WWF, 2010: Living Planet Report. World Wide Fund for Nature, Gland, Switzerland, $119 \mathrm{pp}$.

Yohe, G. and R. Leichenko, 2010: Adopting a risk-based approach. Annals of the New York Academy of Sciences, 1196(1), 29-40.

Yohe, G. and R.S.J. Tol, 2002: Indicators for social and economic coping capacity moving toward a working definition of adaptive capacity. Global Environmental Change, 12, 25-40. 
Yohe, G.W., R.D. Lasco, Q.K. Ahmad, N.W. Arnell, S.J. Cohen, C. Hope, A.C. Janetos, and R.T. Perez, 2007: Perspectives on climate change and sustainability. In: Climate Change 2007: Impacts, Adaptation and Vulnerability. Contribution of Working Group II to the Fourth Assessment Report of the Intergovernmental Panel on Climate Change [Parry, M.L., O.F. Canziani, J.P. Palutikof, P.J. Van Der Linde, and C.E. Hanson (eds.)]. Cambridge University Press, Cambridge, UK, pp. 811-841.

Young, H. and S. Jaspars, 1995: Nutrition Matters. People Food and Famine. Intermediate Technology Publications, London, UK, $151 \mathrm{pp}$.
Zahran, S., L. Peek, and S.D. Brody, 2008: Youth mortality by forces of nature. Children, Youth and Environments, 18(1), 371-388.

Zimmerman, F.J. and M.R. Carter, 2003: Asset smoothing, consumption smoothing and the reproduction of inequality under risk and subsistence constraints. Journal of Development Economics, 71(2), 233-260. 